\title{
Die Tauchmethode, ihre Aufgaben und Leistungen bei der Erforschung des Litorals; eine kritische Untersuchung
}

\author{
RUPERT RIEDL \\ I. Zoologisches Institut der Universität Wien, Wien, Österreich
}

\begin{abstract}
The diving method, its tasks and capacity for exploring the littoral; a critical review. Scientific diving, which was started in 1780 in the Gulf of Naples, has been developed into an important technique for obtaining new knowledge in marine biology. Some 2000 people are presently engaged in scientific diving; their work is more valuable than that of mechanical scraping and dredging. Four different stages of development are discussed on the basis of numerous citations. There are no difficulties under favourable conditions and with good technical equipment; without this, diving is still a dangerous and useless endeavour. The aim is to obtain coordinated information in the fields of ecology, behaviour of submarine organisms, geology, geomorphology and microclimatology. Moreover, the relationships depending upon the place and connecting the place with the organism must be explored first by diving, and then they can be tested by experiments. A survey of the different working places is given, and diving equipments and their necessary technical improvements for the future are described. As the direct exploration of the littoral is still somewhat in the pioneering stage - though the volume of our detailed knowledge has been significantly increased by diving - the founding of working bases, field stations, etc., is suggested. It is also proposed that governments give natural protection to the as yet untouched littoral districts by making some areas inaccessible to traffic, industry, tourism, and all other use except that of scientific research. It would be one of the most noble tasks of European States to secure some well chosen square miles of their littoral in order to promote science and to be respectful towards that part of nature where the cradle of life was on our globe. The possibility of submarine photos taken by the diver employing a T.V. device fixed on a steerable carriage, and by a diving chamber, are mentioned. The principal aim is to observe and secure information. The scientific diver will help to render the automatic mechanism more efficient to develop the photo and data processing stations, so that in the future these apparatuses can work satisfactorily and quite independent of the diver.
\end{abstract}

\section{EINLEITUNG}

Das wissenschaftliche Tauchen als eine Methode zur Gewinnung von meeresbiologischen Erkenntnissen in den Vordergrund eines bedeutenden Kongresses - des „Ersten Europäischen Symposions über Meeresbiologie“ - zu stellen, ist etwas durchaus Neues. Dieser Entschluß zählt mit zu jenen besonderen Verdiensten, die wir Herrn Professor KINNE verdanken. Für mich persönlich ist es eine Auszeichnung, über dieses Arbeitsgebiet vortragen zu dürfen; und nachdem ich gebeten worden bin, das Einführungsreferat $\mathrm{zu}$ übernehmen, darf ich sagen, welche Freude es für alle Mitstreiter im Felde 
dieser neuen Methode ist, nun einmal ernsthaft angehört zu werden. Noch vor zwei Jahrzehnten ist manchen Tauchern an den Schwellen der akademischen Institutionen die Tür gewiesen worden: Welch phantastischer Weg also bis zum heutigen Tag!

Meine Aufgabe wird es nun sein, zusammenzustellen, welche Möglichkeiten in der Methode des Tauchens, namentlich für die Sublitoral-OKkologie, gegeben sind, wo ihre Grenzen liegen und ihre Chancen, indem wir prüfen, was bisher erreicht wurde, und zu welchen Hoffnungen das Erreichte im Rahmen der Meeresbiologie berechtigt. Dieser Aufgabe kann heute schon nicht mehr durch das Referat von Einzelarbeiten entsprochen werden, so groß ist das Gebiet geworden. Allein die Zahl der wissenschaftlichen Taucher hat schon vor 8 Jahren 500 erreicht (DILl 1958); sie wird heute bei 2000 liegen. Auch ist eine Abgrenzung der bisher schon erschienenen 500 bis 1000 einschlägigen Arbeiten gegen die übrigen Methoden nicht möglich, und endlich ist ja die ganze Mitte unseres Symposions diesen Originalarbeiten vorbehalten. Ich muß mich darum auf die Schilderung der prinzipiellen Zusammenhänge und der generellen Entwicklung beschränken.

Zwei Dinge möchte ich kurz voranstellen; nämlich je einen Abriß der Größe des neu erschlossenen Gebietes und des Zieles, welches wir uns gesteckt haben.

\section{Die Größe des Gebietes}

Zunächst war man der Meinung, die Taucherei sei Sache jener abenteuerlichen $\mathrm{Na}$ turen, die unter der Decke des Meeresspiegels mit Kraken, Korallen und versunkenen Schiffen zu tun haben wollen. Wohl keiner von uns ist jener Jugendliteratur entgangen, die diese Vorstellung nährte und noch immer nährt. Und noch heute verbreitet der Meeresgrund jenen leicht verkäuflichen Schauder, den die Boulevard-Illustrierten, Film und Fernsehen in so reichem Maße für naive Gemüter bereithalten. Die Wahrheit über die wissenschaftliche Seite der Sache stand stets an versteckten Stellen, beispielsweise schon in ANTON DoHRns "Arbeitsbericht der Station von Neapel über das Jahr 1879-80" (DohrN 1880), den man kaum kennt und den auch jene, die ihn gelesen haben müßten, offenbar wieder vergessen haben.

Durch die Tätigkeit des wissenschaftlichen Tauchens hat sich an dieser Grundauffassung nur wenig geändert. Auch heute nimmt man vielfach noch an, diese Taucherei sei Sache biologisch ambitionierter Sportler, die wohl allerlei Tiermaterial heraufholen, aber durch die Unzulänglichkeiten der Methode sich ihre Grenzen selbst gesetzt hätten. Manche Meeresstationen haben sogar einen sogenannten Taucher in Dienst genommen als eine Art neuen Sammelgerätes, das anstelle von Zange und Dredge hinuntergelassen wird, wenn das Labor Seeigel oder Hydroiden für Experimente benötigt. Wieder war man einem Mißverständnis zum Opfer gefallen.

In Wahrheit ist das wissenschaftliche Tauchen eine Methode, die uns das Eindringen in jene unglaublich große Fülle von Struktur- und Lebensraumbeziehungen gestattet, welche die untergetauchte Litoralregion bereithält und die die bisherigen Sammelgeräte allesamt zerstören müssen, bevor sie ihren Inhalt aufs Schiffsdeck werfen. Wo immer die Taucherei angesetzt hat, an der Beziehung der Fische zu Substratstrukturen, an den Standortbeziehungen der Sedentarier, den Populationsgefügen der erranten 
Mikrofauna, an Produktions- und Biozönosefragen, in Mikroklimatologie und Geomorphologie, überall hat sich der Detailreichtum unserer Erfahrung, das Nachrichtenvolumen, mindestens verzehnfacht. Diese Situation ist mit jener der Elektronenmikroskopie zu vergleichen, die uns dazu verhilf, die Erforschung des Feinbaus der Organismen nun mit zehnfachem Nachrichtenmaterial neuerlich in Angriff zu nehmen. Wenn man sich vor Augen hält, was das Litoral an Erscheinungen schon bisher erbrachte, so wird evident, welch Riesengebiet wir eben dabei sind, unserem Fache hinzuzugewinnen.

Die folgenden Veröffentlichungen befassen sich mit der Bedeutung des T a u chen s für die Wissenschaft, namentlich für die Biologie. Dabei wird oft von einem historischen Uberblick ausgegangen: ANKEL (1953), BAsCom \& Revelle (1953), Beebe (1941), Biebl (1954), Boutan (1893), Brase (1954, 1957), Cafuta et al. (1955), Demant (1931), Dill (1958), Drach $(1952,1958)$, Fadeew, Pecatin \& Curowikin (1958), Field (1903), Jude (1958), Kirsteuer (1961), Krebs (1906), Kucharski (1927), Kuščer (1947), NiKolić (1958a, 1960), North (1956), Rredl (1947, 1966b), Scheer (1956), Stelzner (1943), Steyaert (1959), Sweeny (1955), Theodor (1958, 1965), Wasmund (1938a) und Zalokar (1941). Auch in fast hundert weiteren Spezialarbeiten wird die Bedeutung der neuen Methode jeweils erneut hervorgehoben, wie sich das aus der Jugend des Gebietes erklärt.

\section{Das allgemeine Ziel}

Generell gefaßt besteht die Aufgabe des wissenschaftlichen Tauchens darin, einen direkten Zugang auch zu den komplexen Strukturen und Lebensbeziehungen im Litoral zu schaffen. Ihr allgemeines Ziel sollte darin bestehen, sich im Methodensystem der Litoralforschung den geeigneten Platz zu erarbeiten. Um das zu erreichen, bedarf es nun nicht nur einer weiteren Vermehrung der Fakten, es wird auch von Nutzen sein, die Gesamtlage zu überblicken, um die für eine gedeihliche Entwicklung des Faches nötigen und fehlenden Vorkehrungen empfehlen zu können.

Wie ich noch zu zeigen haben werde, ist nicht nur die Methode, sondern auch die bisherige Entwicklung nicht frei von Einseitigkeiten, und man muß feststellen, daß die wissenschaftliche Taucherei ihre Pionierzeit noch gar nicht überwunden hat, ja, diese aus sich selbst heraus auch gar nicht überwinden kann. Vielleicht gelingt es uns, manche Fehlleitung und manches Mißverständnis aufzuklären und ökonomisch zu planen.

Den Hauptteil meines Berichtes möchte ich nach fünf Gesichtspunkten gegliedert darlegen, indem ich erstens die Taucherei als Methode prüfe, zweitens das Wesen der gewonnenen Anschauung schildere, drittens und viertens die Schwerpunkte herausarbeite, die sich nach Fragestellung und Untersuchungsgebiet entwickelt haben, um fünftens einen Abriß der Lage des Forschungsgebietes selbst zu geben.

\section{DAS WISSENSCHAFTLICHE TAUCHEN}

Bei der Beurteilung der wissenschaflichen Taucherei als Methode muissen wir bereits sehr kritisch sein, weil davon die weiteren Schlüsse abhängen werden. Auch wird 
hier nicht der Ort sein, das Arsenal der bereits geschaffenen und handelsüblichen Hilfseinrichtungen zu schildern. Die großen Versandhäuser für Taucherei und unterseeische Technologie können darüber erschöpfend informieren. Hier ist vielmehr die Taucherei als eine - wie jede Methode - immer noch mangelhafte Einrichtung zur Erreichung wissenschaftlicher Ziele zu schildern.

Was die Geschichte der wissenschaftichen Taucherei betriff, so wird ein sehr knapper Abriß genügen; ausführlicher werden die Merkmale der Methode und deren Grenzen $\mathrm{zu}$ behandeln sein.

\section{Abriß der Geschichte}

Vier Stufen in der Entwidklung von Methode und Fragestellung sind für uns aufschlußreich. Die erste liegt zeitlich vor der Gründung der Meeresstationen und vor der Entwicklung der ökologischen Fragestellung. Sie umfaßt das 18. und die erste

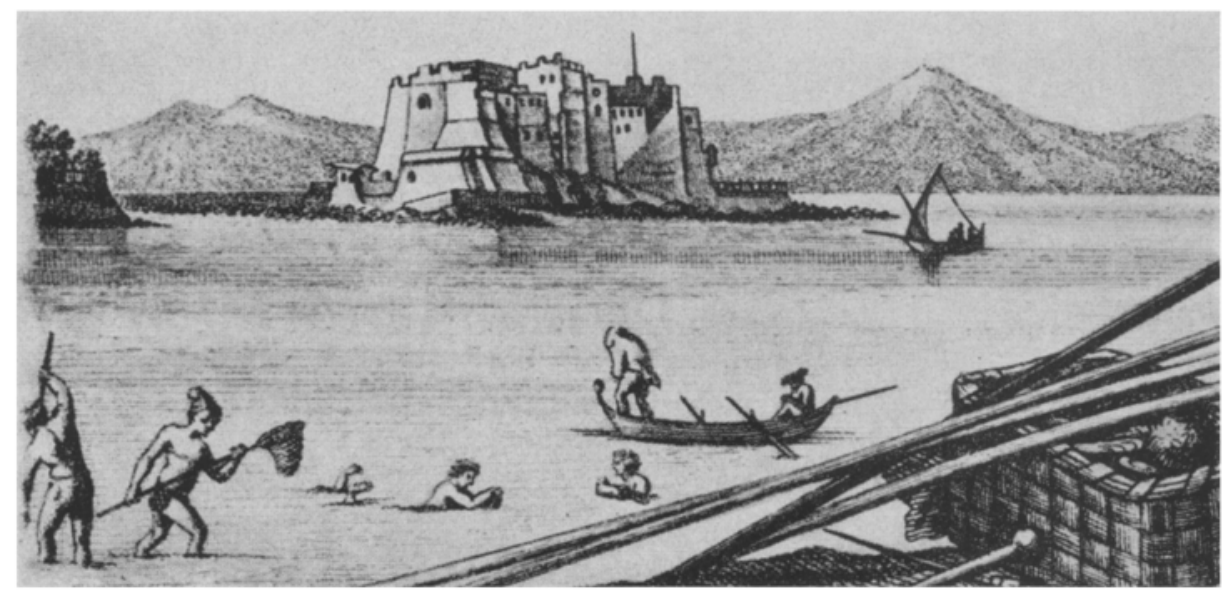

Abb. 1: Beginn der wissenschaftlichen Taucherei. Sammler und Taucher aus der Zeit CAvolinis im Golf von Neapel. Ausschnitt eines Stiches aus Delle.Chiaje 1841-1844)

Hälfte des 19. Jahrhunderts, etwa von CAvolinrs Hydroidenstudien um 1780 (Abb. 1) im Golf von Neapel bis zu den Sammlungen von Mrne-Edwardos und seinem Assistenten Quatrefages um 1840 an der Nordküste Siziliens.

Aus der Frühzeit des wissenschaftlichen Tauchens sind die Arbeiten von AudourN \& Milne-Edwards (1832), Cavolini (1785) und Milne-Edwards (1845) hervorzuheben. Wahrscheinlich haben noch weitere Wissenschafter die Technik benützt, wie eine von Delle-Chiaje (1841-1844) gebrachte Vignette (Abb. 1) andeutet. Vielfach werden selbst die Ergebnisse der Arbeiten nicht mehr darïber schlïssig werden lassen. Größer ist die tauchtechnische Literatur der Zeit, aus welcher ich TRIEWALD (1736) als Beispiel anführen will.

Die nächste Stufe schließt an die Stationsgründungen an, umfaßt hauptsächlich die 
zweite Hälfte des 19. Jahrhunderts (Abb. 2) und ist durch das entstehende Interesse am Standort gekennzeichnet. Besonders eindrucksvoll sind A. Dohrns 1879 niedergeschriebenen Sätze: „Der Taucher“, so führt er in seinem Bericht über die Station aus, „ist natürlich ganz besonders befähigt, diejenigen Teile des Meeresgrundes zu untersuchen, welche den Grundnetzen unzugänglich bleiben, also Felsspalten, Höhlen und die Unterseiten überhängender Felsen. Ich habe mich schon über eine halbe Stunde", so fährt er fort, „in engen Grotten aufgehalten. ... Für den Erforscher sessiler Organismen, ist solche Exkursion natürlich von der größten Bedeutung." Und er stellt

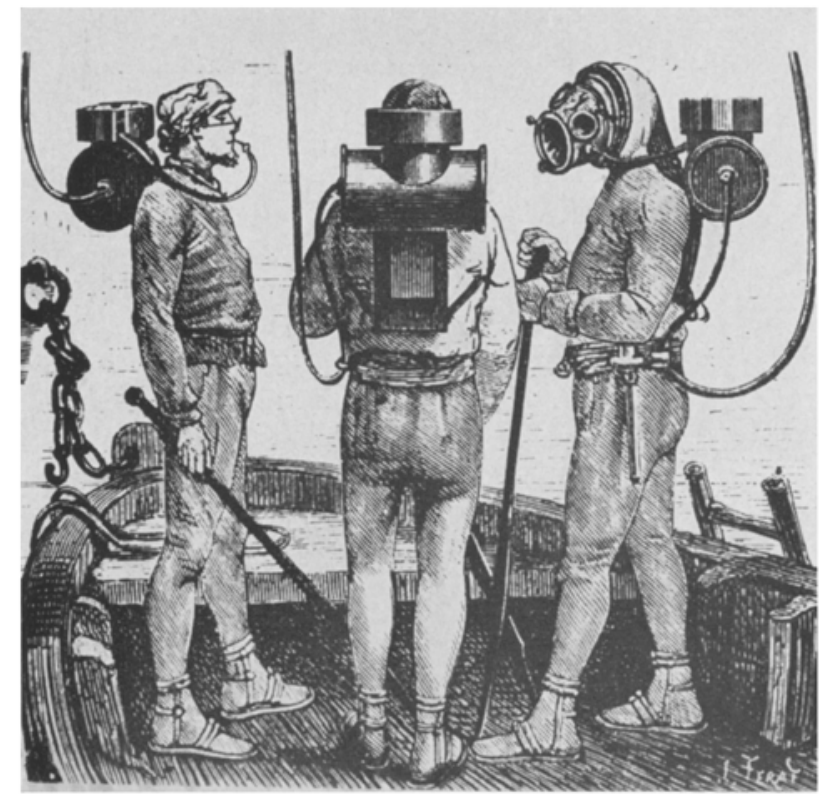

Abb. 2: Tauchausrüstung wie sie zur Zeit der Stationsgründungen verwendet worden ist. (Aus DEACON 1963)

abschließend fest: „Mit Hilfe des Tauchapparates ist es ein Leichtes, ... an Ort und Stelle das Vorkommen und die Verteilung der Formen auf das genaueste zu studieren, was fürdie Erforschung der Verbreitungsgesetze... sich als un umgänglich notwendig herausgestellt hat." Daraus ist ersichtlich, wo dieser große Mann schon damals stand. Heute, nach drei Generationen, sind wir kaum weiter. Wohl ist viel mehr Material erarbeitet worden, aber es gilt noch genauso $\mathrm{zu}$ werben wie damals, und ich darf wiederholen: es hat sich als unumgänglich notwendig herausgestellt! DoHRn hatte die Marine interessiert, BERTHOLD (1882), WEISMANN (1883) und andere hatten sich angeschlossen. Aber der Aufwand war noch sehr groß und das Motiv zum Ausbau unterseeischer Studien zu wenig verbreitet. Die wissenschaftliche Taucherei zur Zeit der Stationsgründungen ist belegt durch: BERTHOLD (1882), Boutan (1893, 1898), Dohrn (1880), Halder (1899), Humphrey (1893), Ransonnet-Villez (1868), Weismann (1883). Oft ist nur aus den Ergebnissen zu 
schließen, daß sich die Autoren direkte Anschauung verschafften: Ihre Zahl wird darum größer sein. Über die Zeit A. Dohrns informieren besonders Heuss (1962) und KüHN (1950).

Erst die dritte Stufe ist durch den Scaphander (Abb. 3) und stark durch das fachliche Motiv bestimmt, durch das Interesse am Verhalten, an der Okologie und an der Geologie des Litorals. Besonders ist an BeEbes (1928) Tauchhelm-Fahrten, an GisLeN

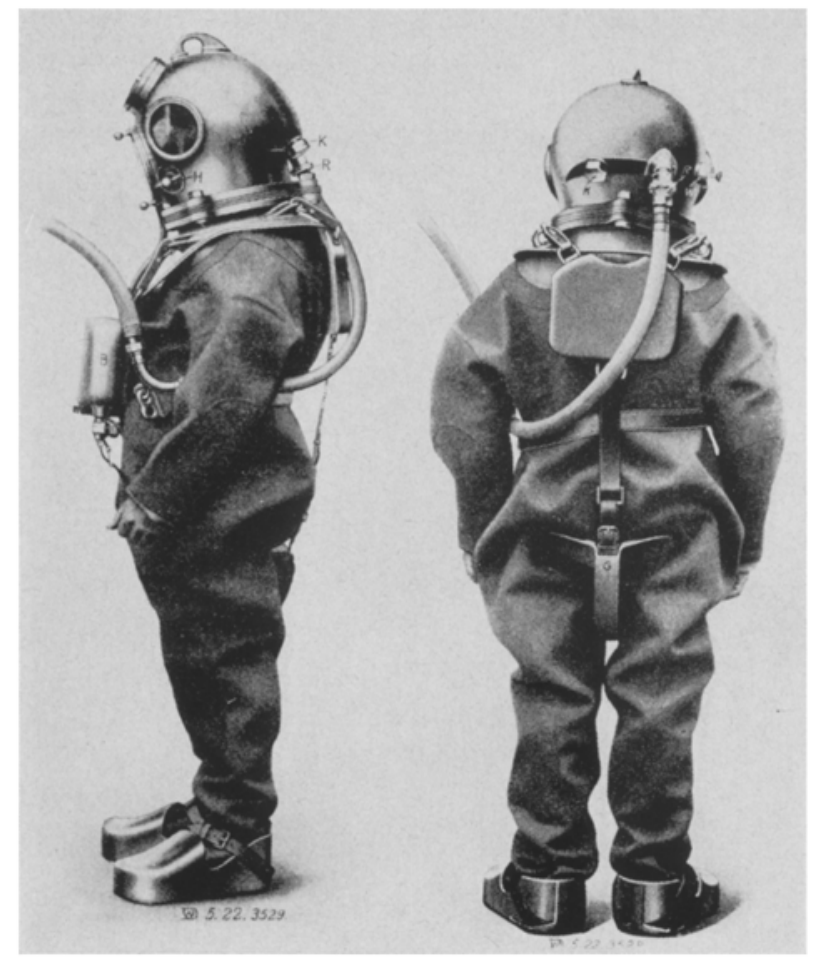

Abb. 3: Ausrüstung mit Helm und schwerem Anzug, wie sie seit ungefähr 1930 noch heute in Gebrauch ist. DräGER-Schlauch-Tauchergerät. (Aus STELZNER 1943)

(1929), Kitching, Macan \& Gilson (1934) und an Wasmund $(1937,1938)$ zu erinnern. Die Zeit liegt zwischen den Kriegen, der Schauplatz ist vom Tyrrhenischen Meer in die Tropen und besonders in die nordeuropäischen Gewässer verlegt (in den Gullmar Fjord, die Wembury Bay, die Ostsee), was mit den schweren Anzügen zusammenhängt, die man verwendete, und mit den organisatorischen Bedingungen, die hier günstiger waren. Die ersten einschlägigen Arbeiten entstanden. Ergebnisse der wissenschaftlichen Taucherei $\mathrm{z} w$ i s $\mathrm{ch}$ e $\mathrm{n} \mathrm{d}$ e $\mathrm{n} \mathrm{K} \mathrm{r}$ i e g e $\mathrm{n}$ sind niedergelegt bei: BEEBE (1926, 1928a, 1941), Conclin (1933), Gislen (1929), Gislen \& Odquist (1935), Ellsberg (1939), Jackson (1913), Kitching (1941), Kitching, Macan \& Gilson (1934), Longley (1916, 1918), Longley \& Martin (1927), Mayor (1924), Miner (1934), Miraglia (1935), Pearson (1928), Perkins (1914), Wasmund (1937a, 1938a), Walker 
(1933), Williamson (1936), Wojtustak \& Wojtusiak (1939) sowie Yonge (1925, 1930). Uberwiegend sind es spezielle ökologische Fragen, die behandelt werden. Auf dem Gebiete der Lichtbildtechnik sind hervorzuheben: Bartsch (1927), HoFman (1938), Longley \& Martin (1927), Perkins (1914), Walker (1933) und Wasmund (1937a). Die tauchtechnische Literatur wird bereits sehr umfangreich. Man entnimmt sie den Büchern von Davis (1935) und STELZNER (1943).

In der vierten Stufe stehen wir heute (Abb. 4). Der Krieg hat leichte, verläßlichere Geräte entwickeln lassen, die Industrie hat einen neuen Markt gefunden, das Interesse am Milieu ist noch stärker geworden, Männer wie HAss und Cousteau haben

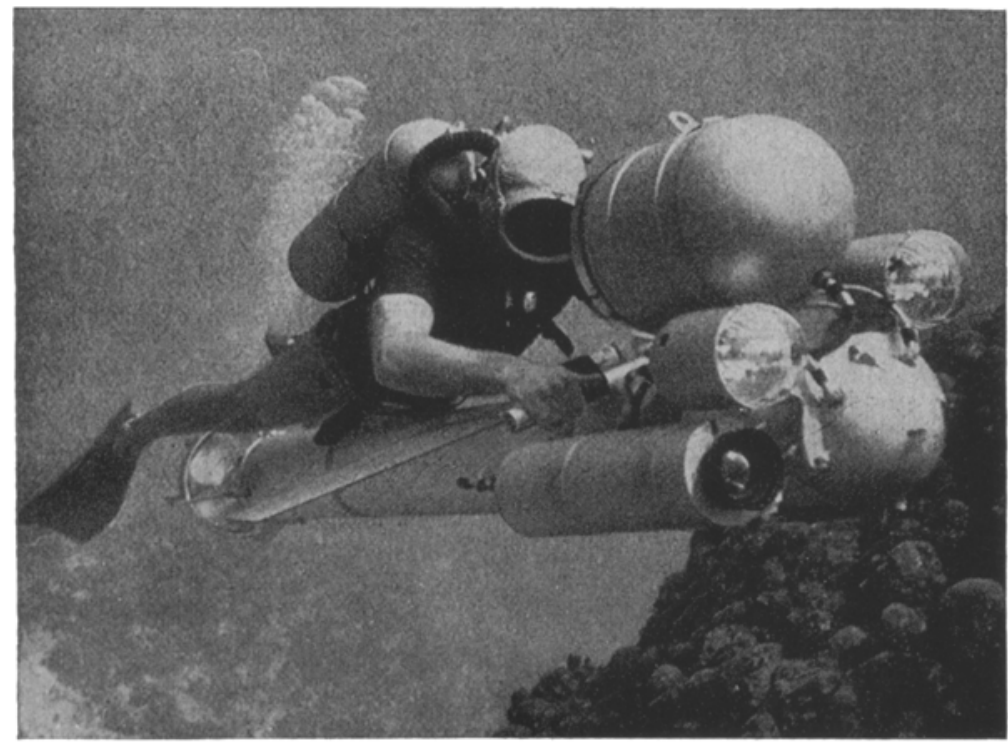

Abb. 4: Moderne Tauchausrüstung mit leichtem Anzug, Preßluft-Atemgerät und großem Aufnahmegerät. Werbeaufnahme der REBIKOFF Oceanics Inc. (Aus „Under Sea Technology“, Mai 1966)

stark in die Breite gewirkt, Tauchen und Schnorcheln sind ein Volkssport, der "Strandwanderer" ist zum "Schnorchler" geworden und die Universitätskurse im Mediterran finden halbtags im Wasser statt. Welch eine Veränderung! Gleichzeitig sind noch OOkologie und Verhaltensforschung gänzlich unentbehrliche Disziplinen geworden, und bald wird jeder Meeresbiologe Motiv und einfache Gelegenheit haben, sich die Dinge selbst anzusehen.

Bereits drei wissenschaftliche bis populärwissenschaftliche Feldführer für das europäische Litoral sind auf den Gebrauch des Tauchers und „Schnorchlers“ abgestimmt: DeHaAs \& Knorr (1965), Luther \& Fiedler (1961) sowie Riedl (1963a). Hinzu kommt noch eine ganze Reihe populärer und tauchsportlicher Einführungen, die ich nicht referiere. Aus der schon sehr umfangreichen populären und populärwissenschaftlichen Taucher-Literatur seien folgende Werke hervorgehoben: BAUER (1955), BEEBE (1928b, 1930, 1932, 1941), Coppleson (1958), Cousteau (1952), Cousteau \& Dugan 
(1963), Cousteau \& Dumas (1953), Cousteau, Talllez \& Dumas (1946), Delatil \& Rivoir (1945), Diolé (1953), Dugan (1956), DuPont (1940), Eibl-Eibesfeldt (1964), Ellsberg (1939), Hass (1939, 1942, 1952, 1961), Heberlein (1956a, 1958), Houot \& Willm (1955), Klingbeil \& Kühlmann (1958), Miner (1934), Möhres (1964), A. Piccard (1954), J. Piccard \& Dietz (1957), Rebikoff (1952a), Taillez (1956), TAIllez et al. (1950) und Williamson (1936).

An populären Taucher- und Tauchsport-Zeitschriften sind mir bekannt: Barracuda (Finnland), CRIS Centro de Recuperacion i Investigacion Submarina (Spanien), Deepsea Digest (USA), Delphin (Deutschland), Etudes et Sports Sous-Marines (Frankreich), Frosch (Schweiz), Giornale della pesca (Italien), La Pesca subaquea (Italien), L'Aventure Sous-Marine (Frankreich), L'Eeau et la Vie sous-marine (Frankreich), Mondo Sommerso (Italien), More (Jugoslawien), Mundo Subacuatico (Spanien), Neptun (Deutschland), Ozean (Ósterreich), Pescasport (Italien), Seesport (Deutschland), Skin Diver Magacine (USA), Spearfishing News (Australien), Spearfishing Sportlight (Australien), Triton (od. Neptun) (England).

Nun ist jene Verbreitung gesichert, die für jede Entwicklung wichtig ist. Geographisch sehen wir die Schwerpunkte wieder verlagert in die warmen, klaren Gewässer. Zentren sind Südjapan, Südkalifornien-Hawaii-Australien, amerikanisches Mittelmeer, in erster Linie aber das europäische Mittelmeer, das vor dem Nordatlantik mit rund 25 gegen 5 auf Tauchstudien beruhende Arbeiten, welche pro Jahr erscheinen, an der Spitze liegt. Ursache sind die leichten Ausrüstungen und das Interesse an der photographischen Dokumentation.

Eine fünfte Stufe der Entwicklung liegt noch vor uns; darauf ist bald näher zurückzukommen.

\section{Merkmale der Methode}

Das Geräte-Arsenal hat sich so entwickelt, daß es in geeigneten Gewässern, geringen Tiefen und bei kurzen Arbeitszeiten keine technischen Probleme mehr gibt: Es ist den Bedürfnissen der allsommerlichen Touristenheere nachgebaut worden. Hingegen gibt es keine Hilfe gegen ungenügende Sichtweite, heftige Wasserbewegung, kaum einen Schutz gegen Raubfische, sehr niedere Temperaturen oder hohe Wasserdrucke mit ihren Folgen für Atmung und Kreislauf. Auch für lange Beobachtungszeiten sehen wir uns praktisch ungerüstet. Diesen Gegensatz ernsthaft in Rechnung zu ziehen, ist sehr wichtig.

An Einzelheiten mag folgendes von Interesse sein. Der Gesichtssinn ist durch Masken gut angepaßt, nur die leichte Vergrößerung des Bildes wäre umständlich auszugleichen, sie ist aber auch kaum störend. Der Tastsinn bleibt unberührt. Der Gehör-

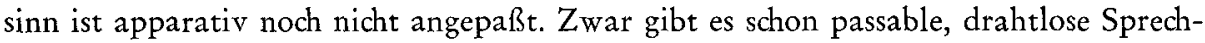
geräte, aber um das Richtungshören und die Übertragung der Ortsgeräusche zum Taucher hat man sich noch wenig bemüht. Beides ist, soweit ich sehe, aber erreichbar. Das Problem des Kälteschutzes ist leidlich gelöst, die sogenannten Naß-Anzüge bringen einen Fortschritt durch bessere Druck-Unabhängigkeit, die heizbaren Anzüge sind noch zu teuer und unverläßlich.

Literatur über die Optik unter Wasser wird weiter unten bei den Arbeiten über 
Lichtbild-Technik aufgeführt. Studien über Unterwasser-Akustik sind selten mit dem Tauchgerät vorgenommen worden. Über das umfangreiche Gebiet orientiert biologisch zuletzt WinN (1964). (Zum Abschnitt Unterkühlung siehe Tauchphysiologie, vgl. auch Reusch 1957 und Schinkowskr 1957.)

Die Bewegungsanpassung durch Fußflossen, welche die Hände frei macht und den Taucher vom Seeboden löst, ist von ausschlaggebender Bedeutung. Alle übrigen Einrichtungen fallen dagegen zurück. Steuerflächen zum Schleppen des Tauchers vom Boot aus funktionieren und sind einfach, aber die Taucherei ist eine Methode für kleinräumige Studien. Das gilt auch für die Cousteauschen Zugpropeller und für sonstige Propellerfahrzeuge. Sie sind wohl besser steuerbar, aber teuer und umständlich. Eine weitere Kategorie bilden die Fahrzeuge mit Druckkabinen; die „soucoupe plon-

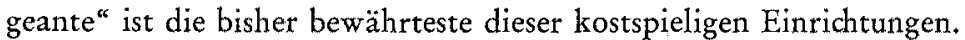

Fragen der Bewegung des Tauchers findet man in der Schwimmsport-Literatur, teilweise bei Rrchter (1958) zitiert. Uber submarine Fahrzeuge und die mit ihnen erzielten wissenschaftlichen Ergebnisse ist nachzulesen bei: ANDERSON (1960), Barton (1930a, 1935), Beebe (1930, 1935), Bernard (1958), Cousteau \& Dugan (1963), Heberlein (1956b), Pérès (1958, 1959, 1960), Pérès \& Picard (1955b), A. Piccard (1954), J. Piccard \& Dietz (1957), Trégouboff (1958), Vaissière \& Carpine (1964) sowie bei Willm (1958).

Wie schon festgestellt wurde, gibt es im Seichtwasser keine Atemprobleme. Der Schnorchel ist eine unentbehrliche Einrichtung. Die meisten Arbeiten lassen sich in Minuten-Intervalle zerlegen und Atemgeräte sind nicht erfolgreich. Moderne Preßluftgeräte sind bei umsichtiger Wartung sehr verlaßßlich im Betrieb und in geringer Tiefe - unter erfahrener Aufsicht benützt - hinreichend sicher. Die Unfallquote liegt unter der eines guten Automobils im europäischen Verkehr. Mit zunehmender Tiefe und stark verlängerten Arbeitszeiten nehmen die Gefahren aber rasch zu. Dabei versagt nicht das Gerät, sondern der Organismus. Schon in 20 bis $30 \mathrm{~m}$ Tiefe wird die dauernde Verwendung bedenklich, und keine der bislang entwickelten Schutzeinrichtungen oder Nährgaszusammensetzungen haben sich wirklich bewährt. Das Tauchgerät ist in der Tiefe wirklich gefährlich und ich rate dringend, aus dieser Erfahrung die Konsequenz zu ziehen.

Von den Schriften über Tauchphysiologie, namentlich die Atmung betreffend, seien hervorgehoben: BehnKe (1955a), Bodet (1931), Chauchard (1947), Héderer (1936), Hill (1911), Lambertsen (1955), Lanpier (1955), Mead (1955), Pohle (1955), Schaefer (1955), Stein (1955) und Stelzner (1943). Spezielle technische Anweisungen über den Umgang mit Atemgeräten, Atemvorschriften und Dekompressionszeiten finden sich in den Handbüchern für Taucher (vgl. Davis 1935, 1951 sowie STELZNER 1943) sowie in den Anweisungen für Taucher der Herstellerfirmen der Geräte.

Das Arsenal der Hilfseinrichtungen ist recht verläßlich geworden. Kamera, Laufbild- und Beleuchtungseinrichtung, Uhr, Kompaß, Tiefenmesser, Fernsehauge, alles ist in guten Gehäusen vorrätig, und der Gehäusebau stellt auch für die kompliziertesten Geräte kein Problem mehr dar. 


\section{Die Grenzen der Methode}

Wenn wir unter der Methode die Taucherei verstehen, dann sind ihre Grenzen wahrlich eng genug. Wenn wir aber nach jener Methode fragen, die uns Anschauung im Sublitoral liefert, dann sind Grenzen wiederum kaum vorhanden. Diesen Zusammenhang möchte ich Ihnen möglichst deutlich machen.

Zunächst einmal ist Tauchen gar nicht jedermanns Sache. Ich kenne hervorragende Meeresökologen, die nichts in der Welt unter die Wasserlinie bringen könnte, aber gerade diese - und man kann dafür sorgen - sollten vom Nutzen der Anschauung nicht ausgeschlossen werden. Auch darf man die physischen Voraussetzungen, so be-

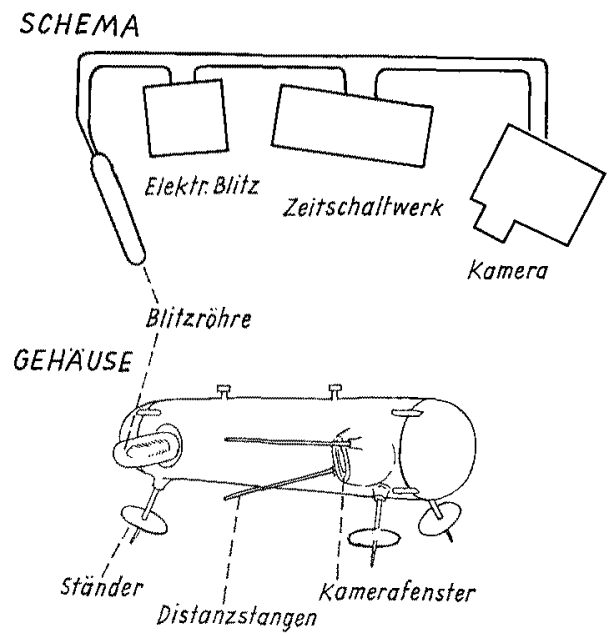

Abb. 5: Zusammensetzung einer automatischen Einzelbild-Blitzlicht-Kamera für selbsttätige Zeitrafferaufnahmen am Seeboden. (Aus RIEDL 1963b)

scheiden diese auch sind, nicht übersehen. Die jüngeren Semester unter uns werden freilich oft im Vorteil sein. Um so mehr wird man versuchen, den jüngeren die Anschauung zu ermöglichen, denn um wieviel verläßlicher kann man komplizierte Verhältnisse rekonstruieren, wenn man sie auch nur einmal gesehen hat.

Gefährlich bleibt das Atemgerät, wenn es nicht nur selten, kurz und in seichten Regionen verwendet wird. Ich muß ausdrücklich hinzufügen, daß Ubung und Erfahrung die Überlebenschancen keineswegs vergrößern. Fast hat man den Eindruck, daß das Gegenteil der Fall ist. Gerade die erfahrensten Taucher sind mit einer schrecklichen Konsequenz von uns weggeholt worden. Ich darf an Männer wie den Franzosen Fargues, den Engländer Hodges erinnern, den Amerikaner Limbaugh, den Osterreicher TEImer und den Deutschen Wissel, die für unsere Wissenschaft mit dem Tauchgerät ihr Leben ließen. Aber die Benutzung des Tauchgeräts läßt sich eben weitgehend vermeiden. Eine vollständige Übersicht der auftretenden Gefahren scheint noch nicht zusammengestellt worden zu sein. Viele einschlägige Darstellungen findet 
man bei Brown (1938), Davis (1911, 1935, 1951), Doston (1953), Héderer (1936), Limbaugh (1957), Pohle (1955), Stelzner (1943), Stipišić (1955), Swezey (1940) und TaILlez et al. (1950). Weitere Angaben enthält die Literatur über die Physiologie des Tauchens.
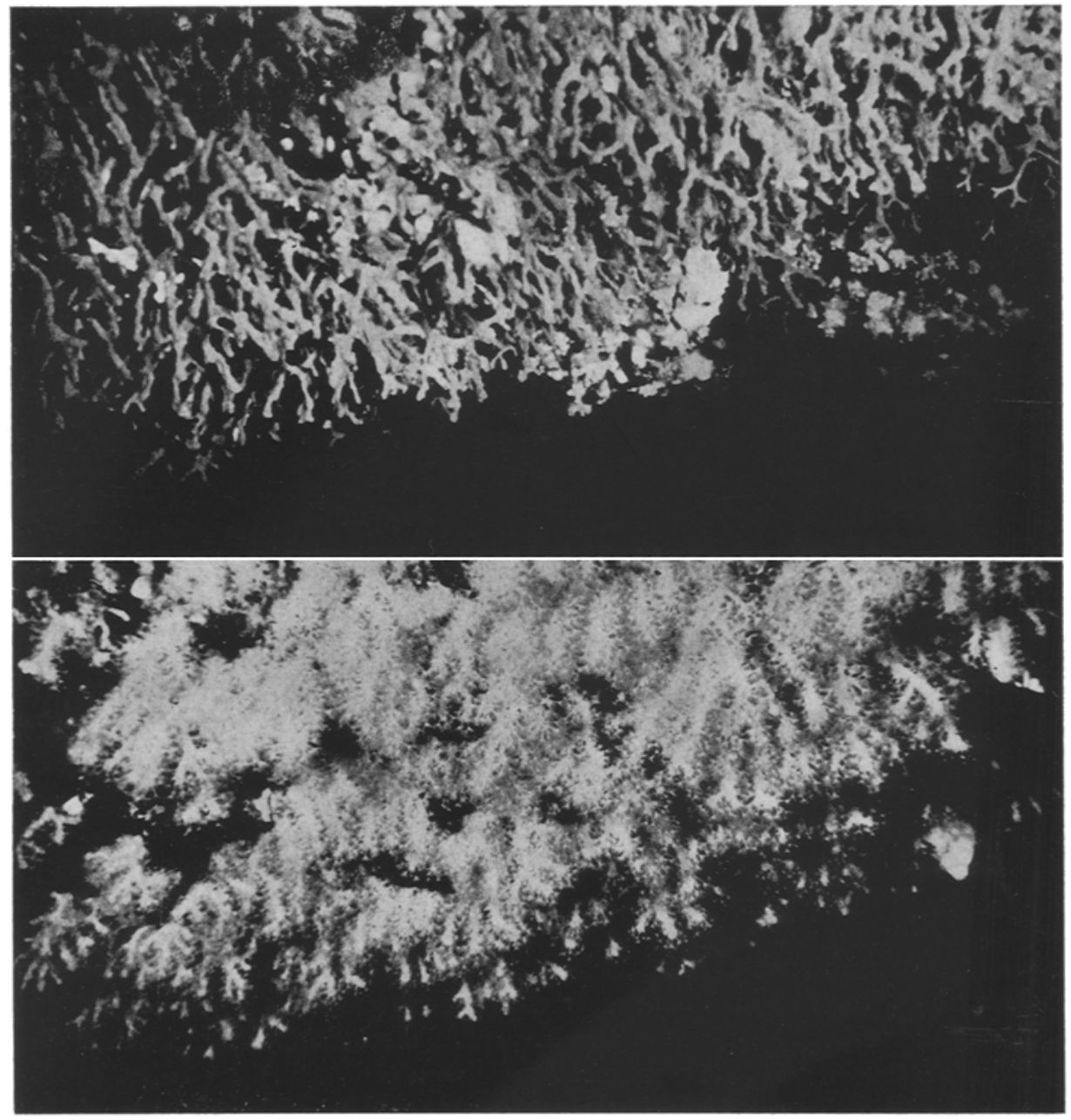

Abb. 6: Tagesrhythmik der Aktivität bei Korallen. Etwa derselbe Bestands-Ausschnitt von Corallium rubbrum an einer Höhlendecke zeigt am Tage (oben) geschlossene, nachts (unten) geöffnete Polypen. (Photo von Svoboda aus Riedl 1966a)

Zuletzt ist auch der begrenzenden Milieubedingungen zu gedenken. Freilich kann man sich gegen fast alle Unbill eine Zeitlang wappnen, aber man wird sich eben nicht nur größeren Gefahren aussetzen, sondern zudem auch noch weniger erreichen; und das ist gewiß unökonomisch. Hohe Wassertrübung, heftige Dynamik, niedrige Temperatur und Raubfische werden immer hinderlich bleiben. Da aber die Mehrzahl unserer 
Probleme nicht an einen geographischen Ort gekettet ist, kann man die für die Beantwortung einer Frage optimalen Gewässer jeweils wählen. Für uns Europäer sind das zumeist bestimmte Küsten des Mediterran, zum Teil des Roten Meeres. Dort sollten naturgemäß die Schwerpunkte liegen. Und wenn es darum geht, lokale Probleme in ungünstigeren Gewässern zu bearbeiten, dann bleibt es doch höchst geraten, das analoge

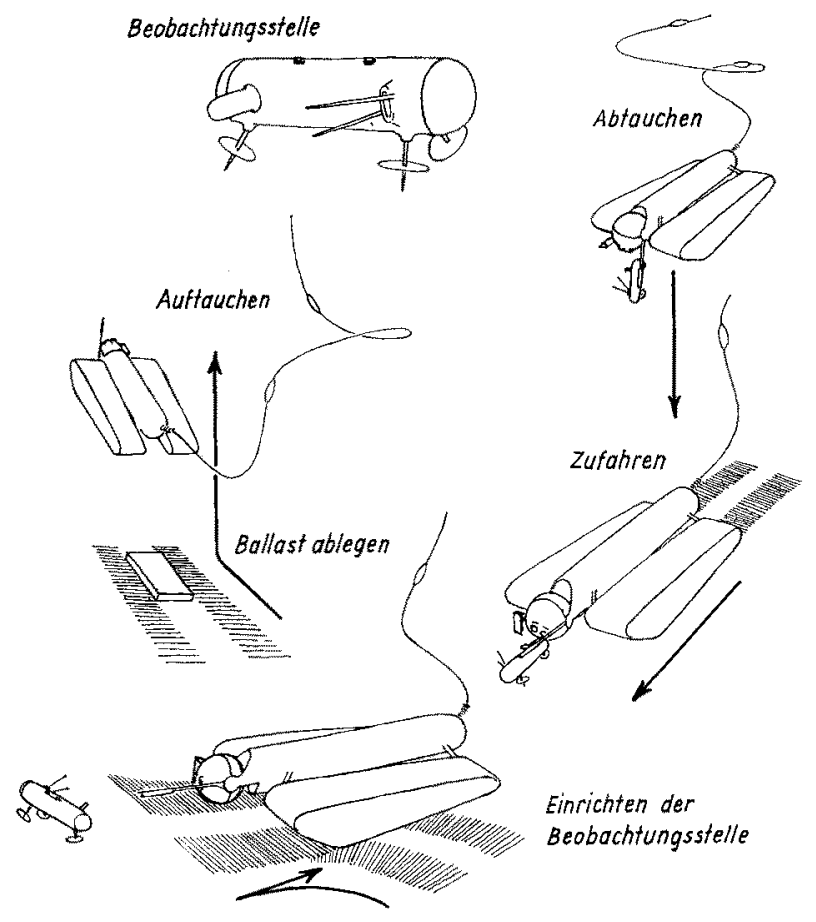

Abb. 7: Plan einer kabelgesteuerten Fernseh-Lafette, die selbständig abtaucht und das automatische Einzelbild-Gerät (vgl. Abb. 5) gezielt in Position bringt. (Aus RiEdr 1963b)

Problem zunächst unter Optimalbedingungen zu studieren, um die gemeinsame Entwicklung (von Fragestellung und Methodenadaptierung) nicht von Anfang an zu behindern, um unser Leben und das unserer Mitarbeiter zunächst nur in den Simulator zu packen. Erst wenn wir die Schwierigkeiten genau kennen, sollten wir uns ungünstigere Startbedingungen leisten.

Wir sind heute in der Lage - und damit skizziere ich mein Projekt einer füntten Ausbaustufe der wissenschaftlichen Taucherei - durch die vielfältigen Einrichtungen der Automation, des Fernsehens, der Bild- und Datenspeicherung, der Fern- und Selbststeuerung von Geräten, den Taucher von allen Fährnissen zu befreien. Zu ersetzen ist er nicht, denn er muß zunächst jene Erfahrungen des Verhaltens, der Handhabungen und Bedachtnahmen gewinnen, bevor wir diese dann in zweckmäßige Automaten umbauen und ihnen überlassen können. Und die Erprobung und Adaptierung solcher Klima-Registrierstationen, Blitzlicht-Einzelbildkameras, Lafetten etc. sollen unter 


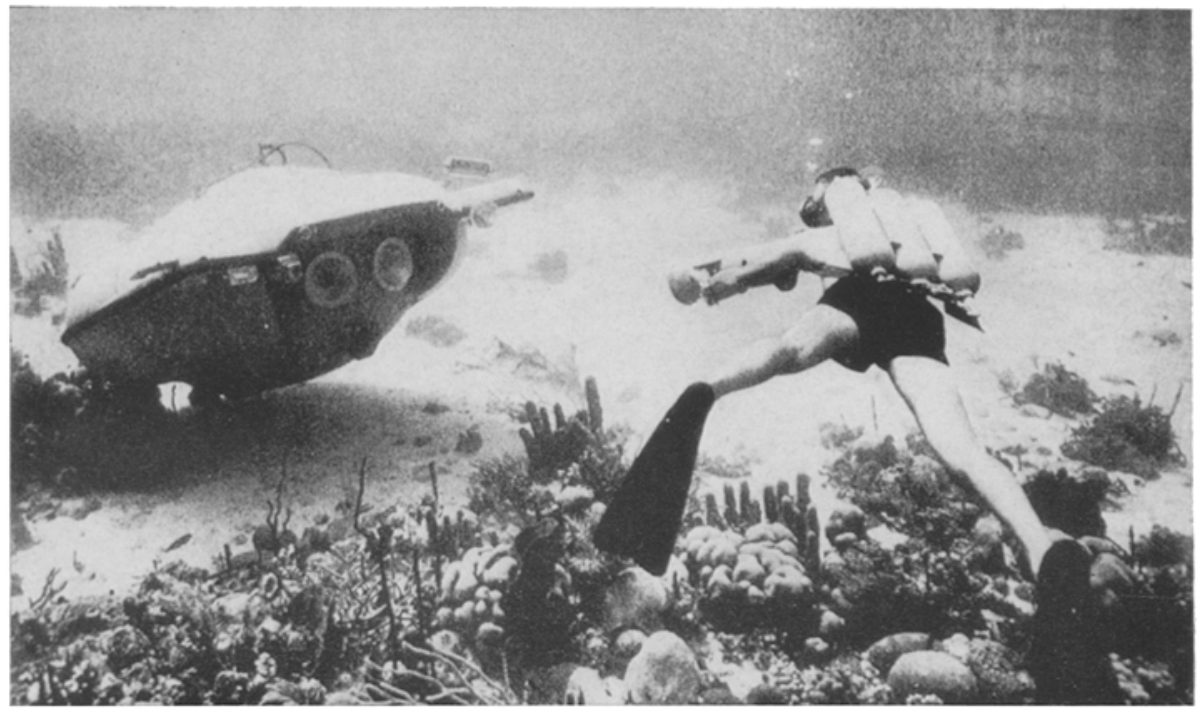

Abb. 8: Die "Tauchende Untertasse ${ }^{\text {ct }}$ noch im Bereich des Tauchers, im Einsatz im Korallenmeer. (Aus Cousteau \& Dugan 1963)

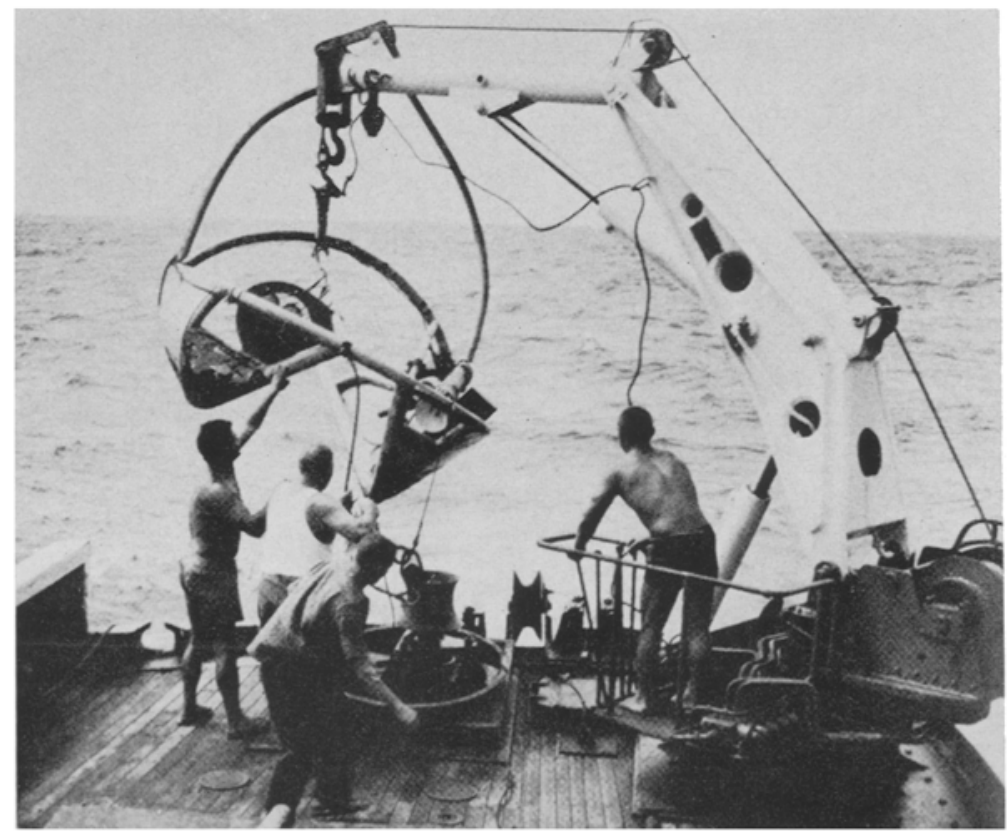

Abb. 9: Der Einsatz der "Troica“ eines vom Schiff aus geschleppten Photo-Schlittens auf dem Forschungsschiff „Calypso“. (Aus Cousteau \& Dugan 1963) 
Optimalbedingungen vorgenommen werden, um damit den Menschen vor Gefahren zu schützen.

\section{ANSCHAUUNG UND SIMULTANE NACHRICHTENAUSWERTUNG}

Wenn wir herausstellen, was das Tauchen den übrigen, wohlvertrauten Methoden der litoralen Feldforschung überlegen macht, so stellen wir fest, daß es sich um die Fähigkeit des Tauchers handelt, zahlreiche Nachrichteninhalte gleichzeitig zu empfan-

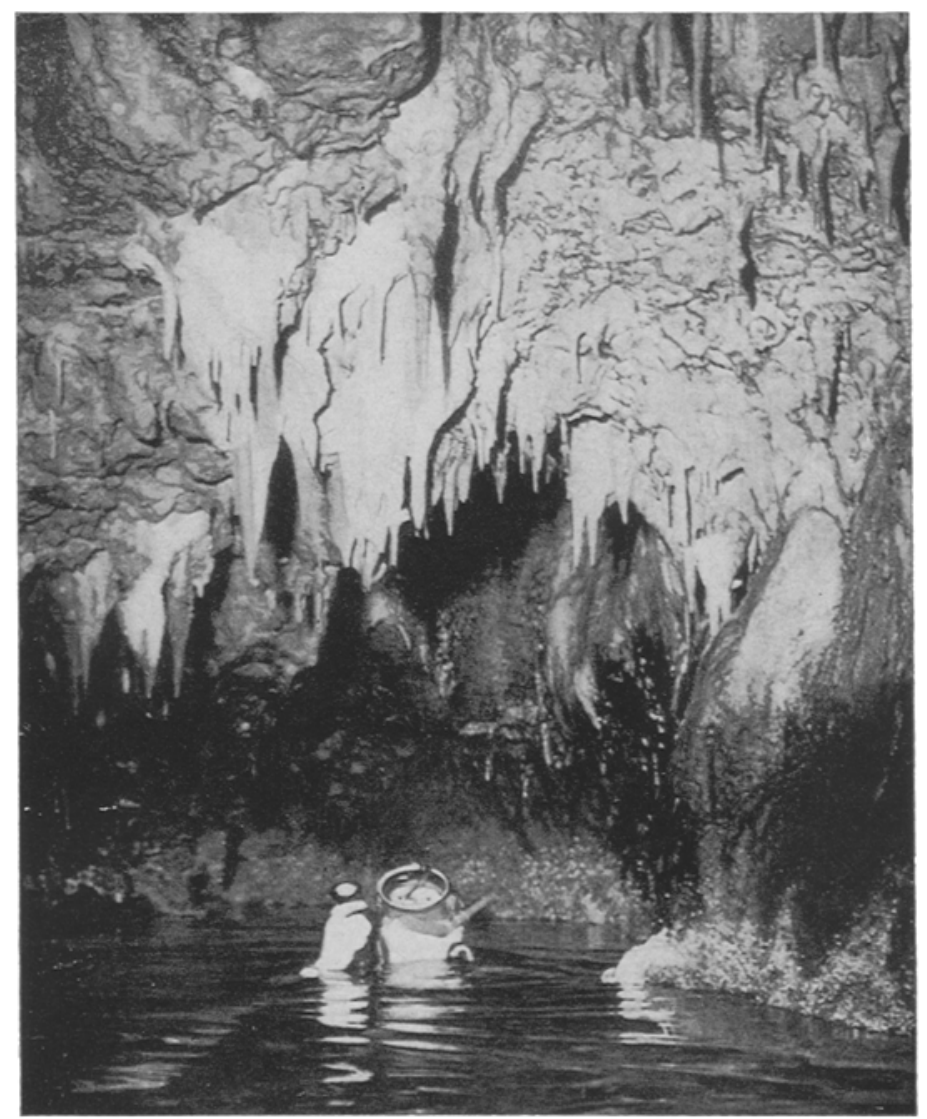

Abb. 10: Untersuchungen in unterseeischen Höhlen. Das Bild zeigt eine unterirdische, nur durch unterseeische Gänge erreichbare Luftkuppel mit ihren Sinterbildungen. (Aus WISSEL 1957a)

gen und auf diese zweckmäßig zu reagieren. Der Bodengreifer, wenn ich so vereinfachen darf, liefert uns immer nur einen Bruchteil jener Nachrichten und informiert uns immer erst zu spät darüber, daß er (beispielsweise) danebengegriffen hat. Die neuen Möglichkeiten haben wir von der Anschauung abhängig gefunden. Damit ergibt sich 
die Frage, in welchen Disziplinen sind wir von der Anschauung abhängig und welche Einrichtungen vermitteln uns diese? Wir werden damit dem Prinzip des Verfahrens näherkommen, denn es geht uns um die Meeresbiologie und nicht um irgendeine Methode.

\section{Anschaung und ihre Gebiete}

In der Biologie kennen wir eine ganze Reihe von Disziplinen, welche der Anschauung unbedingt bedürfen. Namentlich bei jenen Fragestellungen, welche sich - im Vorfelde der Kausalanalyse - mit der Beschreibung komplexer Korrelationen befassen, ist sie ganz unentbehrlich. Die Morphologie kann als ein klassisches Beispiel gelten. Aber auch wichtige Teile der Verhaltensforschung und - was uns hier besonders interessierei

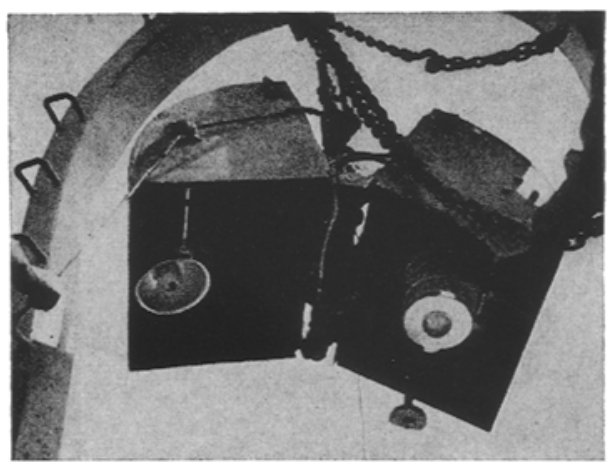

Abb. 11: Kombination eines Bodengreifers mit einer automatischen Tiefenkamera. (Aus MENziEs et al. 1963)

soll - der Okologie befinden sich methodisch in derselben Situation. Bei der letzteren sind es vielfach komplexe Beziehungen, welche Organismen mit ihrem Milieu verbinden, oder solche, welche unter speziellen Milieubedingungen Organismen und Organismengruppen untereinander im Zusammenhang zeigen. Dabei bedürfen die Beziehungsweisen immer erst der Analyse, bis sie verläßlich unter Experimentalbedingungen wiederholt werden können. Diese Fülle von Zusammenhängen muß also zunächst am Ort ihres Wirkens aufgesucht und analysiert werden.

\section{Gewinnung von Anschaung aus dem Sublitoral}

Fragt man nun unter so allgemeinen Voraussetzungen nach den Methoden, welche Anschauung vermitteln, so stellt es sich heraus, daß die der Taucherei nur eine eines ganzen Arsenals ist.

Ist beispielsweise die Abhängigkeit einer Artengruppierung von einem Milieufaktor erkannt, etwa einer Myriapora-Peyssonelia-Assoziation von der Standorthelligkeit, oder die eines Aglaophenia pluma-Bestandes von der Teilchengeschwindig- 
keit der Wasserbewegung, so genügt es, am Standort den entsprechenden Meßfühler zu montieren. Für den Taucher wäre das Beobachten der Meßwerte über längere Zeit ganz unpraktisch. Hat man den Vorgang des Uberwachsens durch Antbo involvens oder der Filterrhythmik von Halocynthia papillosa aufgedeckt, dann kann ihn der Taucher gar nicht verfolgen. Die Aufstellung der Einzelbildkamera (Abb. 5) hat ihn abzulösen. Ahnlich ist es mit dem Zusammenhang zwischen Klima- und Aktivitätsrhythmik der Sedentarier, dem Standortverhalten von Errantiern etc.; man denke beispielsweise an die Beziehungen zwischen dem täglichen Gang der Helligkeit und der Entfaltung vieler Anthozoa, die am Tage geschlossen, nachts aber voll geöffnet stehen (Abb. 6), man denke an die der Gezeitenrhythmik und der Filterhaltung der mobilen

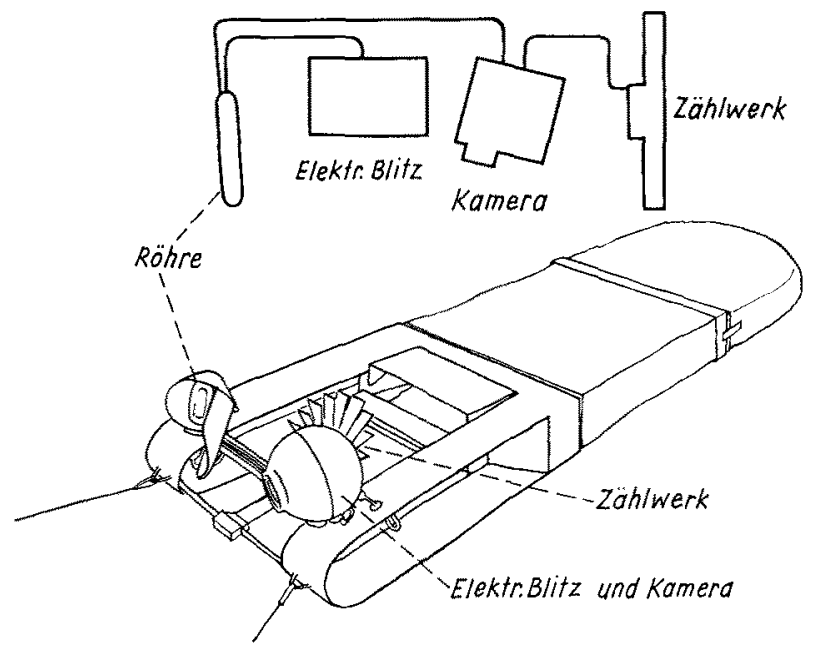

Abb. 12: Kombination einer Schlittendredge mit Zählwerk und automatischer Serien-Bildkamera. (Aus RIEDL 1963b)

Flächentypen, Seefedern, Haarsterne, oder an die der täglichen Schutzsuche von Mysidaceen über großen Anemonen. Jeweils ein Meßfühler und ein Zeitraffer-Satz würden den Taucher mehr als ersetzen. Geht es aber um noch längerzeitige Erscheinungen, etwa um die Bohrtätigkeit in der Paracentrotus-Halde, die Dynamik der Wachstumsoder Sukzessionsvorgänge, dann kann überhaupt nur mehr ein Blitzlicht-ZeitrafferSatz Hilfe bringen.

Das Gebiet der unterseeischen Phototechnik hat bereits einen breiteren Niederschlag in der Literatur gefunden. Dabei haben sich zwei Disziplinen entwickelt.

In der ersten Gruppe stelle ich jene Arbeiten zusammen, welche sich mit der Photographie von $\mathrm{H}$ and a us durch den Taucher befassen, einschließlich einiger Angaben über Gehäusebau und Optik im allgemeinen: Barnes (1953-54, 1959), BARTsCH (1927), Boutan (1893, 1898, 1900), Chesterman (1950), Collins (1950a, b), Conger (1950, 1953), Ernst (1957), Fye (1950), Gast \& Burt (1954), Gislen \& Odquist (1935), Glennan (1914), Halder (1899), Hass (1942), Hofman (1938), Hopkins \& Edgerton (1961), Humphrey (1893), Ivanoff (1951, 1953, 1956), Jackson (1913), 
Knapp (1947), Longlex \& Martin (1927), Nikolić (1957, 1958a), OWen (1958), Perkins (1914), Rebikoff (1952b, 1954), Reighard (1909), Richter (1958), ShumWay (1953-54), STORR (1953), Thorndike (1950), Walker (1933), Wasmund (1937a), Williamson (1913) sowie WISSEL (1957b). Weitere Angaben sind besonders in RICHTER (1958) zusammengestellt.

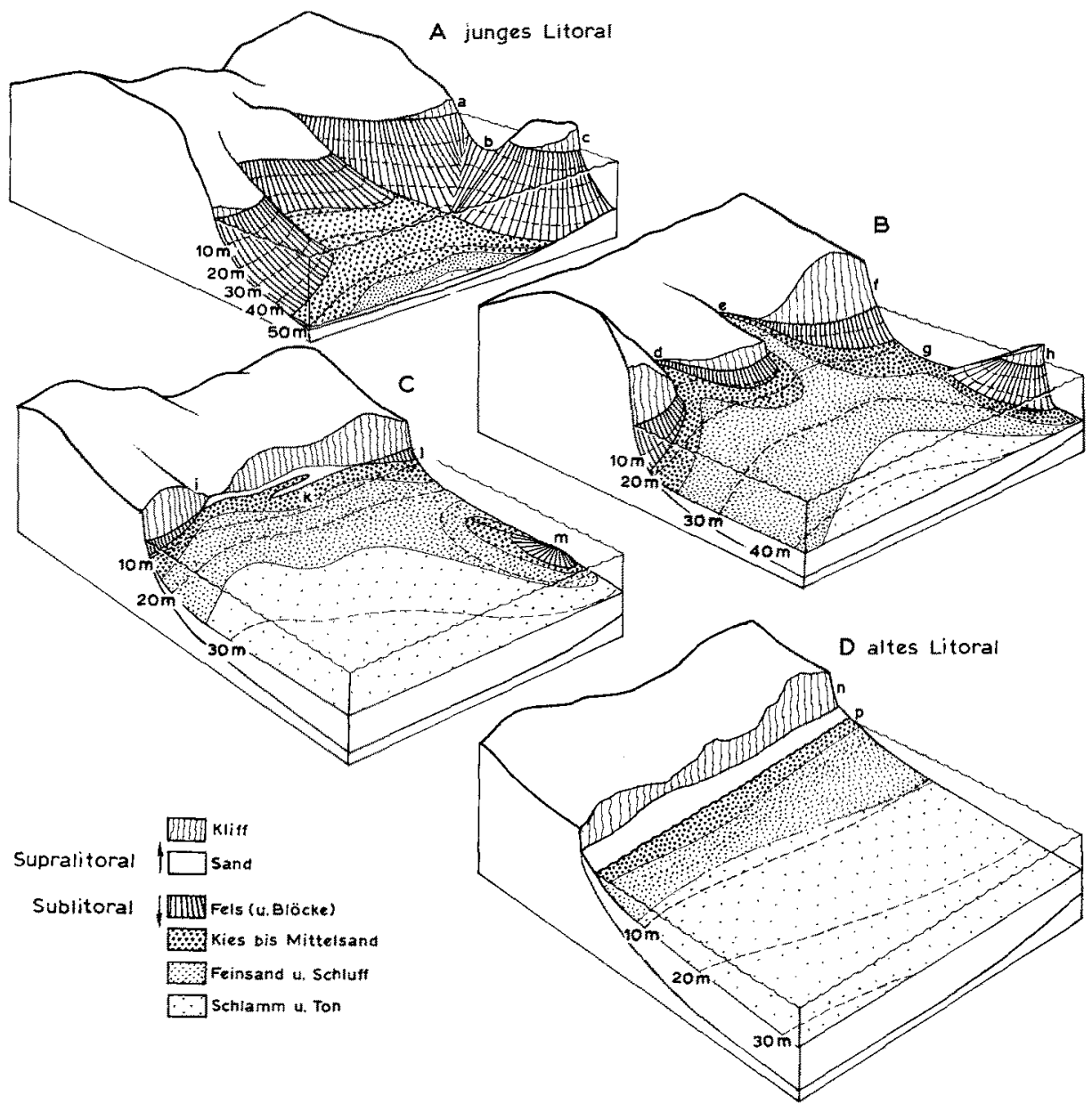

Abb. 13: Schematische Darstellung der Veränderung der Sublitoral-Substrate mit zunehmendem Altern der Küste, von der Kliffbildung (in a) bis zur Ausbildung gestreckter Sandstrande (in p). (Aus RIEDL 1966a)

In der zweiten Gruppe gebe ich eine Ubersicht von Studien mit Phot oa u tomaten, wie sie auch für tiefe Gewässer verwendet werden: BAKER (1957), BARNES (1959), Bonde, Marchand \& Gibbons (1951), Clarke (1958), Cousteau \& Dugan (1963), Cross (1954), Czrhak (1956), Czihak \& Zei (1960), Emery (1952), Ewing, Vine \& Worzel (1946), Ewing et al. (1946), Hahn (1950), Harvey (1939), Harvey 
\& Baylor (1948), Hofman (1938), Laughton (1957, 1959), Longhurst (1958), Menziers, Smith \& Emery (1963), Owen (1951, 1958), Riedl (1956b), Thorndike (1958-59) sowie VeEvers (1951, 1952).

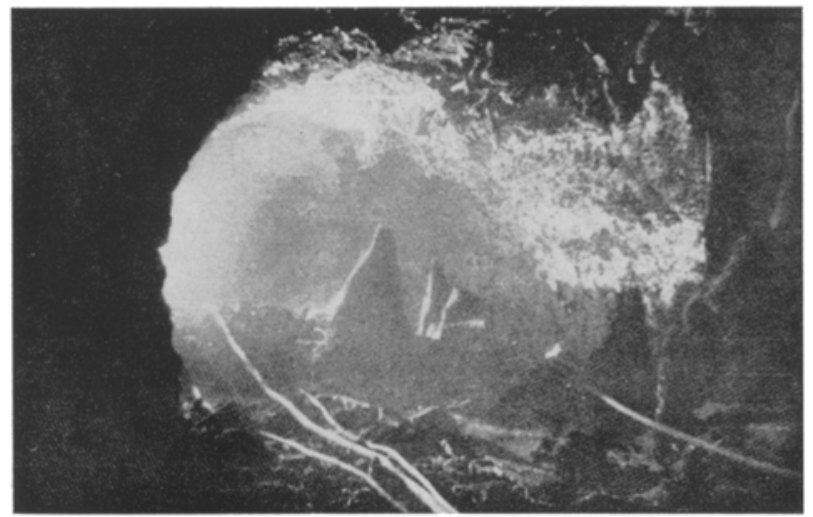

Abb. 14: Unterseeische Stalagmiten in dem wassergefüllten Gang einer Seehöhle. (Aus Corror et al. 1958)
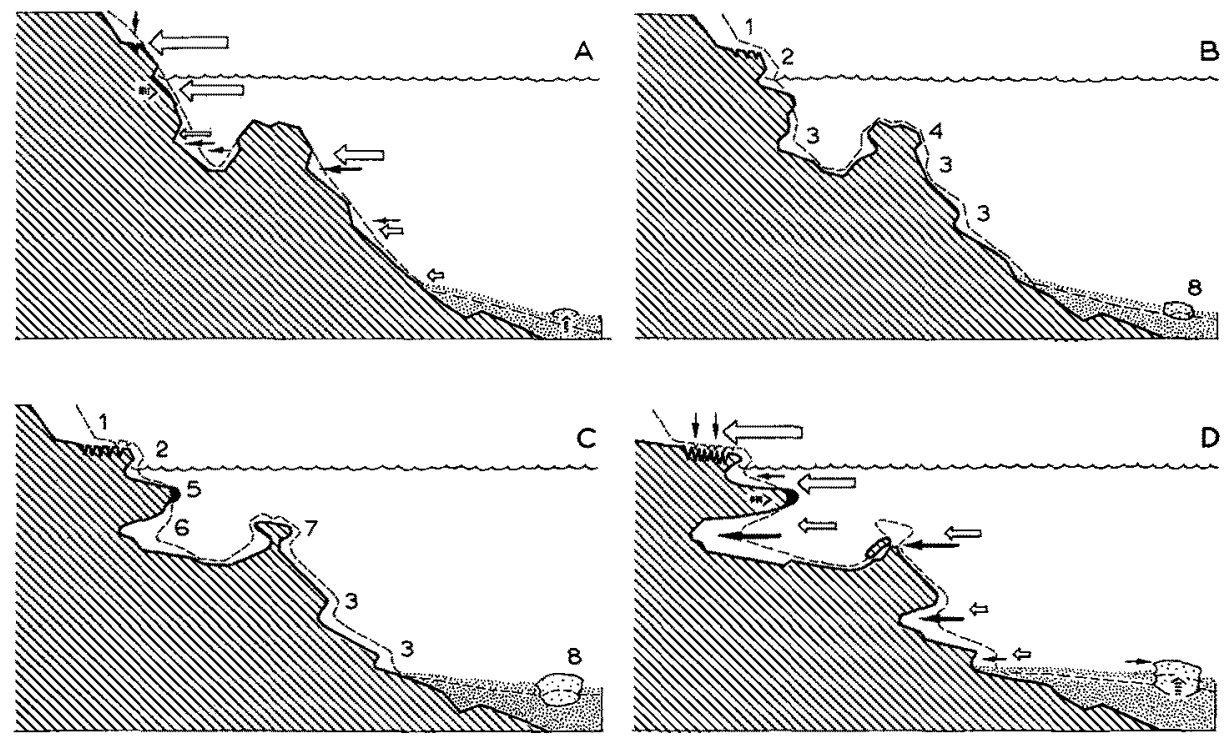

Abb. 15: Die Wirkung der Algen und der Sendentarier auf die Veränderung des Küstenprofiles, in vier Phasen gezeichnet. In A und D sind die Kräfte, in B und C die morphologischen Abschnitte eingetragen. (Aus RIEDL 1966a)

Gilt es nicht zeitlich, sondern bathymetrisch oder geographisch über den Optimalbereich des Tauchers hinauszugreifen, so bietet die Fernseheinrichtung vorzügliche Möglichkeiten, wenn das Aufnahmegerät einer steuerbaren Lafette anvertraut wird (Abb.7). Auch die Deponierung jener Datenspeicher, die im Seichtwasser der Taucher aufgestellt 
hätte, kann man im Tiefwasser der Raupe überlassen. Am Wege zu diesem Ausbau sind namentlich die Arbeiten mit der „tauchenden Untertasse“ (Abb. 8), die Fernsehstudien von BARNEs (1952-1959) und jene mit automatischen Tiefenkameras (Abb. 9) von Bedeutung.

Mitteilungen über Studien mit Hilfe des Unterwasserfernsehens sowie seiner Bedeutung für die Meeresbiologie sind verfaßt worden von: BACKUs \& BARNES (1957), Barnes $(1952,1953 a, b, c, 1955,1959)$, Brandt (1955), Cronenbroek (1956), Cross

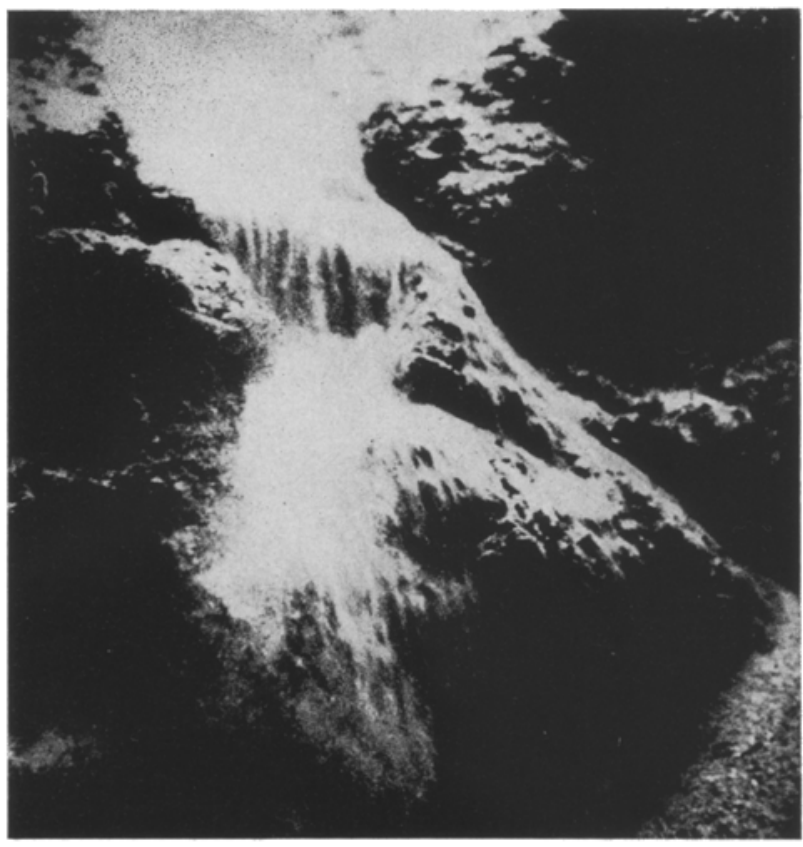

Abb. 16: Unterseeischer, etwa $10 \mathrm{~m}$ hoher Sand-Fall in Cape San Lukas Canyon. (Nach LimBAUGH aUS FRIEDRICH 1965)

(1954), Hempel (1957), Hunger (1955), Nikolić (1958b), Riedl (1963b), Sand (1955), Stamp (1953), Thomson (1956) und Zupanović (1955). Arbeiten aus dem Süßwasser sind hier nicht angeführt; sie gehen aus den zitierten Publikationen hervor.

Weiterhin läßt sich die Anschauung erleichtern durch das Experiment in der Natur, das Einsetzen künstlicher Substrate oder Faktoren, durch eine Taucherkammer oder einen Beobachtungsschacht an der Steilküste, bis der Zusammenhang sicher erkannt ins Labor übertragen werden kann. Ich verzichte darauf, hier noch weitere Beispiele und Anwendungsbereiche zu schildern, und darf die Hauptpunkte zusammenfassen: Es geht also letztlich nicht um die Taucherei, sondern um die Gewinnung von Anschauung und um die koordinierte und gezielte Gewinnung von Nachrichten. Das Tauchen ist nur eine der Methoden; sie kann in immer vielfältigeren Belangen ersetzt werden. Sie ist aber die direkteste der Erfahrungs-Quellen und darum ist von ihr ausgehend weiterzubauen. 
Die Literatur, welche sich mit technischer Automation im submarinen Bereich befaßt, ist noch recht uneinheitlich. Die Mehrzahl der Unterlagen produzieren die Herstellerfirmen. Technische Übersichten liefert die Zeitschrift „Undersea Technology“ (Compass Publ., Arlington, USA). Aus dem Teilgebiet, welches biologische Interessen mit der Gewinnung von Anschauung verbindet, seien hervorgehoben: AnDerson (1960), Dugan (1951), J. Clark (1964), Emery (1952), Emery \& Merrill (1964), Riedl (1963b) und Tregouboff (1955).

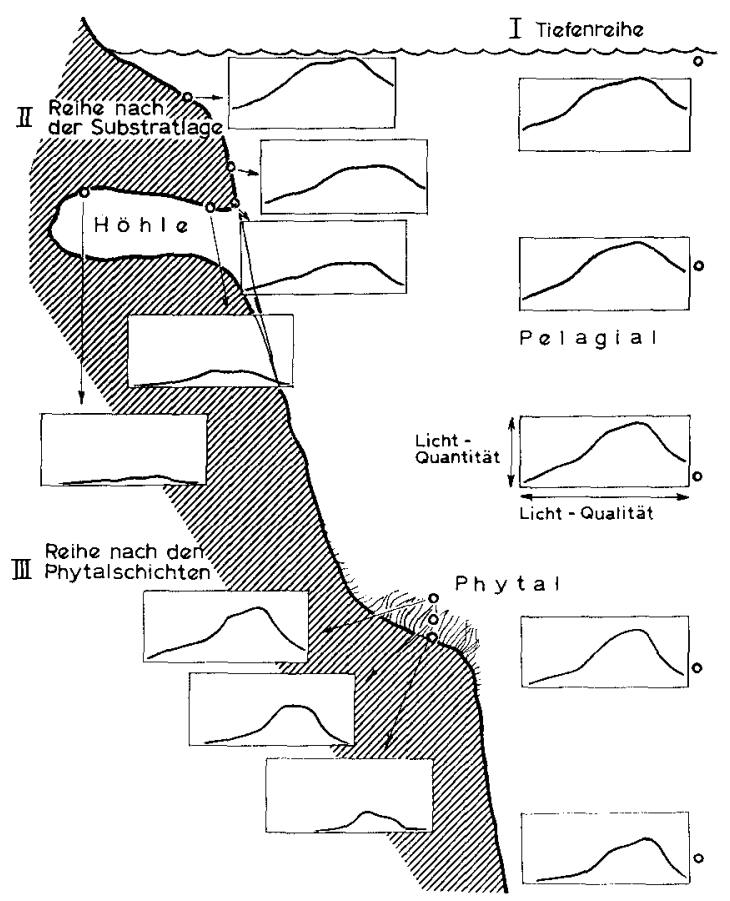

Abb. 17: Schema der drei Lichtgefälle im Litoral. Die Kreise bezeichnen die Meßpunkte, die Rechtecke die zugehörigen Lichtwertkurven. (Aus RiedL 1966a)

\section{NEUE FRAGEN IN DER LITORALFORSCHUNG}

Mit Hilfe der Taucherei sind in der Litoralforschung ganz überwiegend neue Fragestellungen angeschnitten worden. Die Ursache ist ökonomischer Natur. Niemand nimmt auf die Dauer die Unbequemlichkeiten und Risiken auf sich, um Arbeiten durchzuführen, die auch mit den bisherigen Methoden gelungen wären (Abb. 10). Nach den Bedingungen der Methode sind es klein- bis kleinsträumige Untersuchungen, wie zu erwarten, meist kompliziert strukturierter Erscheinungen.

\section{Kontrolle der herkömmlichen Geräte}

Ein kleines, aber sehr aufschlußreiches Gebiet will ich vorwegnehmen, zumal die Ergebnisse meist gar nicht publiziert werden: die Prüfung der Leistungen der konser- 
vativen Sammelgeräte. Zunächst haben uns solche Studien nachgerade beunruhigende Einblicke in bestehende Mängel verschaff. Bald darauf haben sie zur Entwicklung von Verbesserungen Anlaß gegeben, welche durch Kombinationen der Verfahren wiederum auf Anschauung und auf die simultane Gewinnung vermehrter Nachrichten abzielen (Abb. 11, 12). Mit der Prüfung der Leistung unserer Sammelgeräte hat sich die gerätetechnische und auch die faunistisch-ökologische Literatur immer wieder auseinandergesetzt. Diese Kritik ist ein integrierender Bestandteil der Entwicklung des ganzen Arsenals. Mit Hilfe der Anschauung, sei es durch Taucher, Kamera-Automaten oder Fernseher, geschieht das erst in jüngster Zeit: BeHAvior ... (1955), Drach (1956), Emery \& Merrili. (1964), Fried (1957), Margetts (1952), Menziers, Smith \& Emery (1963), Riedl (1955, 1956a, b), Sand (1955), Scarlato, Golikov \& Gruzov (1964).

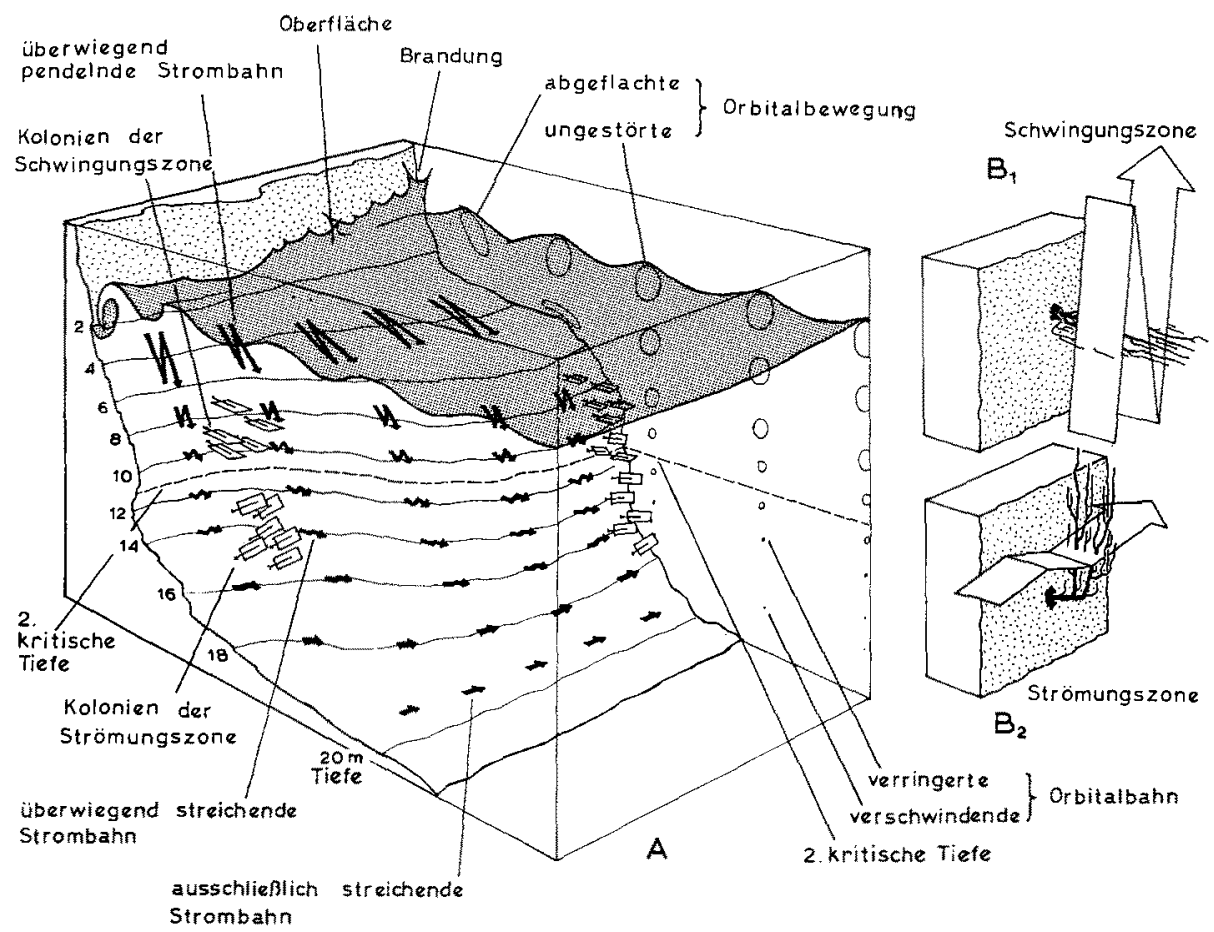

Abb. 18: Schema der Teilchenbewegung im Declivium des Felslitorals und der Stellung der flächenförmigen Filtrierer, am Beispiel von Eunicella. (Aus RuEdi 1966a)

Anorganische Disziplinen

Die anorganischen Disziplinen, eine zweite Gruppe, können nur gestreift werden. Aber viele Ergebnisse geologischer, geomorphologischer und klimatologischer Untersuchungen sind für die Okologie von großer Wichtigkeit; einige Fragen sind daher zu referieren. 
Aus dem Gebiet der Geomorphologie ist für uns zum Beispiel die Analyse des Küstenzustandes von Bedeutung. Bislang ist die Typologie der Küsten, nach der Vertikalbewegung und nach den Zuständen des Küstenalterns, überwiegend auf die Merkmale des Eu- und Supralitorales gestützt worden. Nun beginnen wir jene des Sub-

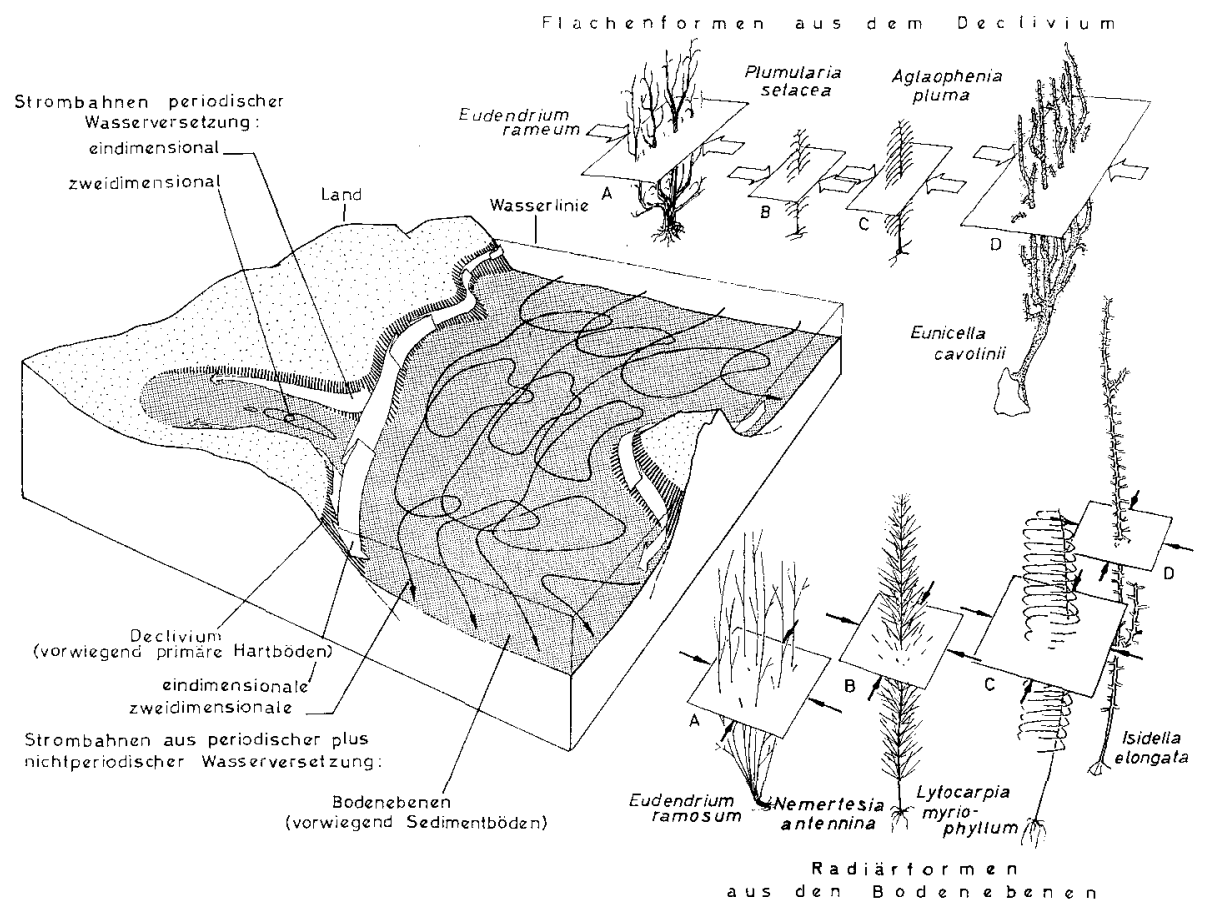

Abb. 19: Zerlegung in den ein- und zweidimensional streichenden Wasserkörper im Litoral und ihre Wirkung auf die Auswahl flächiger und radiärer Cnidarier-Typen. (Aus RIEDL 1964a)

litorales stark vermehrt hinzuzugewinnen, die sich als höchst aufschlußreich erweisen (Abb. 13). Wir begegnen versunkenen Karsthöhlen und Tropfsteinbildungen (Abb. 14) und gewinnen neue Zeugen für das Alter und die Herkunft der Küstengründe. Wir erhalten neue detailreiche Aufschlüsse über die Mitwirkung der Organismen am Litoralprofil (Abb. 15), und in geologischer Hinsicht sei auf die Anschauung der Sedimentströme, zum Beispiel der "turbidity currents“, verwiesen (Abb. 16) sowie auf die Strömungsprofile und Wühlbauten bis in große Tiefen. Die Taucherei ermöglicht letztlich auch jene Feinuntersuchungen der Sedimentdynamik, wie sie im Eulitoral schon vorgenommen werden.

Ein neues Gebiet für sich bildet die sublitorale Mikroklimatologie. Am Strahlungssektor ist klar geworden, daß wir dreierlei Lichtgefälle im Benthos zu entflechten haben (Abb. 17), welche sich quantitativ und qualitativ unterscheiden und noch dazu ungleiche Tages- und Jahresgänge besitzen: die Gefälle nach der Tiefe, der Substratneigung und der Substratabschirmung. Am Sektor der Dynamik des Mediums hat sich eine noch größere Vielfalt an Erscheinungen ergeben. Wir haben die zerreißenden, die 
schwingenden Wasserkörper im Seichtwasser kennengelernt (Abb. 18) sowie die einund zweidimensional streichenden Wasserkörper zwischen Felsdeclivium und der tieferen litoralen Sortierbank der Sedimente (Abb. 19), die Verschiebungen der kritischen Tiefen zwischen ihnen und ihre biologische Bedeutung. Wir haben innerhalb der Bestände, selbst in Räumen der Dezimeter- und Zentimeterdimension Bewegungsgefälle

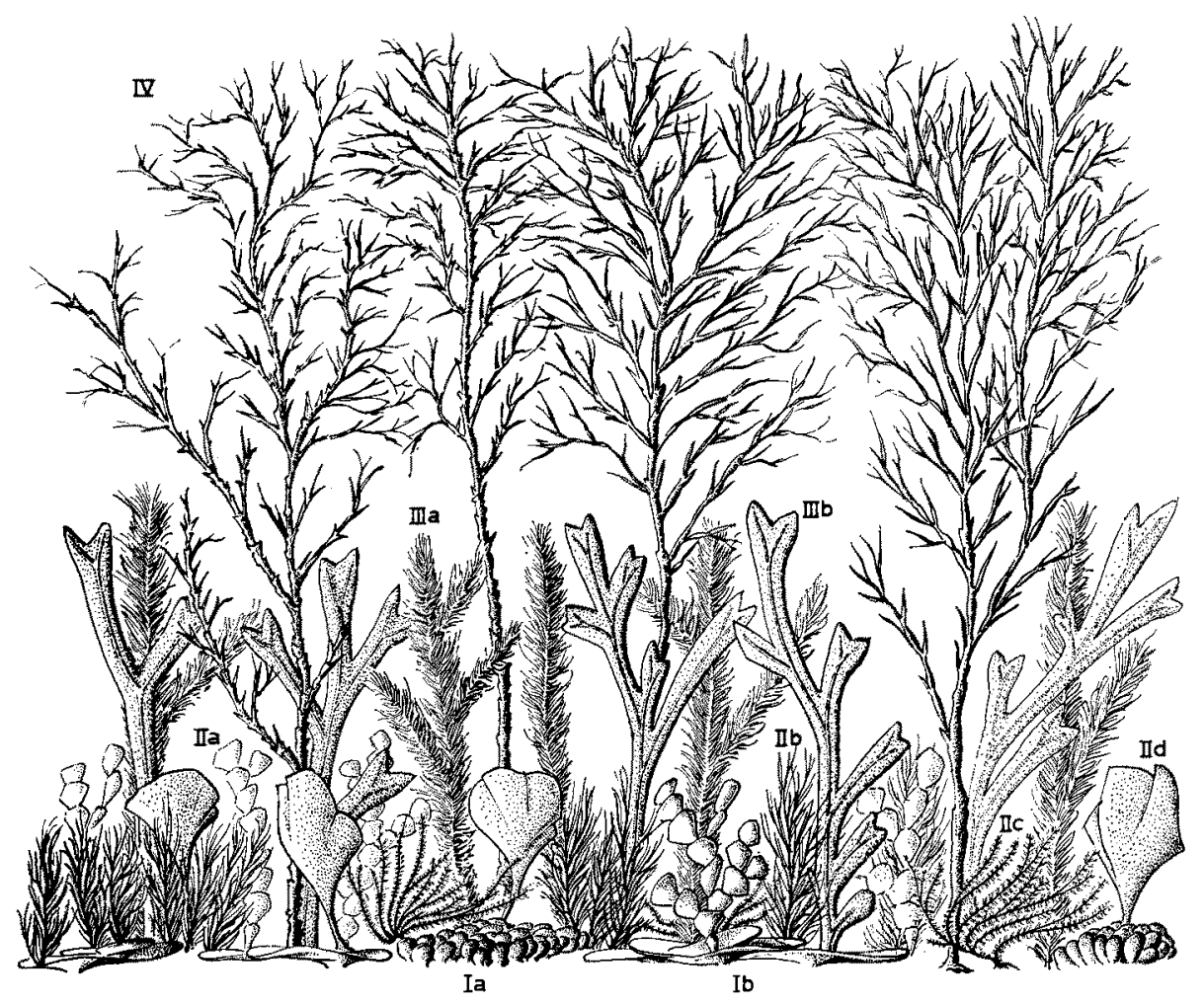

Abb. 20: Der Schichtenbau der Algenvegetation innerhalb von Cystosiren-Beständen im Mediterran. (Nach ERNST 1959 b aus RIEDL 1966a)

gefunden, die über mehrere Dezimalen reichen und räumlich alle bekannten Gefälle in den Schatten stellen. Selbst der Ansatz zur Mikroklimatologie der Gasspiegelschwankungen in den Phytalbeständen ist gefunden worden.

Im Bereiche bioklimatologischer Untersuchungen, sowie jener geologischen und geomorphologischen Arbeiten, die für die Meeresbiologie von besonderem Interesse sind, lieferten folgende Studien einschlägige Ergebnisse: Barnes (1953b), Corroy (1958), Emery (1953), Ernst (1959b), Ewing et al. (1946), Gessner \& Hammer (1960), Gilet (1956), Ledoyer (1961), Limbaugh \& Rechnitzer (1955), Magnus (1964), Menard (1952), Riedl (1959f, 1963b, 1964a), Sarà (1961b), Shepard (1939, 1948), Shepard, Emery \& LaFond (1941), Shepard \& LaFond (1940), Wasmund (1937b, 1938b) sowie ZeNkovitch \& Koplin (1965). 


\section{Biologische Fragestellungen}

Besonders vielfältig sind die neu zugänglichen Fragestellungen im Bereich der Biologie. Namentlich die Gebiete der Faunistik, der Okologie und des Standortverhaltens werden bereits so deckend behandelt, daß ich einigermaßen künstlich zerlegen muß, wenn es gelingen soll, wenigstens die wichtigsten Arbeitsrichtungen herauszustellen.

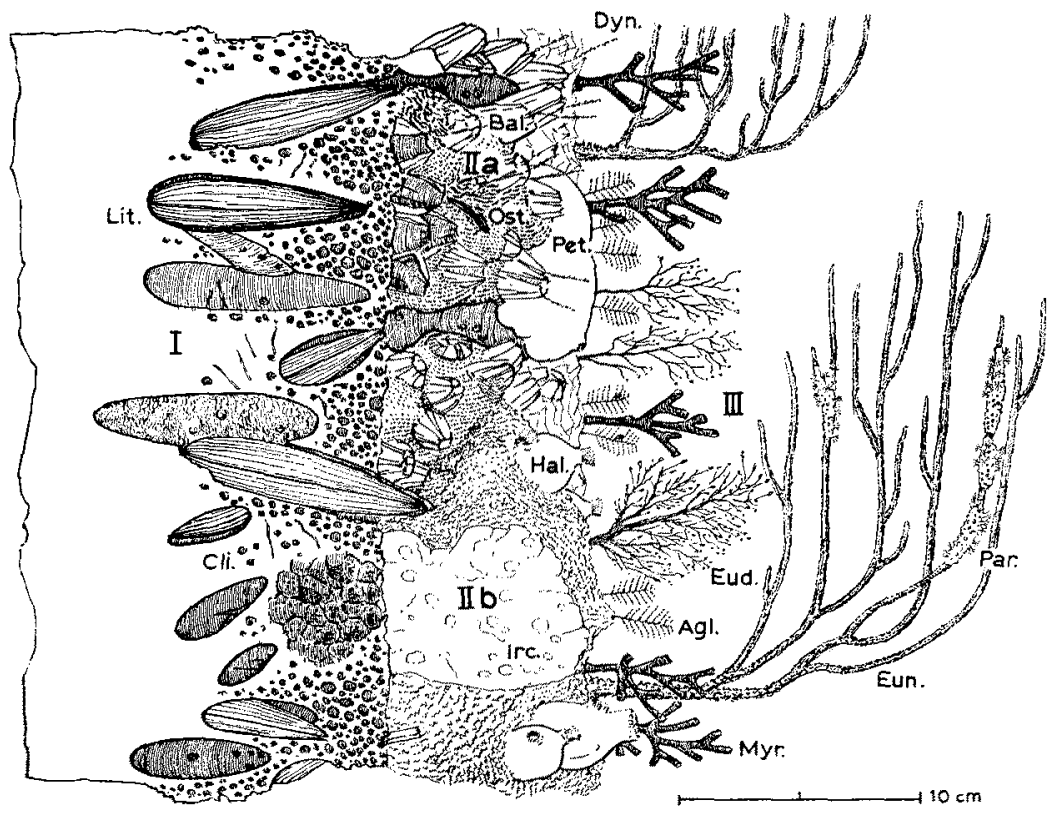

Abb. 21: Organisation der Sedentarier-Bestände im Bereiche unterseeischer Wände von Mittelmeer-Höhlen. I Endolithion, II und III die Teile der Aufwuchs-Schichten. (Aus RIEDL 1966a)

Bereits im Gebiet der quantitativen Bestandsaufnahme ist Neuland erschlossen worden; war es doch bislang unmöglich, beispielsweise aus sublitoralen Felsgebieten quantitative Proben zu gewinnen. Dasselbe gilt aber auch für die Corallinaceenbänke, das Korallenriff, die "kelp-beds“, alle komplizierteren Hartboden-Substrate. Faunistisch-floristische Untersuchungen und Aufsammlungen mit Hilfe der Taucherei, vorwiegend mit ökologischen Absichten, beinhalten oder referieren folgende Arbeiten: Abel (1955), Aleem (1956), Arndt (1936), Audouin \& Mllne-Edwards (1832), Baird \& Gibson (1956), Berthold (1882), Bursa \& Wojtusiak (1948), Cavolini (1785), Drach (1948a, b, 1951), Ernst (1955), Forster (1954, 1958), Gomoin \& MüLler (1962), Haefelpinger (1960, 1962), Klausewitz (1964), Lindberg (1955), Longley (1918), Melone (1963), Müller (1962), Rakovec (1960), Randall (1955), Rützler \& Sarà (1962), Sarà (1959), Sarà \& Melone (1963), Scheer (1964a, b) Tardent (1959), Theodor (1963), Vacelet \& Levi (1958), Waern (1952) sowie ZAvODNiK $(1960,1963)$. 
In der Folge sind Studien der Organismen-Anordnungen hervorzuheben. Gehen wir von den aus Algen und Sedentariern aufgebauten Substratstrukturen aus, so sind es wieder die höher zusammengesetzten der stabilen Böden, die unserer Kenntnis von den Litoralgründen hinzugefügt worden sind. Hier sind die Schichtenbauten der Phytalregion zu nennen, der Laminarien- und Cystosiren-Gebiete (Abb. 20), der Kelps und der Seegraswiesen. Ansätze sind im Gebiet der Korallenbauten und der sekun-

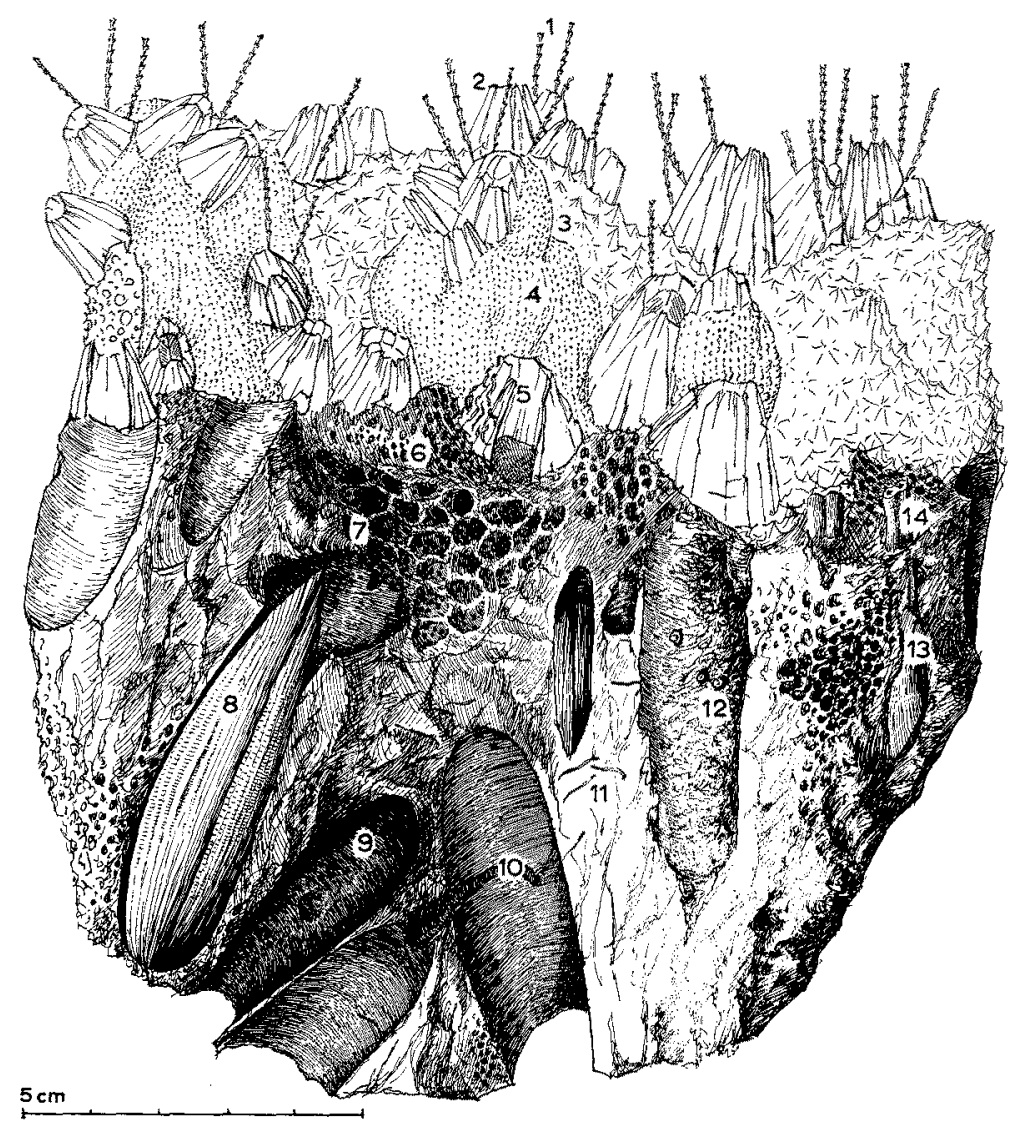

Abb. 22: Detail eines Aufbaues mediterraner Höhlenbestände. Beziehung zwischen Endolithion und der darüberliegenden Krustenschichte Nr. IIa (vgl. Abb. 21). (Nach RiedL 1966a)

dären Hartböden gefunden worden. Mit den Bestandsstrukturen der bisher völlig unzugänglichen unterseeischen Höhlen des Felslitorales (Abb. 21, 22) haben sich allein schon über 60 Arbeiten auseinandergesetzt, und die Erfahrungen sind mit tausend erkannten marinen Höhlenbewohnern so dicht geworden, daß ich dieselben, zu einer Monographie zusammengefaßt, vorlegen kann. Die Untersuchungen der Höhlen der Korallenriffe, deren Abmessungen selbst die Außen-Riff-Fläche übertreffen können, haben begonnen. Speziell mit ökologischen Fragen der Sedentarier- oder der Pflanzen- 
anordnung im Benthos befassen sich folgende mit Hilfe der Tauchmethode vorgenommene Untersuchungen: Aret (1959c), Chapman (1944), Drach (1951, 1952, 1958), Ernst (1955, 1959a, b, 1960, 1966), Forster (1958), Fredj (1964), Gislen (1929), Hass (1949), Kain (1960), Laborel (1956), Laborel \& Vacelet $(1958,1959,1962)$,

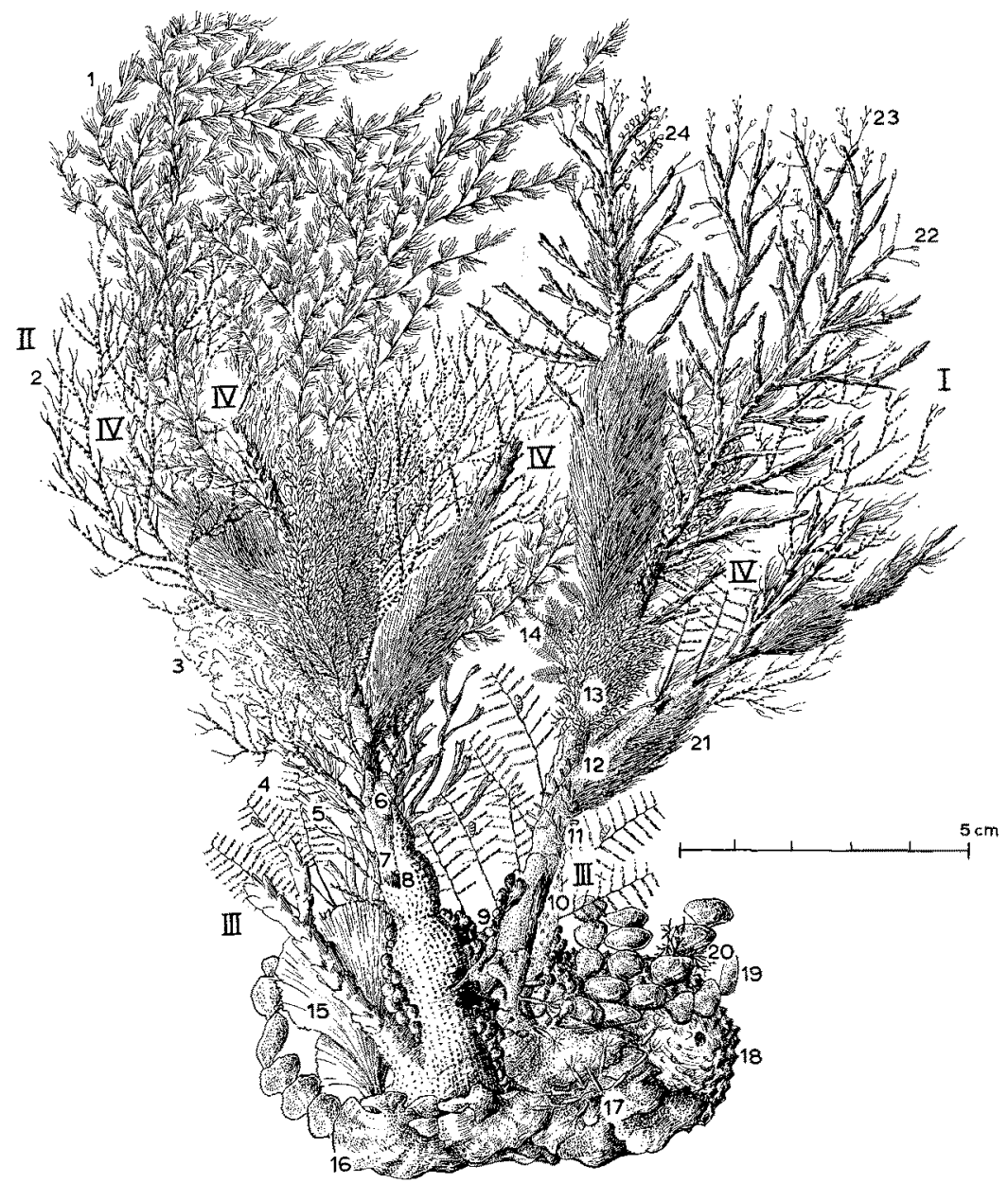

Abb. 23: Beispiel der Komplikation von Aufwuchsverhältnissen im Cystosiren-Gebiet, einer der Grundlagen mehrschichtiger Errantier-Einordnung. (Aus RiEDL 1966a)

Molinier \& Picard (1952), Odum \& Odum (1955), Olsen (1955), Pequegnat (1961a), Pérès (1957a, b, 1961), Pérès \& Picard (1951, 1955a, 1958), Picard (1954a, b, 1956), Res \& Rossi (1965), Rred (1954b, 1956c, 1959f, 1963b, 1964b, c, 1966a), Russ \& RÜtzler (1959), RÜtzler (1965a, b, c, d), SARÀ (1958, 1959a, c, 1960a, b, 1961a, b, 1962, 1962-63, 1964), VACelet (1959, 1961a, b, 1964), VACELET \& VASSEuR (1965), Waern (1962), Wojtusiak et al. (1953) und Zalokar (1942). 
Noch komplizierter aber als die Schichtung und Zonierung der Sedentärbestände hat sich die Einordnung ihrer Mikrofauna erwiesen. Wir kennen aus dezimeterstarken Beständen vielfach gleich mehrere und voneinander geradezu unabhängige Einschichtungen von Errantier-Gruppen der Klein- und Mikrofauna, welche uns die indirekten

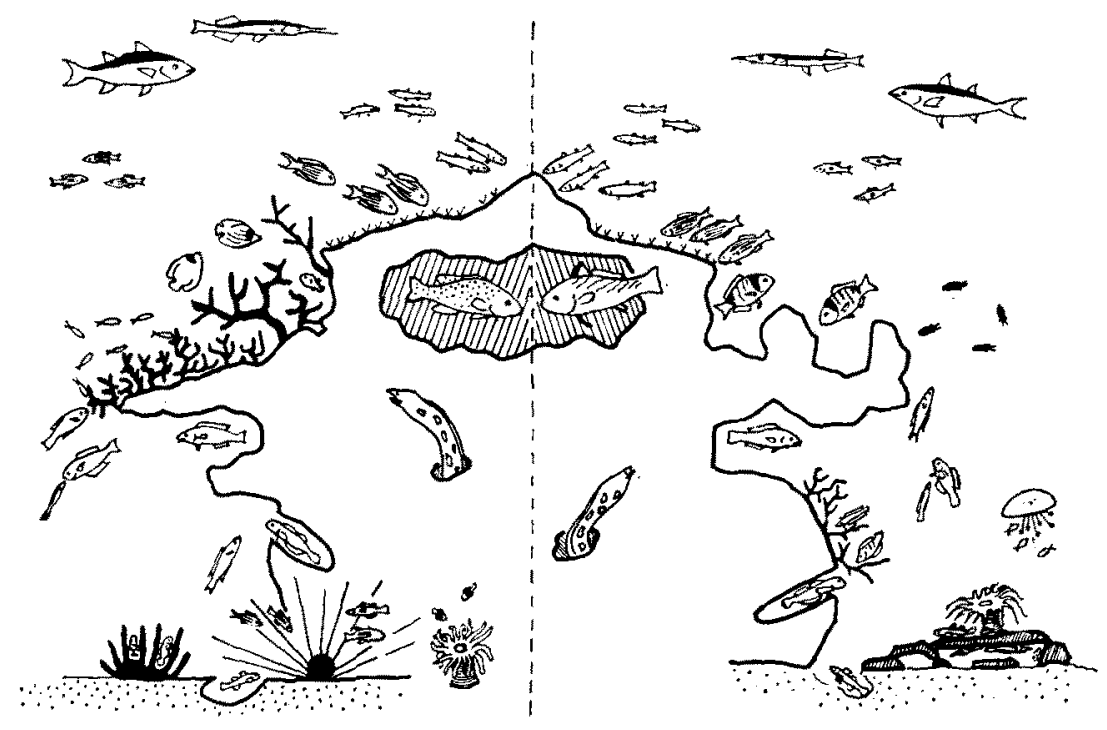

Abb. 24: Gegenüberstellung der Einordnung von Fischen in spezielle Substrat-Strukturen des Roten Meeres (links) und des Mediterran (rechts). (Aus ABEL 1961c)

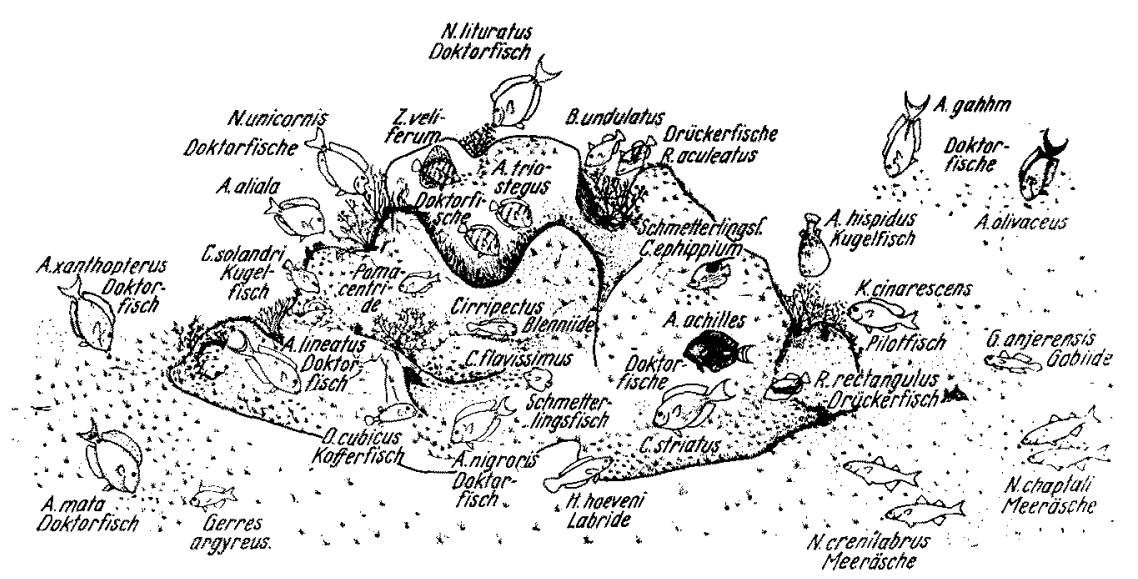

Abb. 25: Anordnung herbivorer Fische und ihre Freß-Stellung im Korallenmeer. (Nach HIaTT \& Strasburg 1960, aus Friedrich 1965) 
Methoden immer vermengen mußten (Abb. 23). In diesem Kleinbereich sind auch konsequente Migrationen und Faunenwechsel gefunden worden, schichtenweise Trennung der Geschlechter, sogar eigene Kinderstuben in speziellen Substratschichten, also ein ganz unerwarteter Reichtum an Differenzierungen. Ein Nematoden-Beispiel aus dem Cystosiren-Gebiet legte mein Schüler OT'T (1967) vor. Studien über errante Gruppen des Benthos, besonders über die Einordnung der Mikrofauna in höher strukturierte Benthos-Bestände, sind mit Hilfe der Taucherei durchgeführt worden von: Czihak (1954), Banse (1959), Kirsteuer (1963), Ledoyer (1961), Müller (1962), Pesta (1959), Riedl (1953, 1954a, 1956c, 1959a, b, c, d, e, 1963b), Ruffo (1959), Ruffo \& Wieser (1952), Starmühlner (1955a, b) sowie Wieser (1951a, b, 1954a, b, 1959).

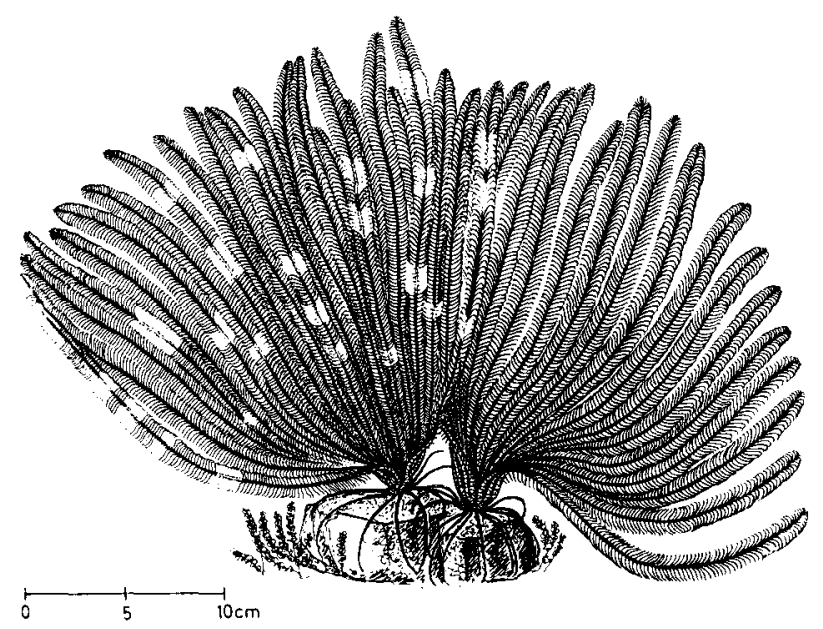

Abb. 26: Filterhaltung zweier Individuen von Heterometra savignyi, die im strömenden Wasserkörper gemeinsam einen geschlossenen Filterfächer bilden. (Aus MAGnus 1964)

Das Gebiet der Okologie berührt auch das Standortverhalten der höheren Formen, der Krabben, Cephalopoden und namentlich der Fische, deren Gestalten, Färbungen, Zeichnungen und Verhaltensweisen sich in der vielfältigsten Weise mit Standort- und Strukturmerkmalen als korreliert erwiesen haben. Aus dem Felslitoral und mehr noch aus dem Korallen-Riffgebiet liegen diese Untersuchungen vor (Abb. 24, 25). Arbeiten über Fragen des Standort-Verhaltens und der Einordnung höherer Errantier, zumeist der Fische, in die Lebensraumstrukturen, mittels der Tauchmethoden verdanken wir: Abel (1954, 1955b, 1958, 1959a, b, 1960b, 1961a, b, 1962, 1964), BARDACH (1958), Beebe (1928), E. Clark (1950), E. Clark \& Gohar (1953), Eibl-Eibesfeldt (1955, 1957, 1960, 1961, 1962), Eibl-Eibesfeldt \& Scheer (1962), Fiedler (1954, 1964), Forstner (1959), Gohar (1948), Graefe (1963), Hiatt \& Strasburg (1960), Kirchshofer (1954), Klausewitz (1960, 1962a), Libaugh (1961), Limbaugh, Pederson \& Chace (1961), Longley (1916), Longley \& Hildebrand (1941), Lut'Her (1958), Magnus (1964, 1966a), Randall (1958), Randall \& Randall (1960), Riedl (1966a), Wahlert (1963), Wahlert \& Wahlert $(1960,1961,1962)$ sowie Wojtusiak \& WOJTUSIAK (1939). 
Zahlreicher noch als diese Standortbeziehungen sind trophische, edaphische oder klimatische Einzelbeziehungen im Bereiche der Wirbellosen zu erwarten, welche die verschiedenen Standort- und Lebensformgruppen mit ihren Milieufaktoren oder untereinander verbinden. Ich muß mich darin noch kürzer fassen. Besonders unerwartet und den herkömmlichen Methoden unzugänglich sind die aufgedeckten Beziehungen zwischen der Filtrierhaltung von Errantiern und der Wasserversetzung (Abb. 26), ferner die Genauigkeit der Anordnung und Haltung flächig filtrierender Sedentarier, nach welchen nicht nur Strömungskarten (Abb. 27), sondern auch die langzeitigen Mittelwerte der örtlichen Teilchenbewegung ermittelt werden können. Ebenso eigentümlich ist die Anordnung vieler Anthozoen nach den Isophoten, der Zusammenhang zwischen der Reduktion der Medusengeneration und der Standortstabilität sowie die Einsicht in die Lebensweise der stoloniferen Formen als eine Lebensformgruppe erranter Sedentarier und deren Bedeutung für die Sukzessionsvorgänge (Abb. 28) in den Bestandsaufbauten (etwa einer Uberwachsung von Poriferen), und vieles andere. Mit Milieu-

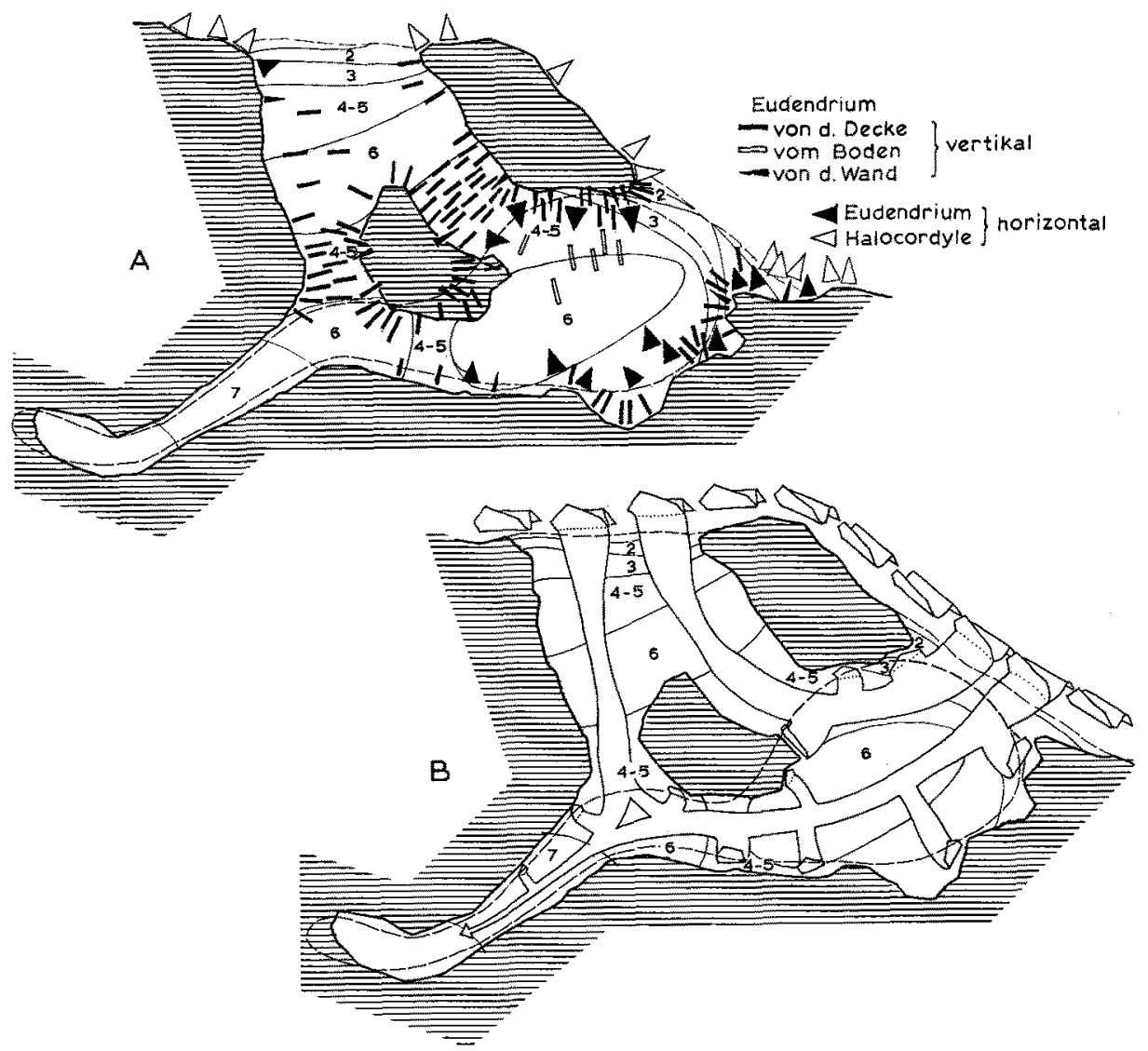

Abb. 27: Schema der Anordnung flächig gebauter Hydroiden-Stöcke im Bereich eines HöhlenGrundrisses (A) und die daraus abgeleiteten Stärken und Figuren der Wasserströmung (B). (Aus RIEDL 1966a) 
beziehungen haben sich eine ganze Anzahl der bereits weiter oben zitierten ökologischen Studien auseinandergesetzt. Das Hauptgewicht auf dieser Fragestellung haben folgende Arbeiten: Abel (1959c, 1960a), Magnus (1962, 1963a, 1964), Riedl (1959f, 1963b, 1964a, b, 1966a), RüTZler (1965a) und Theodor (1963).
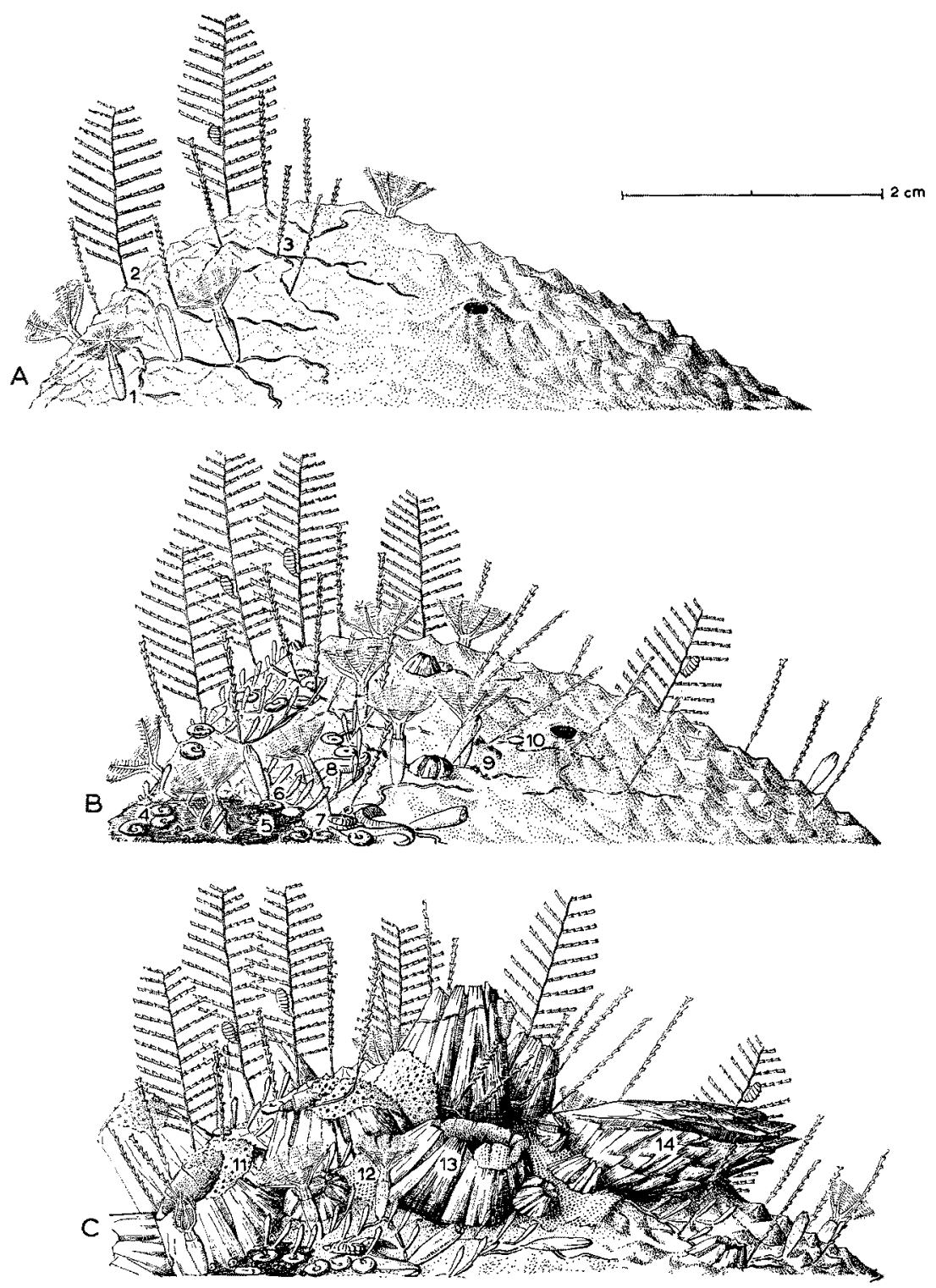

Abb. 28: Drei Schritte bei der Uberwachung eines Hornschwammes durch die Beteiligung erranter Sedentarier, der stoloniferen Formen 1,2,3 und 6 (Cornularia, Aglaophenia, Dynamena und Aetea). (Aus Riede 1966a) 
Zusätzlich zu diesen Einzelbeziehungen sind dann noch Erfahrungen höher zusammengesetzter Erscheinungen zu erwähnen. Hier kann man besonders den Einblick in die assoziationsfördernden Wirkungen der Landschaftsform erwähnen, die beispielsweise im Höhlengebiet über eine Koppelung der Licht- und Bewegungsgefälle zur Assoziierung der sonst ganz unabhängigen Hydroiden- und Anthozoen-Zonen führt (Abb. 29); man kann die Einsicht in den Mechanismus der Entstehung biotischer Bezie-

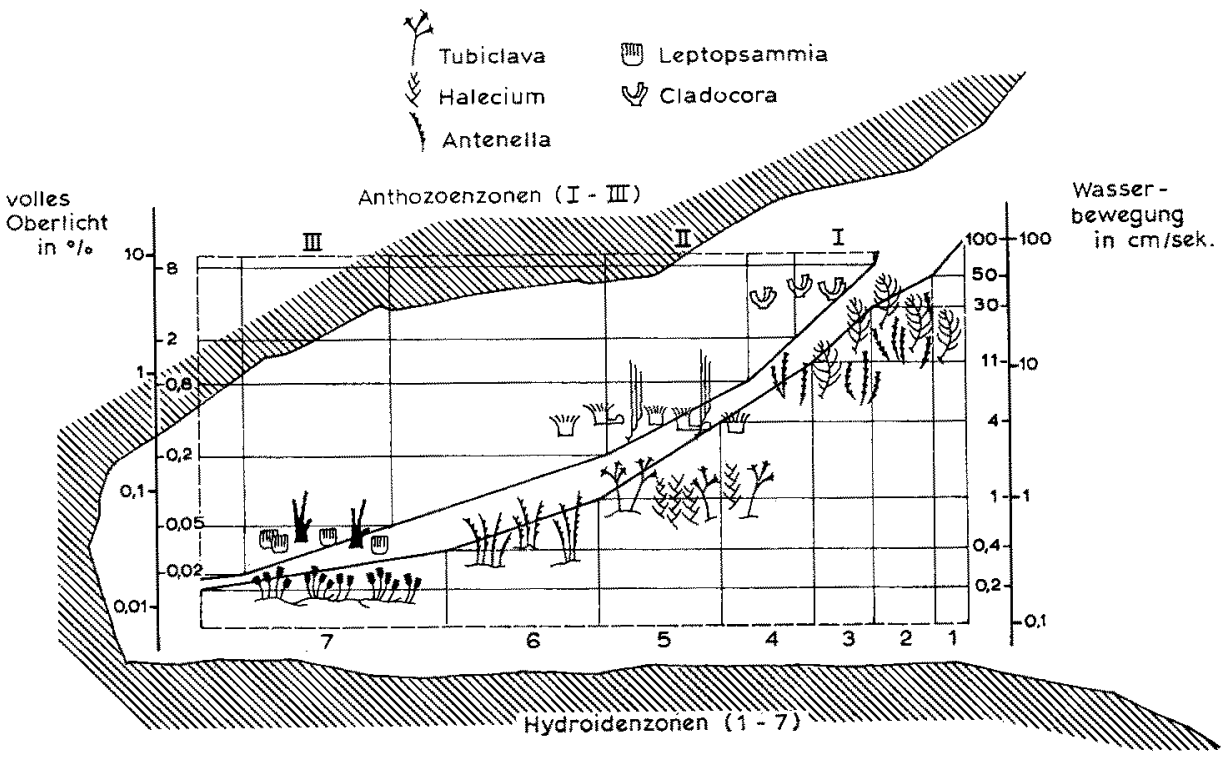

Abb. 29: Die assoziierende Wirkung der "Landschaftsform“ am Beispiel unterseeischer Höhlen. Thre Gestalt veranlaßt die an sich unabhängigen Faktoren Licht und Wasserbewegung zu annähernd gleichartigen Gefällen und führt die mit diesen verknüpften Gruppen, zum Beispiel Hydroiden und Anthozoen, zu Assoziationen. (Aus RiedL 1966a)

hungen zwischen Sedentariern hervorheben, eine veränderte Sicht der Biozönose, sowie die Aufdeckung von Parallelen zwischen Biotopreihen und systematischen Verwandtschaftsgruppen (die zur Fassung des Begriffes Lebensort-Typus Anlaß gegeben haben). Wer versucht hat, einen Überblick über die hier einschlägigen, durch unmittelbare Anschauung gewonnenen Erfahrungen zu gewinnen (was lediglich wegen der höchst verstreuten Literatur und des völligen Mangels einer Referierspalte heute so schwierig ist), wird feststellen, daß schon jetzt, wo sich die direkte submarine Feldforschung erst über zwei Jahrzehnte entwickelt hat, viele Teile des Litorals in einem neuen Licht erscheinen. Es ist von Interesse festzustellen, welche Teile das sind. Schilderungen allgemeiner, mit Hilfe der Tauchmethode erarbeiteter, biologischer Zusammenhänge werden in den folgenden Arbeiten gegeben. Abel (1961c), ErNSt (1958), Gerlach (1959), Laborel \& Vacelet (1962), Magnus (1962-1964), Pequegnat (1961b), Riedl (1963b, 1966a), RützLER (1965d) sowie WiESER (1959). 


\section{ARBEITSGEBIETE UND SCHWERPUNKTE}

Nicht minder kennzeichnend als die Fragestellungen sind für eine Beurteilung des wissenschaftlichen Tauchens die Schwerpunkte der Arbeitsgebiete, die sich in den einzelnen Lebensräumen des Litorales gebildet haben. Wir dürfen nämlich in der heutigen Methode nur insofern ein Zufallsprodukt erblicken, als ihre organisatorische Lage einen mehr zufälligen, historischen Hintergrund hat. Die Schwerpunktbildungen aus den Gegebenheiten der Methode selbst sind aber zwingend und signifikant. Diese will ich hier noch schildern und dabei die Aussichten des weiteren Ausbaues mit ins Auge fassen.

\section{Arbeiten im Epipelagial}

Zunächst war nur das Benthos Studiengebiet der Taucherei. Das strukturenärmere Pelagial wurde gar nicht in Betracht gezogen. Das hat sich geändert. Mit besseren Arbeitsbedingungen hat das wissenschaftliche Tauchen überall dort angesetzt, wo sich

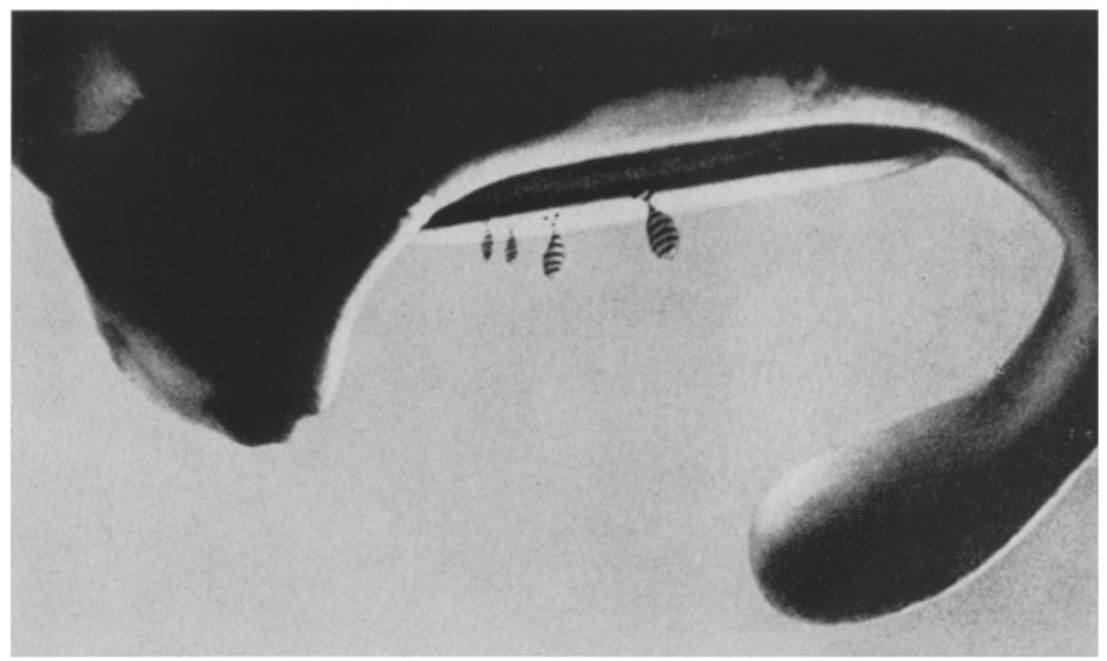

Abb. 30: Maul einer Manta mit vier Individuen des Lotsenfisches Naucrates ductor. (Aus Hass 1952)

auch im Pelagial Strukturen verdichten. Hier sind in erster Linie die Studien an Zookorrenten und Echostreuschichten zu erwähnen sowie jene an Großformen des Pelagials, sofern man diese selbst, von den Scyphomedusen bis zur Manta (Abb. 30) als Lebensraum von Kommensalen, Parasiten und sonstigen Begleitern auffaßt. Ansätze liegen auch vor zu Studien in treibenden Algengebieten und an schwer entnehmbaren Objekten wie Siphonophoren, Ctenophoren und Salpenketten. Die Entwicklung dieser Epipelagialstudien hängt von der Anpassung der Einrichtungen auf den Forschungsschiffen ab. Direkte Untersuchungen im Bereiche des Epipelagial, sei es durch Taucher, 
Anschauung übermittelnde Geräte oder Unterwasserfahrzeuge, haben sich mit Schichtgrenzen, mit Planktonverteilungen und mit dem Verhalten von Großformen auseinandergesetzt: Backus \& Barnes (1957), Baker (1957), Barham (1966), Barnes (1953c), Beebe (1941), Bernard $(1955,1958)$, G. Clarke (1958), Erbl-Erbesfeld t \& Hass (1959), Hass (1952), Klausewitz (1962), Limbaugh \& Rechnitzer (1955), MacGowan (1954) sowie Tregouboff (1958a, b).

\section{Arbeiten im stabilen Benthos}

Uber $90 \%$ der mir bekannten einschlägigen Arbeiten haben sich bisher mit Erscheinungen im stabilen Benthos auseinandergesetzt. Die Ursache dieses Schwergewichtes haben wir schon festgestellt: höhere Wasserklarheit, große Strukturendichte und kleinräumige Biotopgliederung; aber auch die Deutlichkeit der Bestandsorganistation,

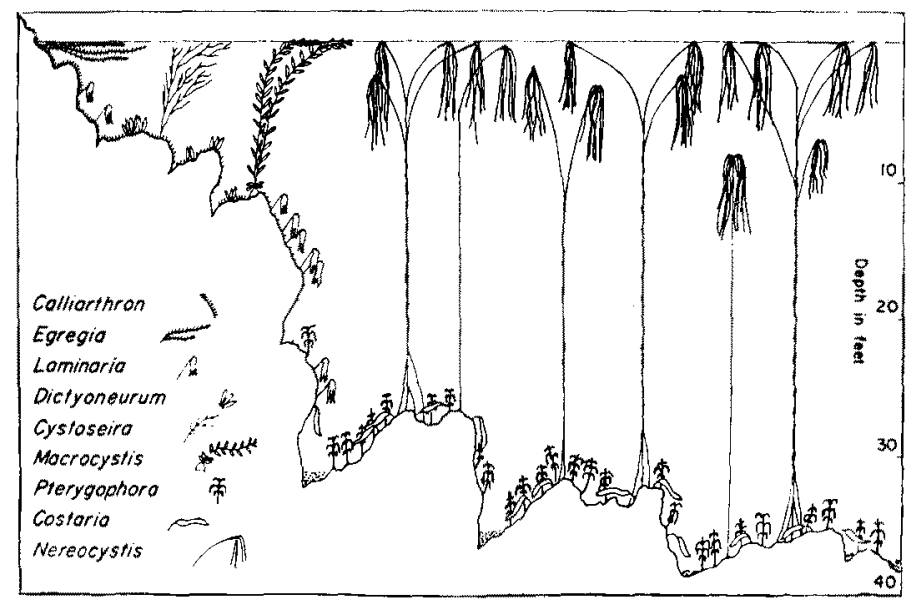

Abb. 31: Schematische Darstellung der Nerocystis-Wälder, der "kelpbeds" an der kalifornischen Küste und ihres Unterwuchses. (Aus McLEAN 1962)

die Küstennähe der Standorte und die hier besonders empfundenen Lücken unserer bisherigen Kenntnisse haben das Gebiet gefördert. Vier Einzelgebiete sind zu unterscheiden:

(1) Arbeiten im seichten Felslitoral stehen wieder an erster Stelle. Sie waren zunächst weitgehend extremen Schattengebieten und den Höhlen gewidmet und greifen nun begrüßenswerterweise stärker auf die Phytalbestände (Abb. 31) über. Diesen Schwerpunkt im seichten Felslitoral zu erhalten ist sehr zu empfehlen. Das Gebiet ist an vielen europäischen Küsten gut repräsentiert, leicht erreichbar, zahlreichen Meeresstationen benachbart, fachlich und wirtschaftlich sehr wichtig und besonders ungefährlich; eine Förderung wäre ökonomisch, weil wir hier die Ansätze zu allen typischen Fragen im stabilen Benthos - von der Substratstruktur bis zum Standortverhalten der Fische - am verläßlichsten erreichen. Das Haupthindernis, das zu überwinden 
bleibt, besteht darin, daß die natürlichen Arbeitsbasen, die Meeresstationen, besonders im Mediterran das die günstigsten Bedingungen liefert, vielfach ins verbaute Gebiet gerieten. Das hat zur Folge, daß die Lebensräume in ihrer unmittelbaren Nähe nun ungeschützt und verdorben sind. Darauf ist noch zurückzukommen.

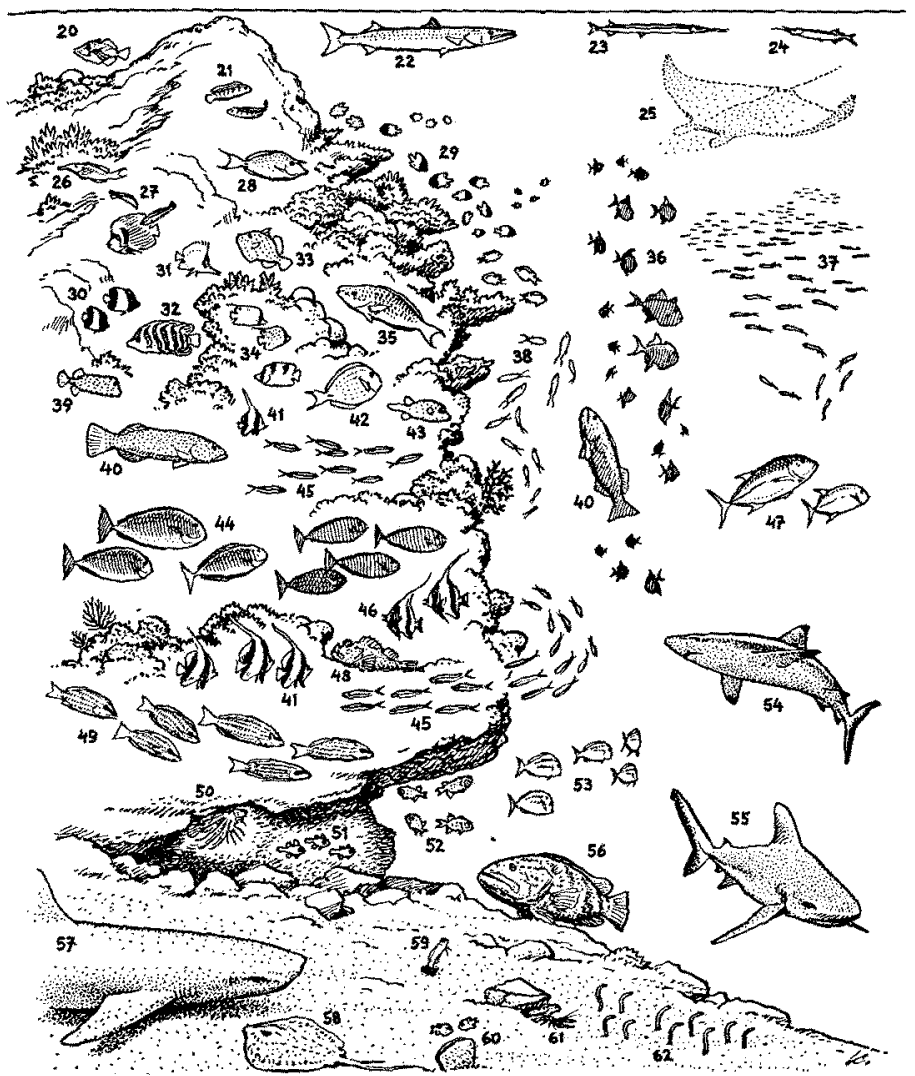

Abb. 32: Schematische Darstellung der Fisch-Anordnung an der Flanke eines Korallenriffes. (Ausschnitt aus ErbL-Erbesfeld 1964)

Den Schattengebieten des Felslitorals (vor allem im Mediterran), namentlich mit den Höhlen sind die folgenden Studien gewidmet: ABEL (1954, 1955b, 1959a, b, c, 1961c, 1962), Arndt (1936), Banse (1959), Cavolini (1785), Corroy (1958), Czihak (1954), ERnst (1959b), Haefelfinger (1960, 1961), Hass (1949), Kirchshofer (1954), Laborel (1960), Laborel \& Vacelet $(1958,1959,1962)$, Pérès \& Picard (1949), Pesta (1959), Riedl (1954b, 1956c, 1959a, b, c, d, e, f, 1963b, 1964a, b, 1966a, b), Ruffo (1959), Russ \& Rützler (1959), Rützler (1965a, b, c), SARÀ (1958, 1959a, c, 1960a, b, 1961a, b, 1962, 1962-1963, 1964), Starmühlner (1955a, b,), VAcelet (1959, 1961a, b, 1964), VAcelet \& LeVi (1958), Wieser (1954a) sowie Wissel (1957a). Mit dem europäischen Nordatlantik befaßten sich: ARNDT 
(1936), Drach (1948b) sowie KIrching, Macon \& Girson (1934). Mit Höhlen in außereuropäischen Felsgebieten: ABEL (1961c) sowie Dellow \& CAssie (1955). Eine allgemeine Darstellung gibt Auger (1955).

Ergebnisse submariner Untersuchungen im Bereich der Phytalbestände des Felslitorals enthalten die folgenden Arbeiten, die ich nach geographischen Gebieten getrennt anführe: Im Mediterran: ABEL (1955a, 1961a, b, c, 1962, 1964), ERNSt (1957, 1959a, b, 1960), Fiedler (1954, 1964), ForstNer (1959), Kirchshofer (1954),

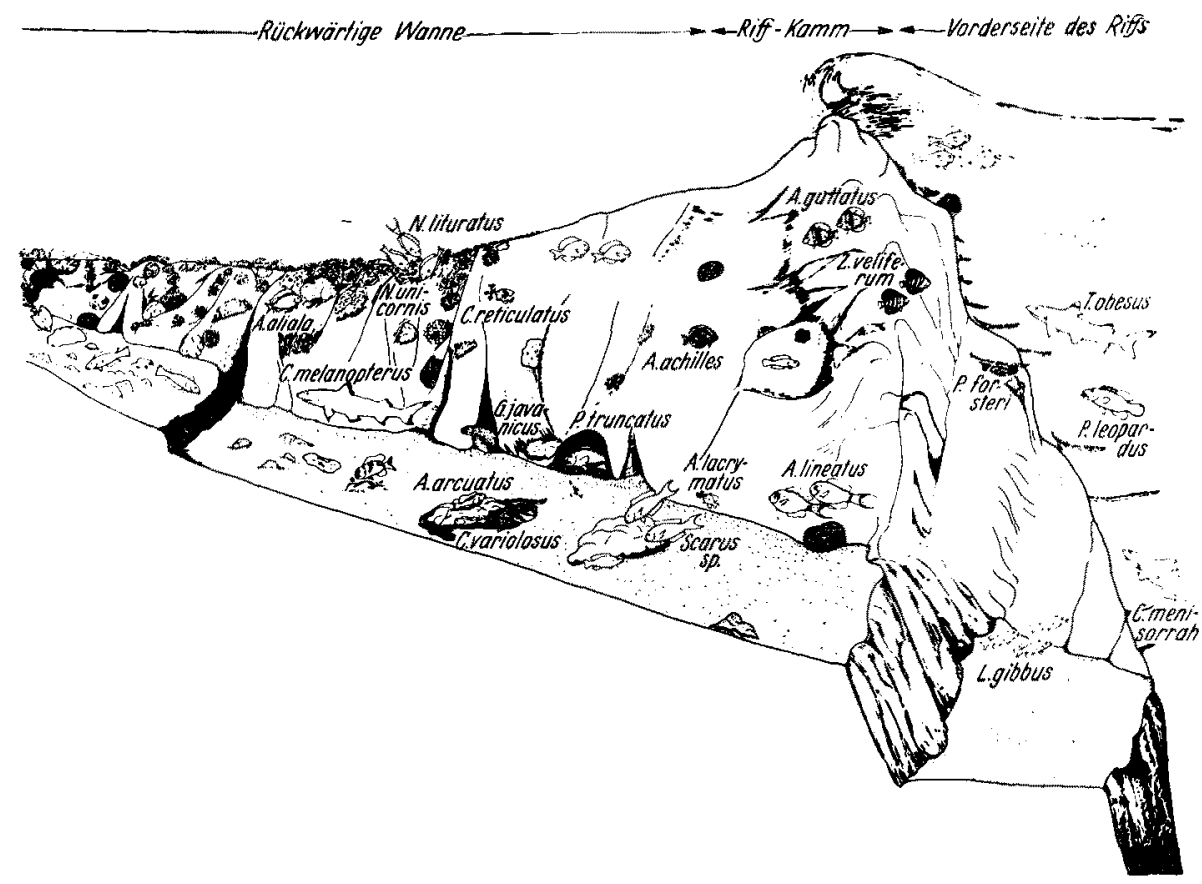

Abb. 33: Seeseitige und küstenseitige Anordnung der Fischtypen in einem Riff der MarshallInseln. (Nach Hiatr \& Strasburg 1960, aus Frifdrich 1965)

Krrsteuer (1963), Riedl (1953, 1954a, 1966a), Ruffo \& Wieser (1952), StarmühlNER (1955a, b), WIESER (1951a, 1954b, 1959) sowie ZaLokAR (1942). An nordeuropäischen Küsten: Bursa \& Wojtusiak (1948), Chapmann (1944), Drach (1948b, 1949), ERNSt (1957, 1958, 1959a, 1960, 1966), Forster (1954, 1959), Gislen (1929), KAIN (1960), Krtching (1941) sowie WIESER (1951a, b). In außereuropäischen Gewässern: Abel (1961c), Aleem (1956) sowie Pequegnat (1961b). Unterwasser-Untersuchungen in den "kelp beds“, den Großtangen an der Küste Californiens, wurden von Aleem (1956), Limbaugh (1955) und McLean (1962) durchgeführt.

(2) Arbeiten im Korallen-Riffgebiet (Abb. 32, 33, 34) wurden in den letzten Jahren stark intensiviert. Tatsächlich sind hier Temperaturen, Sichtweiten und Strukturdichten für die Taucherei noch günstiger; die Abgeschiedenheit schützt vor Störungen. Aber die Gefahr der Raubfische, allerlei andere Fährnisse, ihre ferne Lage und vielfach unzureichende Stationsausrüstungen gleichen die Vorteile weitgehend aus. Für 
Europa liegen die Stationen von Al-Ghardaqa und Ailat am günstigsten. Sie könnten $\mathrm{zu}$ wichtigen Arbeitsbasen werden. An submarinen Untersuchungen im Gebiete der reinen Korallenriffe sind zu nennen (Arbeiten, welche sich hauptsächlich mit Erscheinungen im Korallensand befassen, werden weiter unten bei den "Sedimentgebieten" erwähnt): Abel (1960a, b, c), Bardach (1958), Beebe (1928a, b), E. Clark (1950),

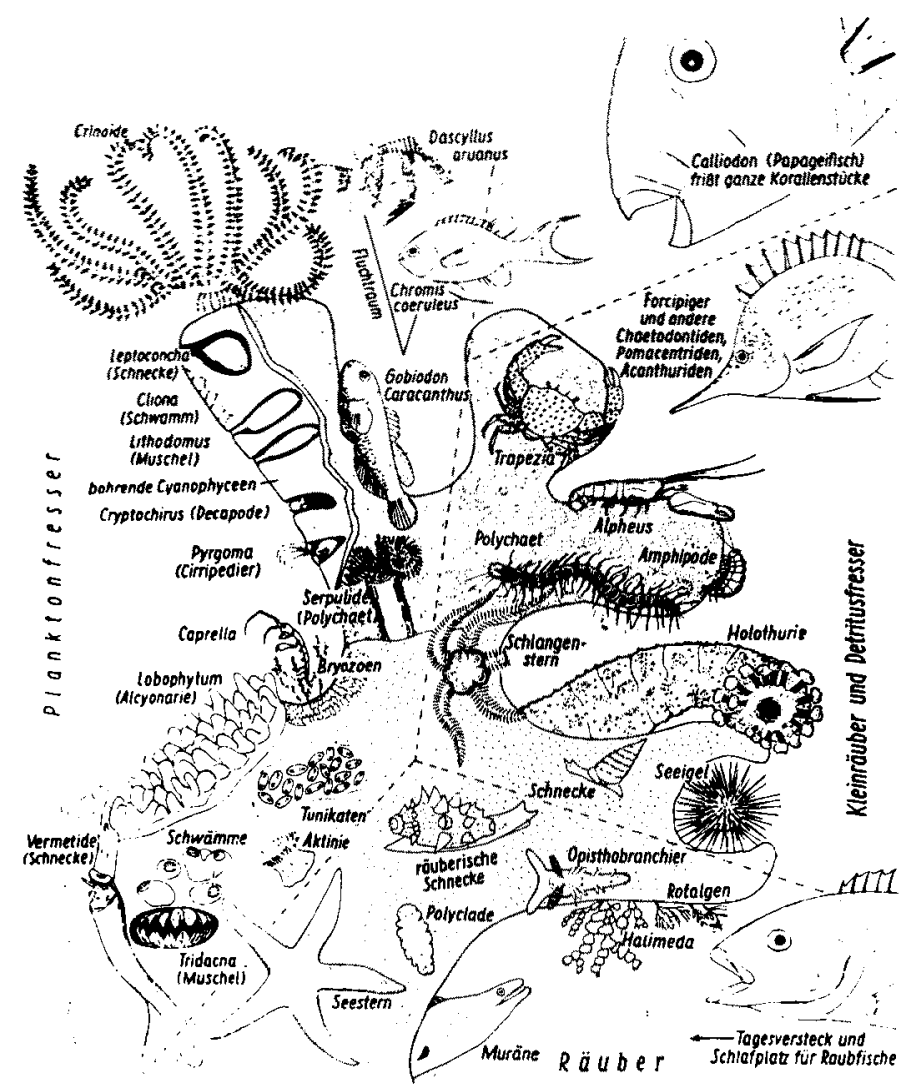

Abb. 34: Schematische Übersicht der wichtigsten makroskopischen Formen im Bereich des Korallenriffes, nach den trophischen Typen geordnet. (Aus GerLACH 1959)

E. Clark \& Gohar (1953), Drach (1952), Erbl-Eibesfeldt (1955, 1960, 1961a, b, 1962), Eibl-Eibesfeldt \& Hass (1959), Etbl-Eibesfeldt \& Scheer (1962), Gerlach (1959), Gohar (1948), Graefe (1963), Hiatt \& Strasburg (1960), Klausewitz (1958, 1960, 1961), Luther (1958), Magnus (1963b, c, 1964), Mayor (1924), Odum \& Odum (1955), Randall \& Randall (1960), Rützler (1964), Scheer (1960, 1964a, b), VAcelet \& VAsseur (1965), Vasseur (1962), WAhlert \& WAhLeRT (1960), Wells (1957) sowie Yonge $(1925,1930)$.

(3) Untersuchungen a f sekundären Hartböden haben erst begonnen. Als Corallinen-, Polychaeten-, Muschel- und Bryozoen-Bänke haben sie die beste Ent- 
faltung meist $\mathrm{z}$ wischen der 30- und 80-m-Isobathe. Auch die seichten unter ihnen liegen also in jenem Bereich, der für den Taucher bereits Dekompressions-Stationen vorschreibt und nicht mehr unbedenklich ist; noch kann in ihnen die Strukturdichte hoch sein (Abb. 35); aber sie sind ungleich küstenferner als die bisher behandelten stabilen

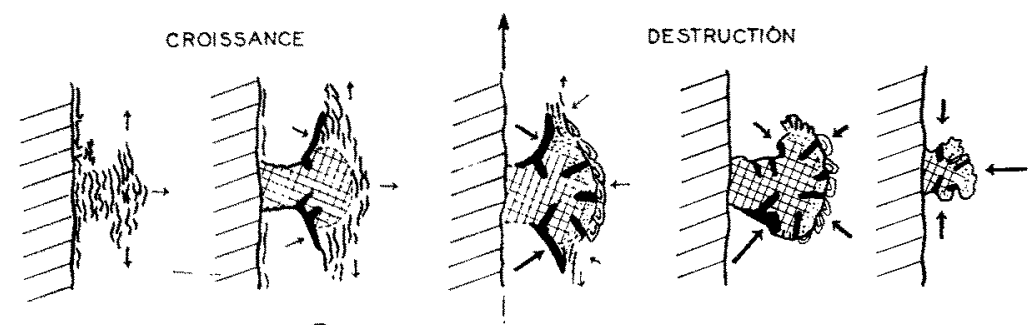

(A) Corniche sur roche verticole

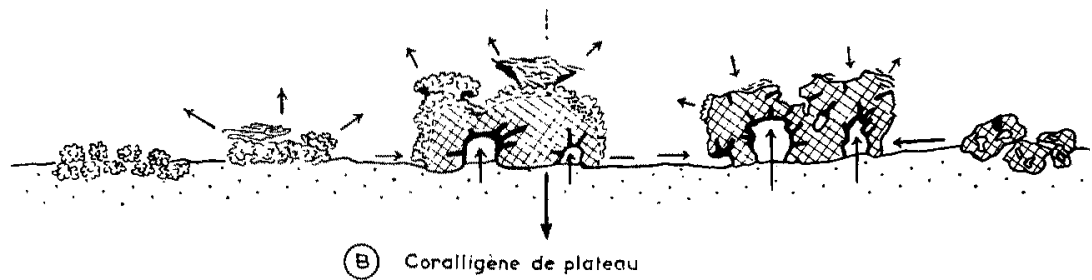

Abb. 35: Schema der Entwicklung und der Zerstörung von Corallinaceen-Bänken im Mittelmeer, (A) an Felswänden, (B) am Sedimentboden, die Pfeile bezeichnen die Richtung des Wachstums und der biologischen Zerstörung. (Aus LABorel 1961)

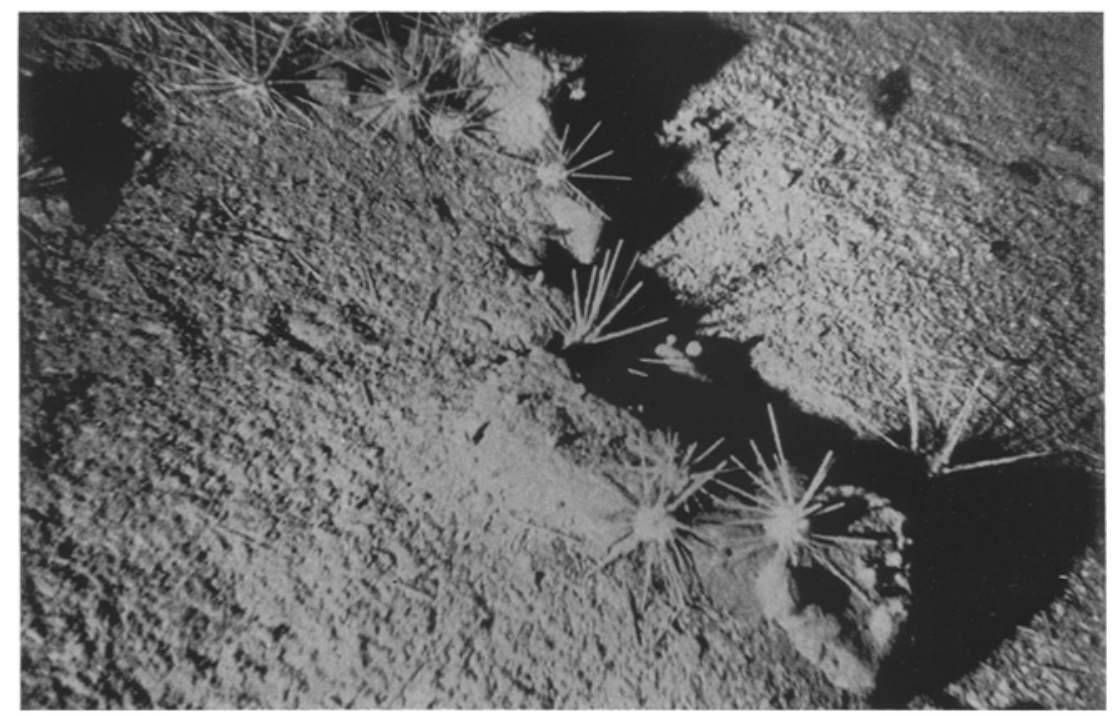

Abb. 36: Felsabhänge in $120 \mathrm{~m}$ Tiefe mit Detritus und Beständen von Cidaris im Mediterran. Aufgenommen mit Hilfe der "Tauchenden Untertasse“. (Aus VaissiÉre \& Carpine 1964) 
Benthosgebiete. Ihre Bearbeitung braucht den Taucher, und mehr noch automatische Geräte, die ihn entlasten. Letztere sowie die Einrichtungen der litoralen Forschungsschiffe, müssen zur Förderung dieses Arbeitsgebietes noch ausgebaut werden. Den Bereich der sekundären Hartböden, der sogenannten Corallinaceen-Böden des Mediterran berühren oder behandeln: Laborel (1961), Pérès \& PiCArd (1951, 1956) sowie Res \& Rossi (1965).

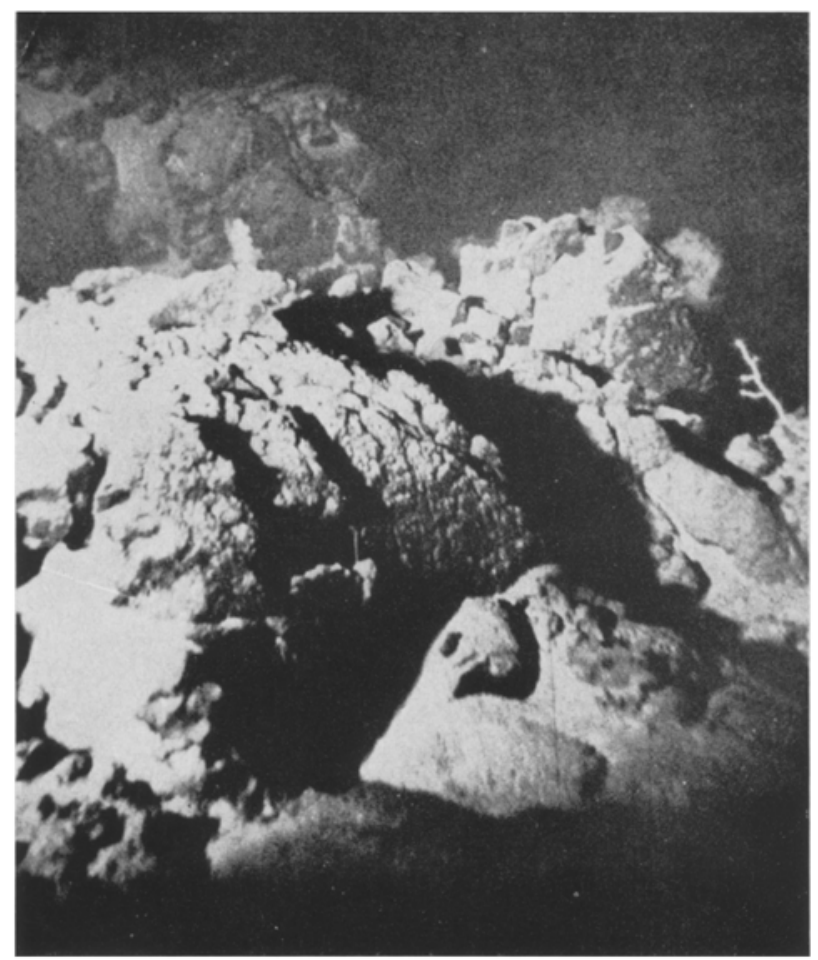

Abb. 37: Felsgebiet am Mittelatlantischen Rücken mit äußerst schütteren Sedentarier-Beständen. (Aus Cousteau \& Dugan 1963)

(4) Studien dertiefen Felsgebiete, welche wir bereits bis zu Tiefen von mehreren hundert Metern und bis über den Litoralrand (über die Kontinentalschulter hinaus) kennen, haben noch kaum begonnen. Durch die "soucoupe plongeante" das "Bathyscaph" (auch schon durch BeEBes Gondel), vorzuiglich aber durch die automatische Tiefenphotographie, wird aber bereits deutlich, was uns dort an Fragen erwartet (Abb. 36, 37). Die künftigen Erfahrungen mit Automaten im seichten Felslitoral werden uns dorthin vordringen lassen. Der Bereich der tiefen Felsgebiete wird von den folgenden, durch Taucher, Tauchfahrzeuge oder Kamera-Automaten Anschauung vermittelnde Untersuchungen berührt: BeEBE (1941), LABOREL et al. (1961), LABOREL \& Vacelet (1962), Laughton, Hill \& Alien (1960), Limbaugh \& Shepard (1957), Peckham \& McLean (1961) sowie Vaissier.e \& Carpine (1964). 


\section{Arbeiten im mobilen Benthos}

Studien aus dem mobilen Benthos, den Sand- und Schlammregionen des Litorales, sind ungleich weniger zahlreich und - das ist wieder kennzeichnend - vorwiegend dem Verhalten der Makrofauna (Abb. 38) und den speziellen Aufwuchsverhältnissen gewidmet. Die Ursachen sind meist geringere Wasserklarheit, geringe Strukturendichte

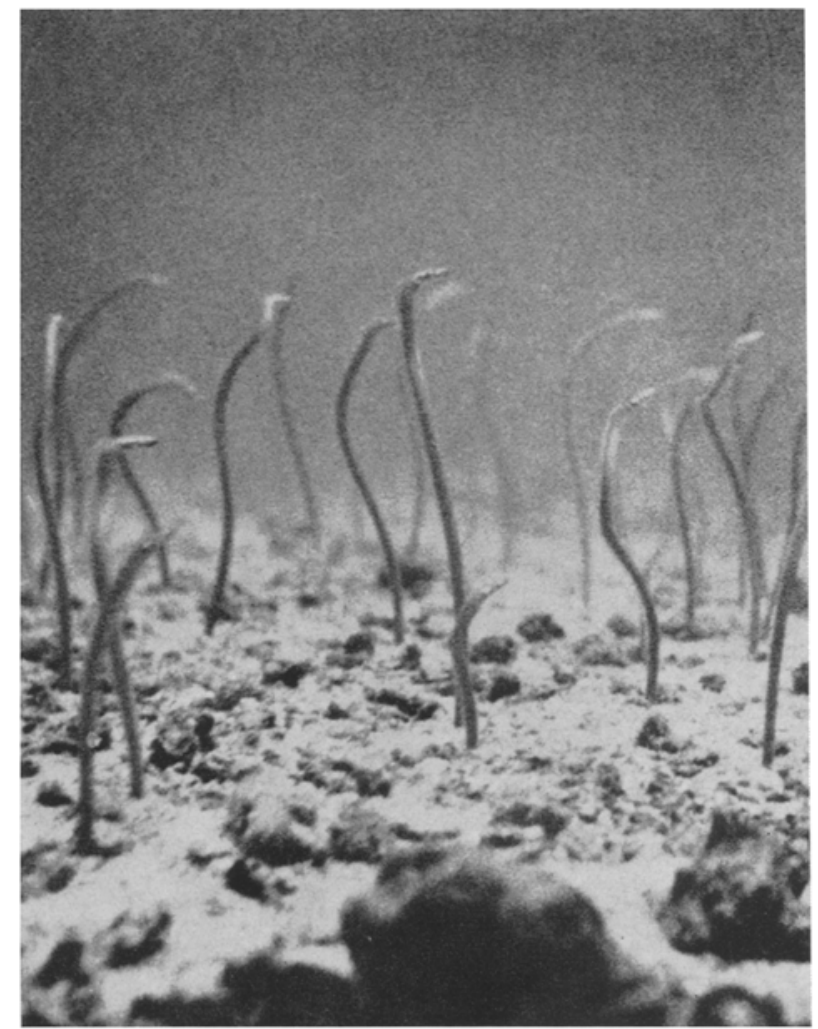

Abb. 38: Eine „Wiese“ von Röhren-Aalen (Gorgasia maculata) im Sedimentboden der Riffgebiete der Nikobaren. (Aus Eibl-Eibesfeld 1964)

und weitläufige Biotope. Auch die Verstecktheit der Strukturen, die oft nicht unbeträchtliche Landferne der interessanten Standorte und die im bisherigen Methodenkreis schon weit vorgetriebenen Kenntnisse spielen eine Rolle.

In den a u f u chslosen Zonen des mobilen Benthos - das sind weitaus die flächengrößten Litoralgebiete - hat die Taucherei noch kaum ökologische Beiträge geleistet. Aber die Ansätze sind schon zu erkennen (Abb. 39, 40), und es läßt sich voraussehen, in welchem Fragenkreis die Taucherei auch im mobilen Benthos nützlich werden wird. Zunächst wird sie helfen können, die cuantitativen Entnahmegeräte noch differenzierter und angepaßter zu gestalten. Sie wird an der Entwicklung der Bild- 
und Daten-Registrierstationen mitwirken, die Geräte zunächst selber einsetzen und dann vom Taucher unabhängig machen können. Wir werden dadurch über die Dynamik der Populationen, den Mikrobereich von Wasserklima und Sedimentumlagerung weiter orientiert werden, um zuletzt auch das Experiment mit noch gezielteren und besser angepaßten Fragestellungen in diesen riesigen Litoralbereich vorzutreiben. Untersuchungen mit Taucheinrichtungen und Bild-Automaten in den phytalarmen oder
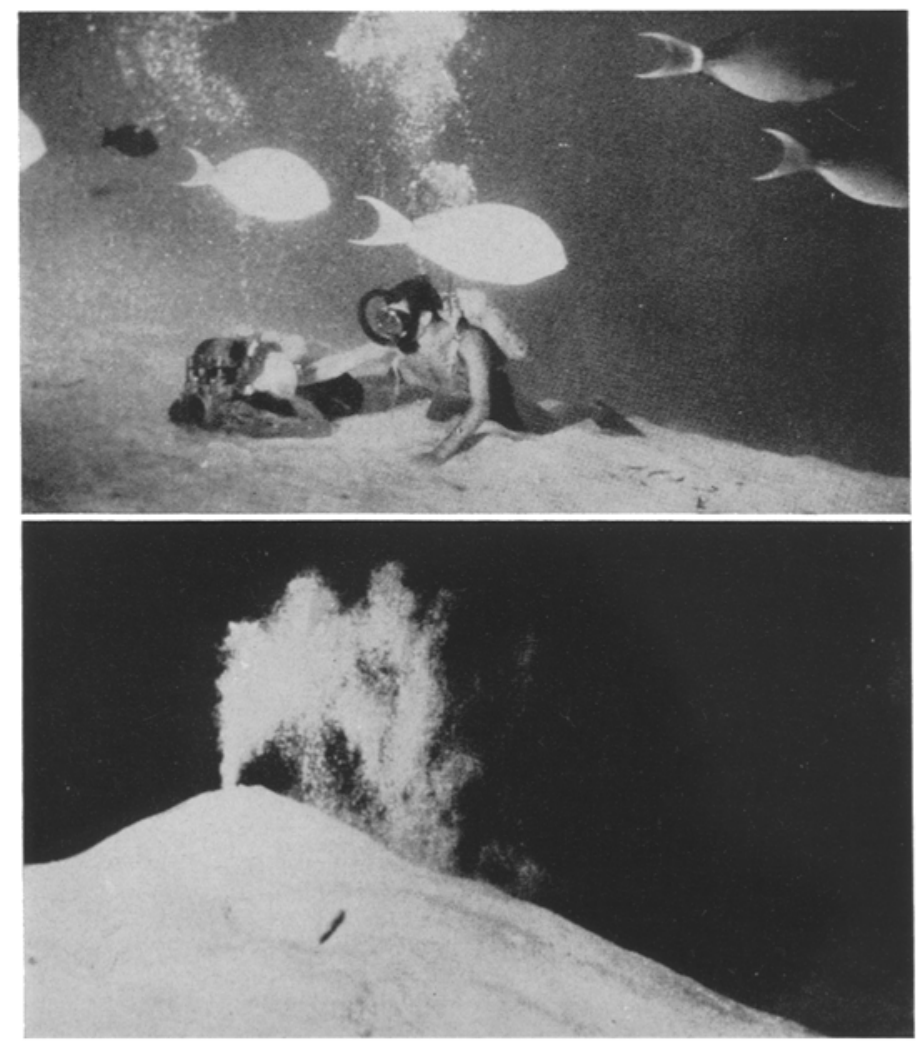

Abb. 39: Kamera-Studien des Verhaltens von Endopsammon-Formen. Oben zwei Taucher in Aufnahme-Stellung, unten ausgeworfene Sandfontäne. (Aus Cousteau \& DUGAN 1963)

phytallosen Sedimentgebieten, namentlich auf sublitoralen Sanden, welche Erscheinungen in diesen Sandgebieten berühren, sind gegeben worden von: ABEL (1955b, 1958), Czihak (1956), Eibl-Eibesfeldt (1961b), Emery (1952), Emery \& Merrill (1964), Klausewitz (1962a), Klausewitz \& Eibl-Eibesfeldt (1959), Magnus (1966b) sowie RÜTZLLER (1964).

In den $A$ uf w u ch s-Z on en der mobilen Böden - hierher kann man die Seegrasgebiete und zum Teil die Mangroven zählen - liegen die Verhältnisse ähnlich wie im stabilen Litoralgebiet, welchem sie biologisch weitgehend entsprechen. Die PosidoniaWiesen, besonders des Mediterran, haben schon eine ganze Reihe von Untersuchungen 
auf sich gezogen. In Problematik und Methode ähneln sie jenen aus dem Phytal des Felslitorals. Tauchuntersuchungen im Mangrovegebiet beginnen in den Antillen. Die Praxis deutet in beiden Bestandsgebieten den Vorteil der beweglichen Außenstellen an, eines in den entsprechenden Buchten oder Lagunen vor Anker legbaren Labor-Kutters.

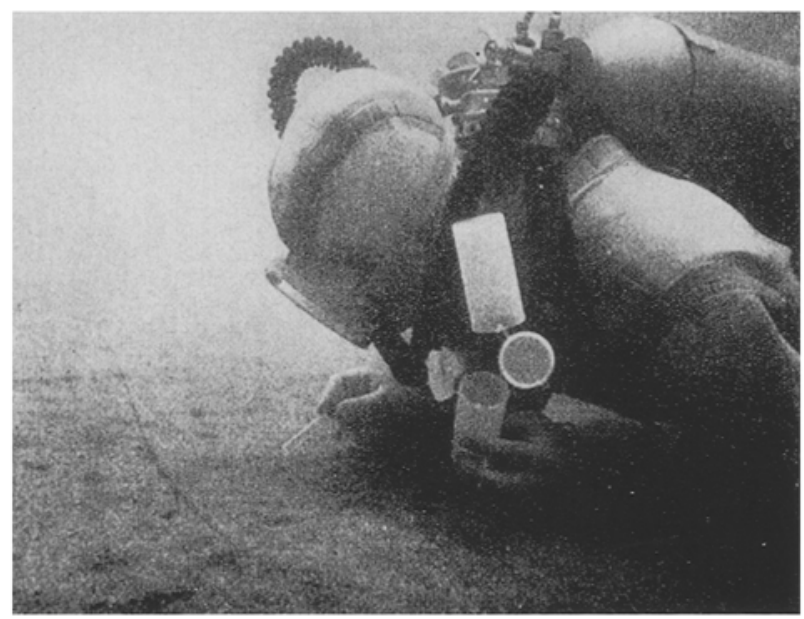

Abb. 40: Aufsammlungen von Kleinorganismen im Sedimentgebiete mit Hilfe der Pipette. (Aus Steyaert 1959)

Mit Hilfe der Taucherei sind im Bereiche der mediterranen Seegras-Bestände (des Sedimentgebietes) folgende Arbeiten durchgeführt worden: AbEL (1961a), FiedLer (1964), Gessner \& Hammer (1960), Gilet (1956), Kerneïs (1960), Ledoyer (1961), MoLINIER \& PiCARd (1952) sowie RiedL (1963b).

Aus den Mangrovegebieten scheinen noch keine speziell mit den Methoden der Unterwasserforschung erarbeiteten Ergebnisse veröffentlicht worden zu sein. Die jüngste Obersicht gibt Gerlach (1958).

Die Schwerpunkte sind also ungleich verteilt. Sie entsprechen einer allgemeinen Planung höchstens vorläufig. Den nützlichen Ausgleich dürfen wir dabei nicht innerhalb des Rahmens der Taucherei erwarten, sondern innerhalb der allgemeinen Organisation der Meeresbiologie, die ihr die Möglichkeit geben soll, den Bereich der Anschauung über ihre eigenen Grenzen hinaus zu erweitern.

\section{LAGE UND AUSBLICK}

Ich habe bisher versucht, die Leistungen der Gebiete des wissenschaftlichen Tauchens darzustellen. Die Lage aber, in welcher dieses Arbeitsgebiet sich heute befindet, hatte ich noch zu verschweigen. Diese will ich nun abschließend beschreiben, weil ich hoffe, dadurch der Sache nützlich zu sein; wir sollten sowohl den schon entfalteten Kräften die Verbindung erleichtern, als auch diejenigen Stellen, in deren Wirkungsbereich der dringlich nötige Ausbau liegt, für die Sache zu gewinnen trachten. Dazu 
habe ich zuerst die Situation von heute zu schildern, um daran einige Empfehlungen anzuschließen.

\section{Die Lage der sublitoralen Feldforschung}

Die Feldforschung im unterseeischen Litoral ist gegenwärtig durch den Umstand gekennzeichnet, daß sie den pionierhaften Zustand, in welchem sie entstand, selbst nicht zu überwinden vermag. Mit dem wachsenden Interesse zunächst am lebenden Organismus sind die Meeresbiologen in zwei großen Schritten dem Meere nähergerückt. Der erste Schritt führte zur Quelle des Materials, die Basen wurden als Meeresstationen nachgezogen. Der zweite Schritt führt soeben bis ins intime Milieu der Organismen, die Arbeitsbasen aber haben wir noch nachzuholen.

Zur Gründerzeit der Meeresstationen war man an die See gezogen, um der Quelle der wichtigen anatomischen Objekte näherzukommen. Unüberwindliche Schwierigkeiten des Seetiertransportes und der Binnenland-Aquarien waren damals die Ursache. Dìe Abgeschiedenheit der Küsten im 19. Jahrhundert und das Fehlen mariner Sammelpraxis ließen die Nähe der einheimischen Fischer suchen und in den Hafenorten Fuß fassen. Damit begann unwiderruflich ein Vorgang der Verlandung. Besonders im Mediterran, dessen Bedingungen die wissenschaftiche Taucherei so sehr begünstigen, wurden viele Meeresstationen durch Verkehrsanlagen vom Meer abgedrängt, von Ansiedlungen und zuletzt von Hafenschmutz endgültig eingewachsen. Die Möglichkeit einer neuerlichen Annäherung an das natürliche Milieu fiel immer mehr zurück, und die Feldarbeit wurde zur Sache der Fischer und Laboranten. Die marinen Lebensräume ihrer unmittelbaren Umgebung wurden preisgegeben und Schritt für Schritt zerstört.

Von den drei Voraussetzungen wissenschaftlicher Feldforschung lassen sich zwei auch an vielen europäischen Küsten vereint finden: Natürliche Verhältnisse und deren Schutz vor Störung durch den Menschen (wenigstens während der Zeit der Beobachtung und noch am verläßlichsten durch Abgeschiedenheit). Die dritte Voraussetzung, die Arbeitsbasis, muß jeweils in Zelten oder Hütten entlegener Küsten improvisiert werden. Meist geschieht das noch dazu mit ganz unzureichenden Mitteln. Folglich hatte man sich fast immer auf deskriptive oder höchst einfach instrumentierte Untersuchungen sowie mit einem Minimum an Sicherheitsvorkehrungen zu beschränken. Man erarbeitete eine Fülle von Fakten zunächst im einschichtigen Problemkreis und mußte so tun, als ob dauerhafte Arbeitsbedingungen und der Methodenschatz von Experiment und Kausalanalyse bald nachgeholt werden könnten. Das geschah bislang noch nicht, denn es bedarf eines ausgreifenderen organisatorischen Entschlusses.

\section{Feldstationen und Naturschutz im Litoral}

Feldstationen könnten, in Ergänzung zu den bewährten Meeresinstituten, die nötigen Funktionen übernehmen. Sie hätten die dritte Voraussetzung der Feldforschung dicht ans natürliche Milieu heranzuführen. In ihnen sollte der Taucher seine Proben selbst anlanden und die Standorte im Auge behalten können. Die Kabel der 
unterseeischen Registrierstellen sollten bis in das Laboratorium und die Seewasserleitung im untersuchten Biotop ihren Ausgang nehmen. Mit der Einrichtung für Haltung und Kultur unter den Wasser- und Nahrungsbedingungen des natürlichen Standortes sowie für den ersten Experimentalansatz unter solchen Laborbedingungen und im Biotop würden sie die nötigen Voraussetzungen erfüllen. Sie ermöglichten ein gedeihliches Gleichgewicht der Fragestellung und die Kontinuität der Entwicklung. Diese ist zum Ausbau jenes Methodenschatzes nötig, der uns des persönlichen Risikos entheben und die Anschauung von den Litoralgründen über die Welt verbreiten wird. Sie ist es auch, die jegliches Gebiet zur Erlangung seiner Reife braucht.

Unsere engsten Untersuchungsgebiete müßten aber zudem geschützt werden. Das Aussetzen von Meß- und Beobachtungsstellen hat keinen Sinn, wenn sie weggefischt, das Markieren oder Versetzen von Individuen ebenso keinen, wenn diese, wie üblich, abgeschlossen oder vertrieben werden. Selbst die einzelne Feldstation kann als verloren gelten, wenn die natürlichen Wasserkörper und Seeböden vor ihren Toren wieder durch Verkehr, Industrie und Tourismus bedroht werden. Naturschutz im Litoral sollten wir heute noch viel deutlicher fordern. Wir müssen das biologische Chaos aufzeigen, welches beispielsweise großen Teilen der mediterranen Küsten erwächst, an welchen sich Sommer für Sommer das halbe Europa versammelt. Noch gibt es unberührte, den zivilisatorischen Knotenpunkten Europas nicht zu ferne Küsten, aber die Zeit ist abzusehen, in welcher die günstigsten Stellen abgezäunt oder verdorben sein werden. Es wäre die vornehme Aufgabe europäischer Staaten, zur Förderung der Wissenschaft und aus Respekt vor jenem Stück Natur, in dem die Wiege des Lebens auf unserem Planeten stand, einige wohlgewählte Qudratmeilen sicherzustellen.

Auf die Schwierigkeiten, in welchen sich die Methode der direkten Litoralforschung im Mediterran befindet, haben AвEL (1963) sowie RIEDL (1964c, 1966a) besonders hingewiesen. In denselben Arbeiten wird auch für den Naturschutz im mediterranen Litoral eingetreten, ein Fragenkreis, mit welchem sich auch HaEfelfinger (1963) auseinandersetzt. Auf den Vorteil der Feldstationen hat RIEDL (1964c, 1966a) hingewiesen.

\section{SCHLUSSBETRACHTUNG}

Abschließend ist folgendes hervorzuheben: Die wissenschaftliche Taucherei ist eine Methode, die uns unter guten Bedingungen ohne Risiko, durch Anschauung und simultane Nachrichtenauswertung, detailreiche Einsicht in eine Reihe von Litoralgebieten liefert. Unter ungünstigen Bedingungen ist sie sehr gefährlich und leistet nichts. Ihre Hauptgebiete hängen mit jenen Erscheinungen zusammen, welche Organismus und Milieu in Beziehung zeigen. Sie bewährte sich zunächst besonders in enggegliederten, hochstrukturierten Lebensräumen, sowie unter bestimmten hydrographischen, also auch geographischen Voraussetzungen. Wir haben aber die Chance durch die Erfahrungen aus dem persönlichen Einsatz des Tauchers, einen Gerätestock zu entwickeln, der den einzelnen des Risikos ganz entheben und den Bereich der Anschauung über alle Litoralprovinzen ausbreiten kann. Feldstationen und Naturschutz im Litoral würden das neue Arbeitsgebiet aus seinem Pionierzustand lösen und über- 
nationale Zusammenarbeit es für die ganze Meeresbiologie nützlich machen können. Viele aus unseren Reihen haben ihr nicht nur ihre Arbeit, sondern auch noch ihren persönlichen Einsatz verschrieben; möge er sich zum Nutzen aller wirklich gelohnt haben.

\section{ZUSAMMENFASSUNG}

1. In den beiden letzten Jahrzehnten hat das wissenschaftliche Tauchen weite Verbreitung gefunden. Die gewonnenen Erfahrungen werden zusammengefaßt und in fünf Punkten kritisch erörtert.

2. Als Methode zeigt die Taucherei vier Stufen der Entwicklung. Motive und Schwerpunkte haben sich dabei verlagert. Technisch und unter günstigen Bedingungen entbehrt sie bereits aller Schwierigkeiten, unter ungünstigen aber ist sie ein gefährliches und untaugliches Verfahren geblieben. Die entscheidenden Punkte werden herausgestellt.

3. Im Prinzip geht es um das Gewinnen von Anschauung, um die koordinierte Gewinnung komplexer Nachrichten. Derlei ist besonders in jenen Disziplinen vonnöten, welche sich, im Vorfeld der Kausalanalyse, mit der Beschreibung der Korrelationen zusammengesetzter Erscheinungen befassen. Verhaltensforschung und Okologie stehen hier an erster Stelle. Jenseits jener engen Grenzen, die dem Taucher zeitlich-örtlich gesetzt sind, kann das Gebiet der Anschauung apparativ geradezu beliebig erweitert werden, wenn das Tauchen zur propaedeutischen Disziplin wird und man auf dieser Grundlage konsequent weiterbaut. Vorschläge zu einer ökonomischen Entwicklung und zum Schutz der Mannschaften werden gemacht.

4. Die Fragestellungen gruppieren sich um die Kontrolle der konservativen Geräte, um die komplexen anorganischen Merkmale unter geologischen, geomorphologischen und mikroklimatologischen Gesichtspunkten; ganz überwiegend aber um jene organischen Beziehungen, die Organismen und Milieu oder Organismen milieuabhängig miteinander verbinden. Stets sind es Erscheinungen, die erst am Ort ihres Wirkens aufgesucht und analysiert werden müssen, bevor sie zerlegt im Experiment nachgeahmt werden können. Typische Beispiele werden vorgelegt.

5. Die Arbeitsgebiete und ihre Schwerpunkte hängen mit der räumlichen Dichte der freilegbaren Phänomene zusammen. Im Küstenpelagial sowie auf den mobilen Seeböden sind sie in der Entwicklung begriffen; im Gebiet hochstrukturierter stabiler Seeböden sind sie schon entstanden: In den Schattengebieten und im Phytal des Felslitorals, im Korallenriff, teils auf den sekundären Hartböden. Sie werden in Übersichten zusammengestellt.

6. Die Lage dieser direkten Litoralforschung ist derzeit noch durch einen pionierhaften Zustand gekennzeichnet, der durch das Nachholen von Arbeitsbasen bis dicht an das natürliche Milieu sowie von Experiment und Kausalanalyse, überwunden werden kann. Feldstationen und Naturschutz im Litoral werden empfohlen. 


\section{ZITIERTE LITERATUR}

AвEL, E., 1954. Lichtrückenreflex eines Fisches in der Blauen Grotte. Öst. zool. Z. 4, 397-401.

- 1955a. Eine neue Prustenanemone der Adria. Öst. zool. Z. 6, 1-6.

- 1955b. Freilandbeobachtungen an Callionymus festivus Pall. und Tripterygion tripteronotus Risso, zwei Mittelmeerfischen, unter besonderer Berïcksichtigung des Fortpflanzungsverhaltens. Sber. öst. Akad. Wiss. 164, 817-854.

- 1958. Beobachtungen über Lichtreaktionen von Ceriantbus membranaceus (L. SPAllaNzani 1784). Zool. Anz. 161, 104-113.

- 1959a. Uber die Verbreitung von Tripterygion minor Kolomb. im Mittelmeer, sowie ergänzende Beschreibung des Fisches. Pubbl. Staz. zool. Napoli 31, 98-108.

- 1959b. Zur Kenntnis der Beziehung der Fische zu Höhlen im Mittelmeer. Ergebnisse der Osterreichischen Tyrrhenia-Expedition 1952. T. 14. Pubbl. Staz. zool. Napoli 30 (Suppl.), 517-528.

- 1959c. Zur Kenntnis der marinen Höhlenfauna unter besonderer Berücksichtigung der Anthozoa. Ergebnisse der Österreichischen Tyrrhenia-Expedition 1952. T. 5. Pubbl. Staz. zool. Napoli 30 (Suppl.), 1-94.

- 1960a. Fische zwischen Seeigel-Stacheln. Natur Volk 90, 33-37.

- 1960b. Zur Kenntnis des Verhaltens und der OKologie von Fischen an Korallenriffen bei Ghardaqa (Rotes Meer). Z. Morph. Ökol. Tiere 48, 430-503.

- 1961a. Das Fortpflanzungsverhalten des Mönchsfisches Chromis cbromis L., einem Vertreter der Pomacentriden im Mittelmeer. Z. Tierpsychol. 18, 414-419.

- 1961b. Liaison facultative d'un poisson (Gobius bucchichii STEINDACHNER) et d'un anémone (Anemonia sulcata Penn.) en Méditerranée. Vie Milieu 11, 517-531.

- 1961c. Uber die Beziehung mariner Fische zu Hartbodenstrukturen. Sber. österr. Akad. Wiss. (Math. nat. Kl. Abt. 1.) 170, 223-263.

- 1962. Freiwasserbeobachtungen an Fischen im Golf von Neapel als Beitrag zur Kenntnis ihrer Okologie und ihres Verhaltens. Int. Revue ges. Hydrobiol. Hydrogr. 47, 219-290.

- 1963. Probleme der ökologischen Forschung im Litoral des Mittelmeeres. Rapp. P.-v. Réun. Comn int. Explor. Mer Méditerr. 17, 79-83.

- 1964. Freiwasserstudien zur Fortpflanzungsethologie zweier Mittelmeerfische, Blennius canevae VINC. und Blennius inaequalis C. V. Z. Tierpsychol. 21, 205-222.

ALEEM, A., 1956. Quantitative underwater study of benthic communities inhabiting kelp beds off California. Science, N.Y.123 (183).

Anderson, V., 1960. A new vehicle for exploring the ocean's floor. Nav. Res. 1960 (June).

ANKEL, W. E., 1953. Schwimmtauchen als Methode der Zoologie. Giessener Hocbsch.-bl. 1 (4).

ARndT, W., 1936. Fortschritte der Kenntnis der tierischen Bewohnerschaft von Meereshöhlen. Mitt. Höbl.- u. Karstforsch. (Jg.) 1936, 137-141.

Audouin, V. \& Milne-Edwards, H., 1832. Recherches pour servir à l'histoire naturelle du littoral de la France. Crochard, Paris, T. 1, 1-406.

Auger, C., 1955. Grouillements obscurs. Visites à la flore et à la faune des grottes souterraines, sous-marines et glaciaires de France et d'ailleurs. Sciences Voyages 7 (115), 25-29.

Backus, R. \& Barnes, H., 1957. Television-echo sounder observation of midwater sound scatters. Deep Sea Res, 4, 1-116.

BarRd, R. \& Gibson, F., 1956. Underwater observations on escallop (Pecten maximus L.) beds. J. mar. biol. Ass. U. K. 35, 555-562.

BAKER, A. DE, 1957. Underwater photographs in the study of oceanic squid. Deep Sea Res. 4, 126-129.

Banse, K., 1959. Über die Polychaeten-Besiedlung einiger submariner Höhlen. Ergebnisse der Osterreichischen Tyrrhenia-Expedition 1952. T. 12. Pubbl. Staz. zool. Napoli 30 (Suppl.), $417-469$.

BARDACH, I., 1958. On the movements of certain Bermuda reef-fishes. Ecology 39, 139-146.

BARHAM, E., 1966. Deep scattering layer migration and composition: observation from a diving saucer. Science, N. Y. 151 (3716), 1399-1403.

Barnes, H., 1952. Underwater television and marine biology. Nature, Lond. 169, 477. 
- 1953a. Underwater television and marine research. Discovery, Lond. 14.

- 1953b. Underwater television and research on marine ecology, bottom topography and geology. Pt 1. A description of the equipment and its use on board ship. Dt. bydrogr. Z. 6, 123.

- 1953c. Underwater television and the fisheries. Fishg News, Aberd. 2089.

- 1953-54. Electrical lead-through plugs. Deep Sea Res. 1, 281-282.

- 1955. Underwater television and research on marine ecology, bottom topography and geology. Pt 2. Experience with the equipment. Dt. bydrogr. Z. 8, 213.

- 1959. Oceanography and marine biology. A book of techniques. Allen \& Unwin, London, $218 \mathrm{pp}$.

Barton, O., 1930a. The bathysphere. Bull. N.Y. zool. Soc. 33, 233-234.

- 1930b. 1400 foot dive. Scient. Am. 254-255.

- 1935. Five hundred fathoms deep. Nat. Hist. Mag. 35, 144-145.

Bartsch, P., 1927. A movie camera for use on the sea bottom. Scient. Am. 136, 127-128.

Bascom, W. \& Revelle, R., 1953. Free-diving: a new exploratory tool. Am. Scient. 41, 624-627.

Bauer, H., 1955. Abenteuerliche Tiefsee. Brockhaus, Leipzig, 216 pp.

BEEBE, W., 1926. The Arcturus Oceanographic Expedition. Zoologica, N.Y. 8, 1-45.

- 1928a. Beneath tropic seas: A record of diving among the coral reefs of Haiti. Putnam, New York, 234 pp.

- 1928b. Das Arcturus-Abenteuer (The Arcturus adventure). A. d. Am. Brockhaus, Leipzig, $331 \mathrm{pp}$.

- 1930. One fourth mile down in the open sea. Bull. N.Y. zool. Soc. 33, 200-234.

- 1932. A wanderer under sea. Natn. geogr. Mag. 62, 740-758.

- 1935. One half mile down in the Bathysphere. Bull. N.Y. zool. Soc. 35.

BEHAvior of shrimp trawl viewed with underwater television, 1955. Comml Fish. Rev. 17 (7), 32-33.

Behnke, A. R., 1955a. Outline of problems of decompression and bends. In: Proceedings of the underwater physiology symposium, Jan. 10-11, 1955, Washington, DC. Ed. by L. G. Goff. Publs natn. Res. Coun., Wash. 377, 50-52.

- 1955b. Oxygen decompression. In: Proceedings of the underwater physiology symposium, ... Publs natn. Res. Coun., Wash. 377, 61-73.

Bernard, F., 1955. Densité du plancton vu au large de Toulon depuis le Bathyscaphe FNRS III. Bull. Inst. océanogr. Monaco 52 (1063), 1-16.

- 1958. Plancton et benthos observés durant trois plongées en Bathyscaphe au large de Toulon. Annls Inst, océanogr., Monaco 35, 287-326.

Berthold, G., 1882. Uber die Verteilung der Algen im Golf von Neapel nebst einem Verzeichnis der bisher daselbst beobachteten Arten. Mitt. zool. Stn Neapel 3, 393-537.

BıввL, R., 1954. Photographische Erforschung des Meeresgrundes. Naturw. Rdsch., Stuttg. 11, $476-478$.

BODET, J., 1931. L'Helium, gaz ininflammable, et les dirigeables modernes. Sci. Vie $\mathbf{1 6 3 .}$

Bonde, C., Marchand, M. \& Gibbons, S., 1951. Preliminary experiments in sea-floor photography in South African water. Trans. R. Soc. S. Afr. 33 (1).

Boutan, L., 1893. Mémoire sur la photographie sous-marine. Archs Zool. exp. gén. 1 (3), 281-324.

- 1898. L’instantané dans la photographie sous-marine. Archs Zool. exp. gén. 26, 299-330.

- 1900. La photographie sous-marine et les progrès de la photographie. Schleicher, Paris.

BRANDT, A. VON, 1955. Unterwasser-Fernsehen. Fischereiwirtschaft $8(6 / 7)$.

Brase, W. A. H., 1954. Submarine bibliography. - Bibliographia submarina. Brase, Braunschweig, $34 \mathrm{Bl}$.

- 1957. (Untersee-)Bibliographie. - International submarine bibliography. Brase, Braunschweig, $51 \mathrm{Bl}$.

BRown, E., 1938. Loss of memory, attention, found in deep sea divers. Sci. News Lett. 33, 385.

Bursa, A. \& Wojtusiak, R., 1948. Investigations of the bottom fauna and flora in the Golf of Gdansk made by using of diving helmet. Pt. 2. Bull. int. Acad. pol. Sci. Lett. (Cl. Sci. mat. nat. Ser. B 2) 2 
Cafuta, Z., Pavlovčič, M., Zevnnik, M. \& Zei, M., 1955. Doprinos k ekologiji morskega litorala. Raspr. slov. Akad. Znan. Umet. (Razr. Prir. ved.) 3.

Cavolini, F., 1785. Memorie per servire alla storia de' Polipi marini. Napoli, 279 pp.

Chapman, V., 1944. Methods of surveying Laminaria beds. J. mar. biol. Ass. U. K. 26, 37-60.

Chauchard, P., 1947. Physiologie du scaphandrier. Revue scient., Paris 85, 369-373.

Chesterman, W., 1950. Photography under the sea. Funct. Photogr. 1, 5-8.

Clark, E., 1950. Notes on the behaviour and morphology of some West-Indian plectognath fishes. Zoologica, N. Y. 35, 159-168.

- \& Gohar, H., 1953. The fishes of the Red Sea: Order Plectognathi. Publs mar. biol. Stn Ghardaqa 8.

CIARK, W., 1964. Remote control in hostile environments. New Scient. 389, 300-304.

Clarke, G., 1958. The luminescence camera. Oceanus 6 (1), 14-15.

Collins, J., 1950a. Underwater photography. Am. Cinematogr. 31 (7), 236; 254-255.

- 1950b. Underwater photography. Am. Cinematogr. 31 (8), 274; 280-282.

Conger, R., 1950. U.S. naval underwater cinematography techniques. J. Soc. Motion Pict. Telev. Engr 55 (6), 627-634.

- 1953. Underwater cinematography. In: American cinematographers handbook and reference guide. 8th ed. Ed. by J. J. Rose. Rose, Beverly Hills, Calif., 303 pp.

Conklin, E., 1933. Use of the diving helmet in biological study. Scient. Mon., N.Y. 37, 380-382.

Coppleson, V. M., 1958. Shark attack. Angus \& Robertson, London, 266 pp.

Corroy, G., 1958. Les résurgences sous-marines de la région de Cassis. Bull. Inst. océanogr. Monaco 55 (1131), 1-36.

Cousteau, J., 1952. Fish men explore a new world undersea. Natn. geogr. Mag. 102, 431-472.

- \& Dugan, J., 1963. The living Sea. Harper \& Row, New York, 325 pp.

- \& Dumas, F., 1953. Die schweigende Welt. A. d. Franz., Blanvalet, Berlin, 232 pp.

- Taillez, P. \& Dumas, F., 1946. Par dix-huit mètres de fond. Histoire d'un film. Durel, Paris, $24 \mathrm{pp}$.

Cronenbroeck, W., 1956. Fernsehen unter Wasser. Orion, Innsbr, 19, 763-766.

Cross, E., 1954. Underwater photography and television. A handbook of equipment and techniques. Exposition Pr., New York, 258 pp.

Czıнaк, G., 1954. Die Schlangensterne einer submersen Höhle des Tyrrhenischen Meeres. Ergebnisse der Österreichischen Tyrrhenia-Expedition 1952, T. 3. Öst. zool. Z. 5, 15-29.

- 1956. Vorkommen und Lebensweise der Ophiotbrix quinquemaculata in der nördlichen Adria bei Rovinj. Thalassia jugosl. 1 (6-10), 19-27.

- ZEI, M., 1960. Photography, television, and the use of the bottom-sampler, compared as methods for quantitative analyses of benthic populations. Rapp. P.-v. Réun. Commn int. explor. scient. Mer Méditerr. 15 (2), 81-83.

DakIN, W. J., 1952. Australian seashores. Angus \& Robertson, London, 372 pp.

Damant, G., 1931. Modern diving devices. Nature, Lond. 128, 324-326.

Davis, R. H., 1919. Diving manual and handbook of submarine appliances. Siebe, Gorman \& Co., London, 278 pp.

- (Ed.), 1935. Deep diving and submarine operations; a manual for deep sea divers and compressed air workers. Siebe, Gorman \& Co., London, 509 pp.

- 1951. Deep diving. St Catherine pr., London, 237-244.

Deacon, G. (Hrsg.), 1963. Die Meere der Welt; ihre Eroberung - ihre Geheimnisse (Seas, maps, and men). Dt. Bearb. von G. Dietrich. Belser, Stuttgart, 297 pp.

De HaAs, W. \& KnORr, F., 1965. Was lebt im Meer? Franckh, Stuttgart, 359 pp.

Delle-ChIaje, S., 1841-44. Animali senza vertebre del Regno di Napoli. Descrizione e notomia degli animali invertebrati della Sizilia citeriore osservati vivi negli anni $1822-1830$. 2a ed. C. Batelli (Tipogr.), Napoli, T. 1-8, XIX, 1-98; 5-146; 5-142; 1-142; 1-65; 1-86; $87-173$.

Dellow, V. \& Cassie, R., 1955. Littoral zonation in two caves in Auckland district. Trans. $R$. Soc. N.Z. 83, 321-331.

Dill, R., 1958. A directory of scientists, engineers and technicans using self-contained underwater breathing apparatus in their work. U. S. Navy Electronic Lab., Washington, D. C. 
DiolÉ, P., 1953. The undersea adventure (Aventure sous-marine). Transl. from the French. Messner, New York, 236 pp.

DohrN, A., 1880. Bericht über die Zoologische Station während der Jahre 1879 und 1880. Mitt. zool. Stn Neapel 2, 495-514.

Dotson, D. \& Krmes, R., 1953. Underwater automatic. Skin Diver 2 (11), 6-7.

Drach, P., 1948a. Limite d'expansion des peuplements benthiques sessiles en zone littorale profonde (facies rocheux). C. r. hebd. Séanc. Acad. Sci., Paris 227, 1397-1399.

- 1948b. Premières recherches en scaphandre autonome sur le peuplement des facies rocheux de la zone littorale profonde. C. r. hebd. Séanc. Acad. Sci., Paris 227, 1176-1178.

- 1949. Premières recherches en scaphandre autonome sur les formations de Laminaires en zone littorale profonde. C. r. somm. Séanc. Soc. Biogéogr. 26, 46-49.

- 1951. Les peuplements de fonds rocheux en zone littorale profond. Année biol. 27, 271-279.

- 1952. Lacunes dans la connaissance du peuplement des mers et utilisation des scaphandres autonomes. Revue scient., Paris 90, 58-72.

- 1956. Perspectives in the study of benthic fauna of the continental shelf. In: Perspectives in marine biology. Ed. by A. A. Buzzati-Traverso. Univ. of Calif. pr., Berkeley, 33-46.

- 1958. Essai methodologique sur les recherches biologiques en scaphandre autonome. In: Journées des 24 et 25 février 1958. Centre belge d'océanographie et de recherches sousmarines, Liege, 29-47.

Dugan, J., 1951. The Cousteau bathygraph. A preliminary report. Photogr. Engng 2, 26-31.

- 1956. Man explores the sea. Hamilton, London, 366 pp.

Du PonT, A. F., 1940. Under sea with helmet and camera. Experiences of an amateur. Dodd \& Mead, New York, 87 pp.

Eibl-EIbesfeldT, I. von, 1955. Uber Symbiosen, Parasitismus und andere besondere zwischenartliche Beziehungen bei tropischen Meeresfischen. Z. Tierpsychol. 12, 203-219.

- 1957. Bericht von einer Reise zu den Galapagos-Inseln unter besonderer Berücksichtigung verhaltenskundlicher, herpetologischer und ichthyologischer Beobachtungen. Aquar.- $u$. Terrar.-Z. $10(1 / 2), 14-20 ; 38-43$.

- 1960. Beobachtungen und Versuche an Anemonenfischen (Amphiprion) der Malediven und der Nikobaren. Z. Tierpsychol. 17, 1-10.

- 1961a. Eine Symbiose zwischen Fischen (Siphamia versicolor) und Seeigeln. Z. Tierpsychol. 18, 56-59.

- 1961b. Gnathypops rosenbergi annulata u. ssp. von den Nikobaren (Pisces, Percomorphi, Opisthognathidae). Senckenberg biol. 42, 421-426.

- 1962. Freiwasserbeobachtungen zur Deutung des Schwarmverhaltens verschiedener Fische. Z. Tierpsychol. 19, 165-182.

- 1964. Im Reich der tausend Atolle. Piper, München, 211 pp.

- \& Hass, H., 1959. Erfahrungen mit Haien. Z. Tierpsychol. 16, 739-746.

- \& SCheer, G., 1962. Das Brutpflegeverhalten eines weiblichen Octopus aegina Gray. Z. Tierpsychol. 19, 257-261.

EllsberG, E., 1939. Men under the sea. Dodd \& Mead, New York, 365 pp.

Emery, K., 1952. Submarine photography with the benthograph. Scient. Mon., N.Y. 75, 3.

- 1953. Some surface features of marine sediments made by animals. J. sedim. Petrol. 23, 201-204.

- \& Merrill, A., 1964. Camera and bottom-grab. Oceanus 10 (4), 2-7.

ErNST, J., 1955. Sur la végétation sous-marine de la Manche d'après des observations en scapandre autonome. C. r. hebd. Séanc. Acad. Sci, Paris 241.

- 1957. Quelques remarques sur la photographie sous-marine en couleurs des communautés algales. Colloques int. Čent. natn Rech. scient. 81, 273-276.

- 1958. The life-forms of some perennial marine algae of Roscoff and their vertical distribution. Int. Seaweed Symp. 3 (Galway), 1.

- 1959a. Phytosociological methods as applied to the study of marine bottom communities. Am. Ass. Advt. Sci., Washington, D.C., 151-153.

- 1959b. Studien über die Seichtwasser-Vegetation der Sorrentiner Küste. Ergebnisse der Osterreichischen Tyrrhenia-Expedition 1952. T. 13. Pubbl. Staz. zool. Napoli 30 (Suppl.), 470-518. 
- 1960. Prospections et levés cartographiques des biocenoses benthiques en eaux côtières françaises. C. r. hebd. Séanc. Acad. Sci., Paris 251, 2566-2568.

- 1966. Données quantitatives au sujet de la répartition verticale des Laminaires sur les côtes nord de la Bretagne. C. r. hebd. Séanc. Acad. Sci., Paris (Ser. D) 262, 2715-2717.

Ewing, M., Vine, A. \& Worzel, L., 1946. Photography of the ocean bottom. J. opt. Soc. Am. 36.

- Woollard, C., Vine, A. \& Worzel, L., 1946. Recent results in submarine geophysics. Bull. geol. Soc. Am. 57.

Fadeew, V., Pecatin, A. \& Curowikin, V., 1958. Čelovek pod vodoj [Der Mensch unter Wasser]. Moskau.

FiedLER, K., 1954. Vergleichende Verhaltensstudien an Seenadeln, Schlangennadeln und Seepferdchen (Syngnathidae). Z. Tierpsychol. 11, 358-416.

- 1964. Verhaltensstudien an Lippfischen der Gattung Crenilabrus (Labridae, Perciformes). Z. Tierpsychol. 21 (5), 521-591.

Field, C., 1903. Quaint diving apparatus of the 18th century. Scient. Am. 89, 9.

Forster, G., 1954. Preliminary note on a survey of Stoke Point rocks with selfcontained diving apparatus. J. mar. biol. Ass. U.K. 33, 341-344.

- 1958. Underwater observations on shallow rocky areas in the neighbourhood of Plymouth. J. mar. biol. Ass. U.K. 37, 473-482.

- 1959. The ecology of Ecbinus esculentus L. Quantitative distribution and rate of feeding. J. mar. biol. Ass. U.K. 38, 361-367.

Forstner, H., 1965. Zur Kenntnis der Verteilung der Brachyura Brachyrhyncha im Litoral Istriens. Thalassia jugosl. (im Druck).

Fredj G., 1964. Contributions à l'etude bionomique de la Méditerranée occidentale. 2. La règion de Saint Tropez: du Cap Taillat au Cap de Saint Tropez. Bull. Inst. océanogr. Monaco 63 (1311), 1-55.

Fried, Z., 1957. Underwater study of the Italian type trawl bear. Proc. tech. Pap. gen. Fish Coun. Mediterr. 4 (42), 363-369.

Friedrich, H., 1965. Meeresbiologie. Eine Einführung in die Probleme und Ergebnisse. Borntraeger, Berlin, $436 \mathrm{pp}$.

Fye, P., 1950. The high-speed photography of underwater explosions. J. Soc. Motion Pict. Telev. Engrs 55 (4), 414-424.

Gast, A. \& Burt, V., Submarine photography in Puget Sound. Science, N. Y. 120 (3119).

GerLACH, S., 1958. Die Mangroveregion tropischer Küsten als Lebensraum. Z. Morph. Ökol. Tiere 46, 636-730.

- 1959. Uber das tropische Korallenriff als Lebensraum. Zool. Anz. (Suppl. Bd) 23, 356-363.

Gessner, F. \& Hammer, L., 1960. Die Primärproduktion in mediterranen Caulerpa-Cymodocea-Wiesen. Botanica mar. 2, 157-163.

GiLeT, R., 1956. L'eau du milieu phytal marine. Note préliminaire sur les variations de sa teneure en oxygène. Rapp. P.-v. Réun Commn int. Explor, scient. Mer Méditerr. 13, 195-198.

GISLÉN, T., 1929/30. Epibioses of the Gullmar Fjord. Pt 1. Geomorphology and hydrography. 2. Marine sociology. (Kristinebergs Zoologiska Station, 1877-1927.) SkrSer. K. svenska VetenskAkad. 3, 1-123; 4, 1-380.

- \& ODquist, G., 1935. Composing submarine landscapes for photographic reproduction. J. biol. photogr. Ass. 4 (3).

GlenNAn, K., 1914. Moving pictures underwater. Scient. Am. 78, 88-89.

Gohar, H., 1948. Commensalism between fish and anemone with a description of the eggs of Amphiprion bicinctus RüpPel. Publs mar. biol. Stn Ghardaqa 6, 35-44.

Gomoln, M. \& Mül.LeR, G., 1962. Studies concerning the benthic association dominated by Barnea candida in the Black Sea. Revue Biol., Buc. 7 (2), 255-271.

Graffe, G., 1963. Die Anemonen-Fisch-Symbiose und ihre Grundlage nach Freilanduntersuchungen bei Eilat/Rotes Meer. Naturwissenschaften 50, 410.

Haefelfinger, H., 1960. Catalogue des Opisthobranches de la rade de Villefranche-sur-Mer et ses environs (Alpes Maritimes). Revue suisse Zool. 67 (27).

- 1961. Beiträge zur Kenntnis von Peltodoris atromaculata BERGH 1880 (Mollusca, Opisthobranchia). Revue suisse Zool. 68, 331-343. 
- 1962. Crimora papillata Adrer 1862, Opisthobranche nouveau pour la Méditerranée. Vie Milieu 13, 161-165.

- 1963. Bedarf die marine Fauna der mediterranen Küstenzone eines Schutzes? Revue suisse Zool. 70, 252-258.

Hahn, J., 1950. Some aspects of deep sea underwater photography. PSA Il (Sect. B) 1950 (June).

Halder, C., 1899. Photographing living fishes at Santa Catalina Zoological Station. Scient. Am. 81, 362-363.

Harvey, E., 1939. Deep sea photography. Science, N.Y.90.

— \& BAYLOR, R., 1948. Deep sea photography. J. mar. Res. 7 (1).

Hass, H., 1939. Jagd unter Wasser. Mit Harpune und Kamera, 3. Aufl. Deutscher Verl., Berlin, $69 \mathrm{pp}$.

- 1942. Fotojagd am Meeresgrund. Erlebnis und Technik der Unterwasserfotografie. Heering, Harzburg, 213 pp.

- 1949. Beitrag zur Kenntnis der Reteporiden. Zoologica, N. Y. 37, 1-138.

- 1952. Manta. Teufel im Roten Meer. Ullstein, Berlin, 179 pp.

- 1961. Expedition ins Unbekannte. Ein Bericht über die Expedition des Forschungsschiffes Xarifa zu den Malediven und Nikobaren ... Ullstein, Wien, $167 \mathrm{pp.}$

Heberlein, H., 1956a. Einsame Inseln. Eine Forscherfahrt im Persischen Golf. Orell Füssli, Zuirich, 219 pp.

- 1956b. Von der Torpille zum, Unterwasser-Flugzeug. Delphin 3, 265-267.

- 1958. Unterwasserwelt. Ozeanographie, Geschichte des Tauchers, moderner Tauchsport,... Mit Unterwasser-Bibliographie (pp. 214-231). Verl. Bea Bücherdienst, Zürich, 231 pp.

HÉderer, C., 1936. Le scaphandre autonome. Etude physiologique et mode d'emploi. Bach $\&$ Co., Straßburg.

Hempel, G., 1957. Unterwasser-Fernsehkamera für Forschungszwecke. Naturw. Rdsch., Stuttg. 10, 388-389.

Heuss, T., 1962. Anton Dohrn. Mit einem Beitrag von M, Boveri. 2. Ausg. Wunderlich, Tübingen, 448 pp.

Hiatt, R. \& Strasburg, D., 1960. Ecological relationships of the fish fauna on coral reefs of the Marshall-Islands. Ecol. Monogr. 30, 65-127.

Hill, L., 1911. Physiology of submarine work. Nature, Lond. 87, 567-573.

Hofman, R., 1938. Unterwasser-Aufnahmen mit einer Tiefsee-Kamera in der Kieler Bucht. Kieler Meeresforsch. 2, 352-353.

Hopkins, R. \& Edgerton, H., 1961. Lenses for underwater photography. Deep Sea Res. 8, 312-317.

Hovot G. \& Willm, P., 1955. 4000 Meter tief (Le Bathyscaph). A. d. Franz. Brockhaus, Wiesbaden, $231 \mathrm{pp}$.

Humphrey, J., 1893. Submarine photography. Science, N. Y. 22, 148-149.

Hunger, H., 1955. Unterwasser-Fernsehen. Schiff Hafen 7 (6), 1-8.

Ivanoff, A., 1951. On underwater photography. J. opt. Soc. Am. 41, 645-646.

- 1953. Systèmes optiques pour photographie sous-marine. Rev. Opt. théor. instrum. 32, 193-202.

- 1956. Ein Vorsatzobjektiv zum Fotografieren unter Wasser. Optik, Stuttg. 13 (2), $54-57$.

JACKSON, R., 1913. Taking moving pictures under the sea. Technical World 20, 384-385.

Jude, Mr., 1958. Stage de plongée sous-marine. In: Petit, G.: Rapport sur le fonctionnement du Laboratoire Arago en 1958. Vie Milieu 9, 508.

KaIn, J., 1960. Direct observations on some Manx sublittoral algae. J. mar. biol. Ass. U.K. 39, 609-630.

Kerneïs, A., 1960. Contribution à l'etude faunistique et écologique des herbiers de Posidonies de la région de Banyuls. Vie Milieu 11 (2), 145-187.

KIRCHHOFER, R., 1954. Okologie und Revierverhältnisse beim Schriftbarsch (Serranus scriba Cuv.). Öst. zool. Z. 5, 329-349.

Kirsteuer, E., 1961. Von der Bedeutung des Tauchens für die Meeresbiologie. Neptun 4, 97-98. 
- 1963. Beitrag zur Kenntnis adriatischer Nemertinen (Genera Tetrastemma, Oerstedia, Oerstediella). Zool. Jb. (Abt. Anat. Ontog. Tiere) 80, 555-616.

Kitching, J., 1941. Studies in sublittoral ecology. 3. Laminaria forest on the west coast of Scotland. Biol. Bull. mar. biol. Lab., Woods Hole 80, 324-337.

- Macan T. \& Grlson, H., 1934. Studies in sublittoral ecology. 1. submarine gully in Wembury Bay, South Devon. J. mar. biol. Ass. U.K. 19, 677-705.

Klausewitz, W., 1958. Die Atollriffe der Malediven. Natur Volk 88, 380-390.

- 1960. Fische aus dem Roten Meer. 4. Einige systematisch und ökologisch bemerkenswerte Meergrundeln (Pisces, Gobiidae). Senckenberg. biol. 41, 149-162.

- 1961. Das Farbkleid der Korallenfische. Natur Volk 91 (6), 204-215.

- 1962a. Röhrenaale im Roten Meer. Natur Mus., Frankf. 92 (3), 95-98.

- 1962b. Wie schwimmen Haifische? Natur Mus., Frankf. 92 (6), 219-226.

- 1964. Die Erforschung der Ichthyofauna des Roten Meeres. Cramer, Weinheim, 32 pp.

- \& Eibl-Eibesfeldt, I., 1959. Neue Röhrenaale von den Malediven und Nikobaren (Pisces, Apodes, Heterocongridae). Ergebnisse der Xarifa-Expedition 1957-58 des Institutes für submarine Forschung, Vaduz, u. d. Ltg. von H. Hass. Senckenberg. biol. 40, 135-153.

KLINGBeIt, K. \& KüHLMANN, D., 1958. Sporttauchen. Verl. Sport und Technik. Berlin-Neuenhagen, $303 \mathrm{pp}$.

KNAPP, R., 1947. Special cameras and flash lamps for high-speed underwater photography. J. Soc. Motion Pict. Telev. Engr. 49 (1).

KREBs, W., 1906. Das Taucherwesen in alter und in neuer Zeit und seine Zukunft. Weltall (Z. Astr, verw. Geb., Beil.) 3.

Kucharski, W., 1927. Zur Entwicklung des Tauchens in größeren Wassertiefen. Werft, Reed., Hafen 8, 65-71.

KüнN, A., 1950. Anton Dohrn und die Zoologie seiner Zeit. Pubbl Staz. zool. Napoli (Suppl. 1950).

Kuščer, J., 1947. Morski poživalnik pri Opatiji. Proteus 9 (6).

LaboRel, J., 1956. Premières notes de plongée sur les peuplements marins en eaux greques. C. r. bebd. Séanc. Acad. Sci., Paris 242, 565-567.

- 1960. Contribution à l'etude directe des peuplements benthiques sciaphiles sur substrat rocheux en Mediterranée. Recl Trav. Stn mar. Endoume 33, 117-173.

- 1961. Le concrétionnement algal "coralligène" et son importance géomorphologique en Mediterranée. Recl Trav. Stn mar. Endoume 23 (37), 37-60.

- Pérès, J., Picard, J. \& Vaceret, J., 1961. Etude directe des fonds des parages de Marseille de 30 à $300 \mathrm{~m}$ avec la soucoupe plongeante Cousteau. Bull. Inst. océanogr. Monaco 58 (1206), 1-16.

- \& VACELET, J., 1958. Etude des peuplements d'une grotte sous-marine du golfe de Marseille. Bull. Inst. océanogr. Monaco 55 (1120), 1-20.

- - 1959. Les grottes sous-marines obscures en Méditerranée. C. r. hebd. Séanc. Acad. Sci., Paris 248, 2619-2621.

- - 1962. Répartition bionomique du Corallium rubrum LмCK dans les grottes et falaises sous-marines. Rapp. P.-v. Réun. Commn int. Explor. scient. Mer Méditerr. 16, 465-469.

LAmbertSen, C., 1955. Respiratory and circulatory actions of high oxygen pressure. In: Proceedings of the underwater physiology symposium, Jan. 10-11, 1955, Washington, DC. Ed. by L. G. Goff. Publs natn. Res. Coun., Wash. 377, 25-38.

LANPHIER, E. H., 1955. Use of nitrogen-oxygen mixtures in diving. In: Proceedings of the underwater physiology symposium, ... Publs natn. Res, Coun., Wash. 377, 74-78.

Latil, P. de \& Rivorre, J., 1954. A la recherche du monde marin. Plon, Paris, 383 pp.

Laughton, A., 1957. A new deep-sea underwater camera. Deep Sea Res. 4, 120-125.

- 1959. Photography of the ocean floor. Endeavour 18 (72).

- Hill, M. \& Allen, T., 1960. Geophysical investigations of a seamount 150 miles north of Madeira. Deep Sea Res. 7, 117-141.

Ledoyer, M., 1961. Relation entre l'accroissement nocturne massif de la faune vagile et les variations de la teneur en gaz dissous dans les herbiers de Posidonies superficiels. C. $r$. hebd. Séanc. Acad. Sci., Paris 252, 4207-4208. 
Limbaugh, C., 1955. Fish life in the kelp beds and the effect of kelp harvesting. Ref. Ser. Inst. mar. Resources Univ. Calif. 55 (9), 1-158.

- 1957. Marine outfall studies by qualified diving investigators (Proc. of the 12th Industrial Waste Conference). Engng Bull. Purdue Univ. 42, 210-216.

- 1961. Cleaning symbiosis. Scient. Am. 205 (Aug.), 42-50.

- Pederson, H. \& Chace, F., 1961. Shrimps that clean fishes. Bull. mar. Sci. Gulf Caribb. $11,237-257$.

- Rechnitzer, A., 1955. Visual detection of temperature density discontinuities in water by diving. Science, $N . Y .121,1-2$.

- \& Shepard, F., 1957. Submarine canyons. In: Treatise on marine ecology and paleoecology. Vol. 1. Ecology. Ed. by J. W. Hedgpeth. (Mem. Geol. Soc. Am. 67, 633-639.)

LINDBERG, R., 1955. Growth, population dynamics, and field behavior in the spiny lobster, Panulirus interruptus (Randall). Univ. Calif. Publs Zool. 59, 157-248.

Longhurst, A., 1958. An ecological survey of the West African marine benthos. Fishery Publs colon. Off. 11.

Longley, W., 1916. The significance of the colours of tropical reef fish. Yb. Carnegie Instn Wash. 15, 209-212.

- 1918. Haunts and habits of tropical fishes. Observations of an explorer, equipped with a diving hood in the unknown world of coral labyrinths at the bottom of the sea. Am. Mus. J. 18, 79-88.

- \& Hildfbrand, S., 1941. Systematic catalogue of the fishes of Tortugas, Florida; with observation on color, habits and local distribution. Pap. Tortugas Lab. 535.

- \& Martin, C., 1927. The first autochroms from the ocean bottom. Natn geogr. Mag. 51.

LUTHER, W., 1958. Symbiose von Fischen (Gobiidae) mit einem Krebs (Alpheus djiboutensis) im Roten Meer. Z. Tierpsycbol. 15, 175-177.

- \& Fiedler, K., 1961. Die Unterwasserfauna der Mittelmeerküsten. Ein Taschenbuch für Biologen und Naturfreunde. Parey, Hamburg, 253 pp.

MAGNus, D., 1962-1964. Wasserströmung und Nahrungserwerb bei Stachelhäutern des Roten Meeres (Untersuchungen an Schlangensternen und Federsternen). Ber. phys.-med. Ges. Würzb. 71, 128-141.

- 1963a. Der Federstern Heterometra savignyi im Roten Meer. Natur Mus. Frankf. 93 (9), 355-368.

- 1963b. Uber das „Abweiden“ der Flutwasseroberfläche durch den Schlangenstern Ophiocoma scolopendrina (Lamarck). Zool. Anz. (Suppl. Bd) 26, 471-481.

- 1963c. Zum Problem der Partnerschaften mit Diademseeigeln. Zool. Anz. (Suppl. Bd) 27, 404-417.

- 1964. Gezeitenströmung und Nahrungsfiltration bei Ophiuren und Crinoiden. Helgoländer wiss. Meeresunters. 10, 104-117.

- 1966a. Bewegungsweisen des amphibischen Schleimfisches Lophalticus kirkii KlausEwiTz (Pisces, Salariidae) im Biotop. Zool. Anz. (Suppl. Bd) 29, 542-555.

- 1966b. Zur Ókologie einer nachtaktiven Flachwasser-Seefeder (Octocorallia Pennatularia) im Roten Meer. Veröff. Inst. Meeresforsch. Bremerh. (Sonderbd) 2, 369-380.

MARGETTS, A., 1952. Some conclusions from underwater observation of trawl behavior. Wld Fishg 1, 161 .

Mayor, A., 1924. Structure and ecology of Samoan reefs. Pap. Dept. mar. Biol. Carnegie Instn Wash. 19 (340/1), 1-25.

McGowan, I., 1954. Observation on the sexual behavior and spawning of the squid, Loligo opalescens, at La Jolla, California. Calif. Fish Game 40, 47-54.

McLean, I., 1962. Sublittoral ecology of kelp beds of the open coast area near Carmel, California. Biol. Bull. mar biol. Lab., Woods Hole 122, 95-114.

MEAD, J., 1955. Resistance to breathing at increased ambient pressures. In: Proceedings of the underwater physiology symposium, Jan. 10-11, 1955, Washington, DC. Ed. by L. G. Goff. Publs natn. Res. Coun., Wash. 377, 112-123.

Melone, N., 1963. Nuovi dati su le specie Microciona toxivaria e Microciona toxistyla trasferite al genere Clathria (Demospongiae). Annuar. Ist. Mus. Zool. Univ. Napoli 15 (3), 1-8. 
Menard, H., 1952. Deep ripple marks in the sea. J. sedim. Petrol. 22, 3-9.

Menzies, R., Smith, L. \& EMERY, K., 1963. A combined underwater camera and bottom grab: a new tool for investigations of deep-sea benthos. Int. Revue ges. Hydrobiol. Hydrogr. 48, $529-545$.

Milne-Edwards, H., 1845. Recherches zoologiques faites pendant un voyage sur les côtes de la Sicile. 1. Rapport. Annls Sci. nat. (Ser. 3. Zool.) 1 (3).

Miner, R., 1934. Diving in Coral Gardens. Scient. Am. 151, 122-124.

Miraglia, L., 1935. Nuovo sistema di osservacione e di caccia subacquea. Boll. Pesca Piscic. Idrobiol. 11, 225-317.

MöHREs, F., 1964. Welt unter Wasser. Tiere des Mittelmeeres. Belser, Stuttgart, 256 pp.

Molinier, R. \& Picard, J., 1952. Recherches sur les herbiers de Phanérogames marines du littoral méditerranéen francais. Annls Inst. océanogr, Monaco 27 (3), 157-234.

Müller, G., 1962. Contributii la Studiul Nemertienilar diu Marea Neagră (Litoralul Romînesc). Studii Cerc. Biol. (Ser. Biol Animal.) 14 (3), 371-384.

Nikolıć, M., 1957. Neka iskustva stečena pri fotografiranju morskog dna u okolini Rovinja. Morsko Ribarst. 6.

- 1958a. Pod Morsko Gladino. Mladinska Knjiga, Ljubljana, 133 pp.

- 1958b. Underwater television in the adriatic sea (Kroat. nebst engl. Zsfssg.). In: Posebni Otisak iz Hidrografskog. Godisnjaka. Split, 253-259.

- 1960. Diving as a method of the sea research. In: Posebni Otisak iz Hidrografskog Godisnjaka. Splic (1959), 129-150.

North, W. J., 1956. Scientific diving. (Yale scient. Mag. 31 [3]). Contr. Scripps Instn Oceanogr. 1956 (872), 699-702.

Odum, H. \& Odum, E., 1955. Trophic structure and productivity of a windward coral reef community on Eniwetok atoll. Ecol. Monogr. 25, 291-320.

Olsen, A., 1955. Underwater studies on the Tasmanian commercial scallop Notovola meridionalis (TATE) (Lamellibranchiata: Pectinidae). Aust. J. mar. Fresbwat. Res, 6, 392-409.

OTт, J., 1967. Vertikalverteilung von Nematoden in Beständen nordadriatischer Sargassaceen. Helgoländer wiss. Meeresunters. 15, 412-428.

OWEN, D., 1951. Deep sea underwater photography and some recent stereoscopic applications. Photogramm. Engng 17 (March).

- 1958. Photography underwater. Oceanus 6 (1), 22-39.

Pearson, J., 1928. Diving experiment at the University of Miami. Science, N.Y. 68, 85-86.

Pecrham, O. \& McLean, J., 1961. Biological exploration at the head of the Carmel Submarine Canyon. Rep. Am. malac. Un. Pacif. Div. 1961, 43.

Pequegnat, W., 1961a. New world for marine biologists. Nat. Hist., N.Y. 70, 8-17.

- 1961b. Life in the Scuba zone. Nat. Hist., N. Y. 70, 46-55.

Pérès, J., 1957a. Problème de l'etagement des formations benthiques. Recl Trav. Stn mar. Endoume 21 (12).

- 1957b. Essai de classement des communautés benthiques marines du Globe. Recl Trav. Stn. mar. Endoume 22, 23-54.

- 1958. Remarques générales sur un ensemble de quinze plongées effectuées avec le Bathyscaphe F.N.R.S. III. Annls Inst. océanogr., Monaco 35, 259-286.

- 1959. Deux plongées au large du Japon avec le bathyscaphe français F.N.R.S. III. Bull. Inst. océanogr., Monaco 56 (1134), 1-28.

- 1960. La „soucoupe plongeante“, engin de prospection biologique sous-marine. Deep Sea Res. 7, 208-214.

- 1961. Océanographie biologique et biologie marine. Pr. Univ. de France, Paris, T. 1, 1-541.

- \& Picard, J., 1949. Notes sommaires sur le peuplement des grottes sous-marines de la region de Marseille. C. r. somm. Séanc. Soc. Biogéogr. 26, 42-45.

- - 1951. Notes sur les fonds coralligènes de la règion de Marseille. Archs Zool. exp. gén. 88, 24-38.

- - 1955a. Biotopes et biocoenoses de la Mediterranée occidentale comparés à ceux de la Manche et de l'Atlantique nord-oriental. Archs Zool. exp. gén. 92. 
- - 1955b. Observations biologiques effectués au large de Toulon avec le Bathyscaphe FNRS III de la Marine Nationale. Bull. Inst. océanogr., Monaco 52 (1061), 1-8.

- - 1958. Manuel de bionomie benthique de la mer Méditerranée. Recl Trav. Stn mar. Endoume 14, 7-122.

Perkins, F., 1914. Submarine photography. Photogr. Times Bull. 46, 473-482,

Pesta, O., 1959. Harpacticoiden (Crust. Copepoda) aus submarinen Höhlen und den benachbarten Litoralbezirken am Kap von Sorrent (Neapel). Ergebnisse der österreichischen Tyrrhenia-Expedition 1952. T. 6. Pubbl. Staz. zool. Napoli 30 (Suppl.), 93-177.

PiCard, J., 1954a. Modifications saisonnières des peuplements de l'horizon inférieur de la roche littoral. C. r. hebd. Séanc. Acad. Sci., Paris 238, 1358.

- 1954b. Notes de plongée sur le tombant est de l'Ile Maïre. Recl Trav. Stn mar. Endoume 13.

- 1956. Les peuplements benthiques des amphores du Grand-Congen. Résult scient. Camp. Calypso 2, 155-161.

Piccard, A., 1954. Über den Wolken, unter den Wellen. Brockhaus, Wiesbaden, 304 pp.

Piccard, I. \& Dietz R., 1957. Oceanographic observations by the bathyscaph "Trieste". Deep Sea Res. 4, 221-229.

Pohle, F., 1955. Physiologie und Pathologie des Tauchens. Sportmedizin 6 (3), 70-78.

Rakovec, R., 1960. Prispevki k poznavanju vrste Parazoanthus axinellae SchмidT. - Beiträge zur Kenntnis der Art ... Biol. Vest. 7, 39-53.

Randall, I., 1955. Fishes of the Gilbert Islands. Atoll Res. Bull. 47.

- 1958. A review of the Labrid fish genus Labroides with description of two new species and notes on ecology. Pacif. Sci. 12, 327-347.

- \& Randall, H., 1960. Examples of mimicry and protective resemblance in tropical marine fishes. Bull. mar. Sci. Gulf Caribb. 10, 444-480.

Ransonnet-Villez, E. von, 1868. Ceylon. Skizzen seiner Bewohner, seines Thier- und Pflanzenlebens und Untersuchungen des Meeresgrundes nahe der Küste. Westermann, Braunschweig.

Rébrkoff, D., 1952a. Licht im Meer (Exploration sous-marine). A. d. Franz. Barakuda Ges., Hamburg, 208 pp.

- 1952b. Photo sous-marine. [Arthaud,] Paris, 48 pp.

- 1954. Kino-Farbfilmaufnahmen in größeren Meerestiefen. Kinotechnik, Warsz. 8 (3), 62-65.

Reighard, J., 1909. Sub-aqueous photography. Scient. Am. 67, 252-255; 268-270; 284-286.

Res, L. \& Rossi, L., 1965. Il Coralligeno di Punta Mesco (La Spezia). Annali Mus. civ. Stor. nat. Giacomo Doria 75, 144-180.

Reusch, J., 1957. Unterkühlung und Auskühlung. Delphin 4 (10), 407.

Richter, H., 1958. Unterwasserphotographie und -Fernsehen. Fotokinoverlag, Halle a. d. Saale, T. $1,2$.

RIEDL, R., 1947. Was ist Unterwasserforschung. Umwelt 3, 98-100.

- 1953. Quantitativ ökologische Methoden mariner Turbellarienforschung. Öst. zool. Z. 4, 108-145.

- 1954a. Neue Turbellarien aus dem mediterranen Felslitoral. Ergebnisse der „UnterwasserExpedition AUSTRIA 1948-49“. Zool. Jb. (Abt. Syst., Ókol., Geogr. Tiere) 82, 157-244.

- 1954b. Unterwasserforschung im Mittelmeer, Osterreichische Tyrrhenia-Expedition 1952. Naturw. Rdsch., Stuttg. 2, 65-71.

- 1955. Aufsammlung tiefer Meeresböden in abgegrenzten Schichten und Flächen. Arch. Hydrobiol. 51, 189-208.

- 1956a. An attempt to test the efficiency of ecological field methods and the validity of their results. In: Perspectives in marine biology. Ed. by A. A. Buzzati-Traverso. Univ. of Calif. pr., Berkeley, 57-65.

- 1956b. Anatomische Photographie von Meeresböden für ökologisch faunistische Zwecke. Öst. zool. Z. 6, 532-541.

- 1956c. Über Tierleben in Höhlen unter dem Meeresspiegel. Zool. Anz. (Suppl.Bd) 19, $429-440$.

- 1959a. Turbellarien aus submarinen Höhlen. 1. Archoophora. Ergebnisse der Osterreichischen Tyrrhenia-Expedition 1952. T. 7. Pubbl. Staz. zool. Napoli 30 (Suppl.), 178-208. 
- 1959b. Turbellarien aus submarinen Höhlen. 2. Prolecithophora. Ergebnisse der Osterreichischen Tyrrhenia-Expedition 1952. T. 8. Pubbl. Staz. zool. Napoli 30 (Suppl.), 209 bis 304 .

- 1959c. Turbellarien aus submarinen Höhlen. 3. Seriata und Neorhabdocoela. Ergebnisse der Österreichischen Tyrrhenia-Expedition 1952. T. 9. Pubbl. Staz. zool. Napoli 30 (Suppl.), 305-332.

- 1959d. Turbellarien aus submarinen Höhlen. 4. Faunistik und Ókologie. Ergebnisse der Osterreichischen Tyrrhenia-Expedition 1952. T. 10. Pubbl. Staz. zool. Napoli 30 (Suppl.), 331-401.

- 1959e. Das Vorkommen von Nemertinen in unterseeischen Höhlen. Ergebnisse der Osterreichischen Tyrrhenia-Expedition 1952. T. 15. Pubbl. Staz. zool. Napoli 30 (Suppl.), 527-590.

- 1959f. Die Hydroiden des Golfes von Neapel und ihr Anteil an der Fauna unterseeischer Höhlen. Ergebnisse der Osterreichischen Tyrrhenia-Expedition 1952. T. 16. Pubbl. Staz. zool. Napoli 30 (Suppl.), 589-755.

- 1963a. Fauna und Flora der Adria. Ein systematischer Meeresführer für Biologen und Naturfreunde. Parey, Hamburg, 640 pp.

- 1963b. Probleme und Methoden der Erforschung des litoralen Benthos. Zool. Anz. (Suppl. Bd) 26, 505-567.

- 1964a. Die Erscheinungen der Wasserbewegung und ihre Wirkung auf Sedentarier im mediterranen Felslitoral. Helgoländer wiss. Meeresunters. 10, 155-186.

- 1964b. 100 Jahre Litoralgliederung seir Josef Lorenz, neue und vergessene Gesichtspunkte. Int. Revue ges. Hydrobiol. Hydrogr. 49, 281-305.

- $1964 \mathrm{c}$. Lo studio litorale marino in rapporto alla moderna biologia. Atti Semin. Stud. biol. Bari 1, 3-30.

- 1966a. Biologie der Meereshöhlen. Parey, Hamburg, 636 pp.

- 1966b. Spelaeologie und Meeresbiologie, eine Brücke zwischen Forschungsgebieten. Höble $17,28-44$.

Rufro, S., 1959. Contributo alla conoscenza degli Anfipodi delle grotte Sottomarine. Ergebnisse der Osterreichischen Tyrrhenia-Expedition 1952. T. 11. Pubbl. Staz. zool. Napoli 30 (Suppl.), 402-416.

- \& WiEser, W., 1952. Osservazioni sistematiche et ecologiche su alcuni Anfipodi delle coste Mediterranee Italiane. Memorie Mus. civ. Stor. nat. Verona 3, 11-30.

Russ, K. \& Rützler, K., 1959. Zur Kenntnis der Schwammfauna unterseeischer Höhlen. Ergebnisse der Österreichischen Tyrrhenia-Expedition 1952. T. 17. Pubbl. Staz. zool. Napoli 30 (Suppl.), 756-787.

RüTzler, K., 1964. Aspects of littoral life in the Indian Ocean. Atti Semin. Stud. biol. Bari 1, 1-17.

- 1965a. Substratstabilität im marinen Benthos als ökologischer Faktor, dargestellt am Beispiel adriatischer Poriferen. Int. Revne ges. Hydrobiol. Hydrogr. 50, 281-292.

- 1965b. Systematik und Ókologie der Poriferen aus Litoral-Schattengebieten der Nordadria. Z. Morph. Ökol. Tiere 55, 1-82.

- 1965c. Die Poriferen einer sorrentiner Höhle. Ergebnisse der Osterreichischen TyrrheniaExpedition 1952. T. 18. Zool. Anz. 176, 303-319.

- Zwischenartliche Beziehungen bei Schwämmen, insbesondere die anatomischen Einrichtungen bei Überwachsungsvorgängen. Z. Morphol. Ökol. Tiere (im Druck).

- \& SARÀ, M., 1962. Diplastrella ornata, eine neue mediterrane Art der Familie Spirastrellidae (Demospongiae), Zool. Anz. 169, 231-236.

SAND, R., 1955. Use of underwater television in fishing gear research (preliminary report). Comml Fish. Rev. 17 (4), 1-5.

SARÀ, M., 1958. Studio sui Poriferi di una grotta di marea del Golfo di Napoli. Archo zool. ital. 43, 203-280.

- 1959a. Considerazioni sulla distribuzione ed ecologia dei Poriferi nelle grotte. Annwar. Ist. Mus. Zool. Univ. Napoli 11 (2), 1-7.

- 1959b. Specie nuove di Demospongie provenienti da acque superficiali del golfo di Napoli. Annuar. Ist. Mus. Zool. Univ. Napoli 11 (7), 1-22. 
- 1959c. Sulla coesistenza di specie strettamente affini di Poriferi in biotopi litorali. Boll. Zool. 26, 1-8.

- 1960a. Aspetti e problemi di una ricerca sinecologica sui Porifera del Golfo di Napoli. Boll. Zool. 27, 51-65.

- 1960b. Poriferi del litorale dell'isola d'Ischia e loro ripartizione per ambienti. Pubbl. Stn zool. Napoli 31, 421-472.

- 1961a. La fauna di Poriferi delle grotte isoli Tremiti. Studio ecologico e sistematico. Archo zool. ital. 46, 1-59.

- 1961b. Zonazione dei Poriferi nella grotta della „Gaiola“. Annuar. Ist. Mus. Zool. Univ. Napoli 13 (1), 1-32.

- 1962. Distribuzione ed ecologia dei Poriferi an acque superficiali del Golfo di Policastro (Mar Tirreno). Annali Ist. sup. Sci. Lett. S Chiara 12, 191-214.

- 1962-63. Una nuova specie di Fartronidi (Petrobiona incrustans) dal Mediterraneo e considerazioni sulla sistematica delle Calcispongie. Monitore zool. ital. 70-71, 229-237.

- 1964. Distribuzione ed ecologia dei Poriferi in acque superficiali della Riviera ligure di Levante. Archo zool. ital. 49, 181-248.

- Melone, N., 1963. Poriferi di acque superficiali del litorale pugliese presso Bari. Annali pont. Ist. sup. Sci. Lett. S Chiara 13, 1-28.

Scarlato, O., Golikov, A. \& Gruzov, E., 1964. Die Tauchermethode bei hydrobiologischen Untersuchungen. Okeanologija 4, 707-719.

Schatfer, K. E., 1955. The rôle of carbon dioxide in the physiology of human diving. In: Proceedings of the underwater physiology symposium, Jan. 10-11, 1955, Washington, DC. Ed. by L. G. Goff. Publs natn, Res. Coun., Wash. 377, 131-141.

SCHeER, G., 1956. Biologie mit Maske und Schnorchel. Delphin 3, 190-191.

- 1960. Der Lebensraum der Riffkorallen. Ber. naturw. Ver. Darmstadt 1959/60, $29-44$.

- 1964a. Bemerkenswerte Korallen aus dem Roten Meer. Senckenberg biol. 45, 613-620.

- 1964b. Korallen von Abd-el-Kuri. Zool. Jb. (Abt. Syst. Ókol. Geogr. Tiere) 91, 451-466.

Schinkowski, K., 1957. Taucher im Eis. Seesport 6 (2), 1-11.

SHEPARD, F. P., 1939. Nearshore sediments-hemipelagic deposits. In: Recent marine sediments. A symposium. Ed. by P. D. Trask. Am. Assoc. of. Petrol. Geologists, Tulsa, Okla.

- 1948. Submarine geology. Harper \& Brs, New York, 348 pp.

- Emery, K. \& LA Fond, E., 1941. Rip currents: a process of geological importance. J. Geol. 49, 337-369.

- \& LA Fond, E., 1940. Sand movements along the Scripps Institution pier. Am. J. Sci. 38, 272-285.

Shumway, G., 1953-54. High pressure electrical lead-through plugs and gravity switches for deep sea cameras. Deep. Sea Res. 1, 121-125.

Stamp, W., 1953. Underwater television. Scient. Am. 158 (6), 34-37.

Starmühlner, F., 1955a. Zur Molluskenfauna des Felslitorals und submariner Höhlen am Capo di Sorrento. (T. 1.) Ergebnisse der Österreichischen Tyrrhenia-Expedition 1952. T. 4. Öst. zool. Z. 6, 147-249.

- 1955b. Zur Molluskenfauna des Felslitorals und submariner Höhlen am Capo di Sorrento. (T. 2.) Ergebnisse der Österreichischen Tyrrhenia-Expedition 1952. T. 4. Öst. zool. Z. 6, 631-713.

Stern, S. N., 1955. Neurophysiological effects of oxygen at high partial pressure. In: Proceedings of the underwater physiology symposium, Jan. 10-11, 1955, Washington, DC. Ed. by L. G. Goff. Publs natn. Res. Coun., Wash. 377, 20-24.

Stelzner, H., 1943. Tauchertechnik. Handbuch für Taucher. Coleman, Lübeck, 404 pp.

Steyaert, M., 1959. Le scaphandre autonome au service des sciences naturelles. Naturalistes belg. 40, 57-67.

Stipsšrc, A., 1955. Les mesures de sécurité du travail des scaphandriers. Proc. tech. Pap. gen. Fish. Coun. Mediterr. 3 (30), 277-287.

StorR, J., 1953. Techniques in underwater photography. PSA Jl 19 (9), 22-27.

SwEenEY, J., 1955. Skin diving and exploring underwater. McGraw-Hill, New York, 176 pp. SwEZey, K., 1940. How our navy trains its divers. Pop. Sci. Mon. 136, 98-101. 
TAllliez, P., 1956. In den Tiefen der Meere (Plongées sans câble). A. d. Franz. Ullstein, Wien, 213 pp.

- Dumas, F., Cousteau, J., Alinat, J. \& Devila, 1950. La plongée en scaphandre. Ed. Elzévir, Paris, 120 pp.

Tardent, P. \& Tardent, G., 1959. Capture d'un Abudefduf saxatilis vaigiensis Q. (Pisces, Pomacentridae) dans le Golfe de Naples. Revue suisse Zool. 66, 347-351.

THEODOR, J., 1958. Das Tauchen mit Kreislaufgeräten. In: Unterwassersport-Notizen des Unterwassersport-Zentrums Genf 5 (9).

- 1963. Contribution à l'étude des Gorgones. 3. Trois formes adaptives d'Eunicella stricta en fonction de la turbulence et du courant. Vie Milieu 14, 815-818.

- 1965. Aperçu sur l'histoire de la plongée et de la photographie sous-marines au service de la biologie. Vie Milien (Suppl.) 19, 347-350.

THomsen, W., 1956. Das Unterwasserfernsehen und seine technische Anwendung. Umschau 56, $565-568$.

Thorndike, E., 1950. A wide-angle, underwater camera lens. J. opt. Soc. Anm. 40, 823-824.

- 1958-59. Deep-sea cameras of the Lamont Observatory. Deep Sea Res. 5, $234-237$.

TrÉgoubofF, G., 1955. Sur l'emploi de la tourelle submersible Galeazzi pour des observations biologiques sous-marines à faibles profondeurs. Bull. Inst. océanogr. Monaco 52 (1070), 1-5.

- 1958a. Le bathyscaphe au service de la planctonologie. Annls Inst. océanogr. Monaco 35, $327-341$.

- 1958b. Prospection biologique sous-marine dans la région de Villefranche-sur-Mer au cours de l'année 1957. 1. Plongées en bathyscaphe. Bull. Inst. océanogr. Monaco 55, (1117), 1-37.

Triewald, M., 1736. A letter to ... J. T. Desaguiliers ... from Mr. Martin Triewald, ..., concerning an improvement of the diving bell. Stockholm. Nov. 1, 1732. Phil. Trans. R. Soc. 444, 377-383.

VACELET, J., 1959. Répartition générale des éponges et systematique des éponges cornées de la région de Marseille et de quelques stations mediterranéennes. Recl Trav. Stn mar. Endoume 16 (26), 1-101.

- 1961a. Quelques éponges remarquables de Méditerranée. Revue Trav. Inst. Pêch. marit. 25, 351-354.

- 1961b. The order Pharetronida in Hartman's Classification of the Calcarea. Syst. Zool. 10, $45-47$.

- 1964. Etude monographique de l'éponge calcaire pharétronide de Mediterranée, Petrobiona massiliana VACELET et LÉvi. Les Pharétronides actuelles et fossiles. Louis-Jean [Gap/ Hautes-Alpes], 125 pp. (Aix-en-Provence/Marseille, Thèse de la Fac. des sci. de l'Université.)

- \& LÉvi, C., 1958. Un cas de survivance, en Méditerranée, du groupe d'éponges fossiles des Pharétronides. C. r. hebd. Séanc. Acad. Sci., Paris 246, 318-320.

- \& Vasseur, P., 1965. Spongiaires des grottes et surplombs des récifs de Tuléar (Madagascar). Recl Trav. Stn mar. Endoume (Suppl.) 4, 71-123.

Vaissière, R. \& Carpine, C., 1964. Compte rendu de plongées en soucoupe plongeante SP 300 (région A 1). Bull. Inst. océanogr. Monaco 63 (1314), 1-36.

VASSEUR, P., 1962. Note préliminaire sur l'aspect topographique, morphologique et biologique des surplombes et des grottes sous-marines sciaphiles en avant du Récif de Songeritelo. Recl Trav. Stn mar. Endoume (Suppl.) 1, 169-179.

Vevers, H., 1951. Photography of the sea flor. J. mar. biol. Ass. U. K. 30, 101-111.

- 1952. A photographic survey of certain areas of sea floor near Plymouth. J. mar. biol. Ass. U. K. 31, 215-221.

WaErn, M., 1952. Rocky-shore algae in the Oeresund Archipelago. Acta phytogeogr. suec. 30, $1-298$.

W AHLERT, G. von, 1963. Die ökologische und evulotorische Bedeutung der Fischschwärme. Veröff. Inst. Meeresforsch. Bremerh. (Sonderbd [1]), 197-213.

- Wahlert, H. von, 1960. Beobachtungen am Trompetenfisch in der Caribischen See. Z. Tierpsychol. 17.

- 1961. Le comportement de nettoyage de Crenilabrus melanocercus (Labridae) en Méditerranée. Vie Milieu 12, 1-10. 
- - 1962. Beobachtungen und Bemerkungen zum Putzverhalten von Mittelmeerfischen. Veröff. Inst. Meeresforsch. Bremerh. 8, 71-78.

Walker, J., 1933. Making movies under water. Am. Cinematogr. 14, 144; 150-151.

Wasmund, E., 1937a. Bedingungen der Unterwasser-Photographie für Taucher. Annln $H y-$ drogr. Berl. 65, 537-555.

- 1937b. Geologisch-hydrologische Taucherbeobachtungen. Geologie Meere Binnengewäss. 1 (2).

- 1938a. Entwicklung der Naturforschung unter Wasser im Tauchgerät. Geologie Meere Binnengewäss. 2, 87-151.

- 1938b. Zur Nomenklatur subaquatischer Sedimente. Geologie Meere Binnengewäss. 2, 444-448.

Weismann, A., 1883. Die Entstehung der Sexualzellen bei Hydromedusen. G. Fischer, Jena, 295 pp.

WELLS, J., 1957. Coral reefs. In: Treatise on marine ecology and paleoecology. Vol. 1. Ecology. Ed. by. J. W. Hedgpeth. (Mem. Geol. Soc. Am. 67, 609-631).

WIEsER, W., 1951a. Ober die quantitative Bestimmung der algenbewohnenden Mikrofauna felsiger Meeresküsten. Oikos 3, 124-131.

- 1951b. Untersuchungen über die algenbewohnende Mikrofauna mariner Hartböden. Óst. zool. Z. 3.

- 1954a. Beiträge zur Kenntnis der Nematoden submariner Höhlen. Ergebnisse der Osterreichischen Tyrrhenia-Expedition 1952. T. 2. Öst. zool. Z. 5, 172-230.

- 1954b. Untersuchungen über die algenbewohnende Mikrofauna mariner Hartböden. Hydrobiologia 6, 144-217.

- 1959. Zur Okologie der Fauna mariner Algen mit besonderer Berücksichtigung des Mittelmeeres Int. Revue ges. Hydrobiol. Hydrogr. 44, 137-180.

Williamson, J., 1913. Photographing under water. Scient. Am. 109 (6).

- 1936. Twenty years under the sea. Hale, Cushman \& Flint, Boston, 320 pp.

Willm, P., 1958. Résultats scientifiques des campagnes du Bathyscaphe F.N.R.S. III 1954-1957. 3. - Notes techniques. Annls Inst. océanogr., Monaco 35 (4), 245-253.

Winn, H. E., 1964. The biological significance of fish sounds. In: Marine bioacoustics. Ed. by W. N. Tavolga. Pergamon pr., Oxford, 213-231.

WiSSEL, K., 1957a. ... die noch keines Menschen Fuß betreten. Delphin 4 (3), 321-323.

- 1957b. Uber das Filmen unter Wasser. Filmkreis 3 (3/4), 24-27; 19-22.

Wojtusiak, R., Kalkowski, W., Medwecka-Kornas, A. \& Kornas, J., 1953. Investigations of the bottom fauna and flora in the Gulf of Gdansk made by using a diving helmet. $P_{t} 5$. Bull. Acad. pol. Sci. (Cl. 2. Sér. Sci. biol.) 1.

Wojtusiak, H. \& Wojtusiak, R., 1939. Uber die Schatten und Lichtreaktion und ihre biologische Deutung. Zoologica Pol. 3, 85-114.

Yonge, C. M., 1930. A year on the Great Barrier Reef; the story of corals ard of the greatest of their creations. Putnam, London, $246 \mathrm{pp}$.

Young, C., 1925. Walking the ocean floors. World's Work 50, 155-160.

Zalokar, M., 1941. Morski zivelj ob obali Jadrana. Proteus 7 (6).

- 1942. Les associations sous-marines de la côte adriatique au dessous de velebit. Bull. Soc. bot. Genève 33, 172-195.

Zavodnik, D., 1960. Echinodermata der Insel Krk. - Echinodermata otoka Krka. Acta adriat. S (2), 3-19.

- 1963. Pinna nobilis L. comme centre d'association. Rapp. P. - v. Rèun. Commn int. Explor. scient. Mer Méditerr. 17 (2), 273-275.

Zenkovitch, V. \& Koplin, P., 1965. Geomorphologische Unterwasserforschungen im dalmatinischen Küstengebiet. [Russ.] Izv. Akad. Nauk SSSSR (Ser. geografičesk. 1965 (3), 18-34.

Županović, Š., 1955. Život u moru i podvodna televizija. Morsko Ribarst. 7 (9). 


\section{Diskussion im Anschluß an den Vortrag RIEDL}

KINNE: In Ihren interessanten Ausführungen über die Geschichte und Gegenwart des wissenschaftlichen Tauchens haben Sie wiederholt auf die Notwendigkeit der direkten Beobachtung hingewiesen. Ich möchte noch einen Schritt weitergehen: Zusätzlich zu der Möglichkeit einer direkten Beobachtung unserer submarinen Untersuchungsobjekte bedürfen wir des Experiments in situ. Man könnte beispielsweise daran denken, in einem geeigneten, kleinen Areal alle Vertreter der Makrofauna zu entfernen (absammeln; abtöten, etwa durch längere Trockenlegung oder Ausfrierung) und nun die einzelnen Phasen der Wiederbesiedlung ad hoc zu studieren. Oder man könnte bestimmte Arten, etwa die Vertreter der Gattung Asterias, durch fortgesetztes Absammeln eliminieren und die Auswirkungen eines solchen Eingriffs auf die übrigen Glieder der Lebensgemeinschaft - insbesondere die den Asteriden als Nahrung dienenden Mollusken - richten. Möglicherweise würde man dabei zu ganz neuen Einsichten über die Faktorenhierarchie kommen, welche etwa die Vertikalverteilung von Mytilus edulis kontrolliert. Weitere Möglichkeiten für Experimente in situ sind: Anlage von "Unterwassergärten“ (Untersuchungen über Wachstums-, Assimiliations- und Reproduktionsraten), Unterwasserkäfigen (Vergleichsuntersuchungen über Stoff wechselrate, Wachstum und Vermehrung größerer Fische oder Krebse in gleich großen Laboraquarien und Unterwasserkäfigen), Verhaltensstudien, Transplantationsversuche oder Einfügung neuer, dem Gefüge der Lebensgemeinschaft ursprünglich fremder Arten.

RiedL: Die Ergänzungen durch das Experiment in der Natur werden zweifellos eine wesentliche Bereicherung bringen. Derlei Untersuchungen haben wir auch immer wieder begonnen, und es war von Interesse festzustellen, daß die Schwierigkeiten keineswegs in der Kontrolle durch den direkten Beobachter gelegen sind, sondern in der zumeist nicht erreichbaren Uberwachung, im nicht erreichbaren Schutz der Test-Areale. Wir benötigen eben dringend Feldlaboratorien im ungestörten Litoral und Naturschutzgebiete dicht vor deren Toren.

KINNE: Noch ein zweiter Punkt. Experimentell-ökologische Arbeiten unter Wasser setzen in höherem Maße eine kontinuierliche Messung der Intensitätsmuster der wichtigsten Umweltfaktoren voraus, als das bisher üblich war. Wenn wir nicht in der Fülle derartiger „Backgrounddata-measurements" ertrinken wollen, müssen wir in verschiedenen Wassertiefen automatischkontinuierlich registrierende Meßinstrumente einsetzen, und zwar für Temperatur, Licht (Trübung), Salzgehalt sowie für eine Anzahl chemischer Parameter. Die Meßdaten müßten dann später von Computern verarbeitet werden.

RIEDL: Die ungleich genauere Kenntnis der Verhältnisse des Benthos, die durch die direkte Anschauung erreicht werden kann, verlangt tatsächlich die Aufstellung von Klimastationen im natürlichen Standort. Ich habe schon vor 20 Jahren derartiges versucht. Durch die heute gegebenen Möglichkeiten der Speicherung und Übertragung von Daten ist das auch technisch kein Problem mehr. Die Organisation von solchen Unternehmungen bedürfte einer gemeinsamen Vorbereitung. Der einzelne Litoralforscher hat weder für die Montage noch für die nötige Betreuung und Uberwachung die nötigen Mittel oder den erforderlichen Apparat. Aber wir hoffen, daß es auch auf dem Gebiet der Litoralforschung gelingen wird, die für uns alle wichtigen Grundlagen größerer und gemeinsamer Projekte einmal zu verwirklichen.

Jones: I just want to say that Dr. RIEDl has perhaps exaggerated the danger of diving. To my knowledge nearly all accidents that have occured, even to experienced divers, have been due to lack of elementary safety precautions or to carelessness. Even down to 30 meters or so diving can be quite safe with good training and safety measures.

RiEDL: Es war zu erwarten, daß ich selbst - so paradox das scheinen mag - vor einer zu weiten Anwendung jener Methode warnen muß, für welche ich hier eben eingetreten bin. Ich kann verstehen, daß man den Warnungen, die ich ausgesprochen habe, nicht sofort Glauben schenkt. Wenn man aber bedenkt, daß das, was wir riskieren, das wertvollste ist, was wir auf der Welt besitzen, nämlich Gesundheit und Leben eines Menschen, so wird man sich meinem Rat zur Zurückhaltung nicht verschließen. Nicht ein einziges, durch die Taucherei erzieltes wissenschaftliches Ergebnis kann so wichtig sein, daß wir deswegen ein Menschenleben aufs Spiel setzen dürften. 